\title{
Licófitas e monilófitas das Unidades de Conservação da Usina Hidroelétrica - UHE de Tucuruí, Pará, Brasil ${ }^{1}$
}

\author{
Rozijane Santos Fernandes ${ }^{2,5}$, Sebastião Maciel $^{3}$ e Marcio Roberto Pietrobom ${ }^{4}$
}

Recebido: 1.09.2010; aceito: 24.05.2012

\begin{abstract}
Lycophytes and monilophytes from Unidades de Conservação da Usina Hidroelétrica - UHE Tucuruí, Pará, Brazil). This work presents a survey of lycophytes and monilophytes in the Conservation Unit named Zonas de Preservação da Vida Silvestre da Usina Hidrelétrica de Tucuruí, Pará State, Brazil. This Conservation Unit is located at southeastern Pará and comprises about 29,700 ha, composed mainly of tropical rainforest. Our results recorded 18 families, 37 genera and 82 species. The richest family is Pteridaceae, with 21 species, and Adiantum is the richest genus, with 14 species. Three species are new records for Pará State: Didymoglossum ovale, Danaea nodosa, and Pecluma hygrometrica. Furthermore, two new species were identified. One has already been described, Thyelypteris amazonica. The other new species belongs to the genus Adiantum and shall be published soon. The floristic richness of the area, associated with the taxonomic novelties, attests for its biological importance and for the necessity of increasing the efforts on research and conservation of the study area. Key words: Amazon Forest, fern, floristic
\end{abstract}

RESUMO - (Licófitas e monilófitas das Unidades de Conservação da Usina Hidroelétrica - UHE de Tucuruí, Pará, Brasil). O presente estudo refere-se às espécies de licófitas e monilófitas ocorrentes nas Zonas de Preservação da Vida Silvestre da Usina Hidroelétrica de Tucuruí, Estado do Pará, Brasil. A área de estudo localiza-se na região sudeste do Pará, com cerca de 29.700 hectares, composta, predominantemente, por floresta ombrófila aberta. Os dados obtidos demonstraram a ocorrência de 18 famílias, 37 gêneros e 82 espécies. A família com maior riqueza de espécies é Pteridaceae (21 spp.) e o gênero mais representativo é Adiantum com 14 espécies. Três espécies são novas referências para o Pará: Didymoglossum ovale, Danaea nodosa e Pecluma hygrometrica. Além disso, duas espécies novas foram identificados, uma delas já descrita, Thyelypteris amazonica. A outra espécie pertence a Adiantum e será publicada em breve. A riqueza florística da área, associada com as novidades taxonômicas, atesta a sua importância biológica e aponta para a necessidade de aumentar os esforços em pesquisa e conservação da área estudada.

Palavras-chave: Floresta Amazônica, florística, samambaia

\section{Introdução}

No Brasil, as licófitas e monilófitas estão concentradas principalmente nas áreas da Mata Atlântica nas regiões Sudeste e Sul (Prado \& Sylvestre 2012). No que se refere à Floresta Amazônica, a composição de espécies é bem menos rica, e os Estados que apresentam um melhor conhecimento das plantas vasculares sem sementes são Amazonas, Pará e Acre (Pietrobom \& Souza 2008, Prado \& Moran 2009).
Na região amazônica, a diversidade das licófitas e monilófitas é considerada relativamente pobre e de baixo endemismo (Tryon \& Conant 1975). Isto representa um contraste acentuado em relação ao elevado endemismo de muitos gêneros de Angiospermas. Para a Amazônia brasileira, são reconhecidas 440 espécies (Prado \& Sylvestre 2012). Para o Estado do Pará, são referidas 200 espécies (Prado \& Sylvestre 2012), entretanto, Silva \& Rosário (2008) citaram 313 espécies.

1. Parte da Dissertação de Mestrado da primeira Autora

2. Universidade Federal de Minas Gerais, Instituto de Ciências Biológicas, Departamento de Botânica, Av. Antonio Carlos 6627, 31270-901 Belo Horizonte, MG, Brasil

3. Museu Paraense Emílio Goeldi - MCT, Campus de Pesquisa, Coordenação de Botânica, Av. Perimetral 1901, 66017-970 Belém, PA, Brasil

4. Universidade Federal do Pará, Campus de Bragança, Instituto de Estudos Costeiros, Laboratório de Biologia Vegetal, Alameda Leandro Ribeiro s.n., 68600-000 Bragança, PA, Brasil

5. Autor para correspondência: rozijanef@hotmail.com 
Os estudos referentes às licófitas e monilófitas realizados no Pará têm crescido nos últimos anos, no entanto, estão concentrados na microrregião de Belém (Rodrigues et al. 2004, Costa et al. 2006a, b, Costa \& Pietrobom 2007, Maciel et al. 2007, Ferreira et al. 2009, Costa \& Pietrobom 2010) apresentando enormes lacunas de dados referentes às demais regiões do Estado. Até o presente, foram realizados estudos somente para a região nordeste (Maciel \& Pietrobom 2010a, b), para o norte do Estado e na região do Marajó (Silva \& Rosário 2008, Pietrobom et al. 2009). No entanto, para o sudeste paraense, onde está inserido o Mosaico de Unidades de Conservação da UHE de Tucuruí, as licófitas e monilófitas não foram incluídas no inventário que foi realizado para a avaliação do impacto ambiental pela construção da barragem (Leão et al. 2005a, b).

Portanto, o objetivo do presente estudo foi inventariar as espécies de licófitas e monilófitas provenientes das Zonas de Preservação da Vida Silvestre (ZPVS) Base 3 e 4 da UHE de Tucuruí, bem como discutir os tipos e ambientes de ocorrência e formas de vida, elaborar chaves de identificação, comentários taxonômicos e indicar a distribuição geográfica das mesmas.

\section{Material e métodos}

A área de estudo compreende um mosaico de Unidade de Conservação, sendo duas Zonas de Preservação da Vida Silvestre (ZPVS) Base 3 e 4, e duas Reservas de Desenvolvimento Sustentável, Alcobaça e Pucuruí-Ararão, denominado de Lago de Tucuruí, localizadas no reservatório da Usina Hidroelétrica (UHE) de Tucuruí, na Mesorregião Sudeste do Pará, com cerca de $42 \mathrm{~m}$ de altitude, entre as coordenadas de $3^{\circ} 43^{\prime}-5^{\circ} 15^{\prime} \mathrm{S}$ e $49^{\circ} 12^{\prime}-50^{\circ} 00^{\prime} \mathrm{W}$. A extensão do reservatório percorre os municípios de Tucuruí, Breu Branco, Goianésia do Pará, Novo Repartimento, Jacundá, Nova Ipixuna e Itupiranga (figura 1) (Leão et al. 2005b).

A vegetação da área é composta por Floresta Ombrófila Aberta com cipós e palmeiras sobre alto platô (Leão et al. 2005a), além de incorporar fitofisionomias como baixios e formações rupestres.

Segundo Fisch et al. (1990), a região de Tucuruí possui duas estações bem definidas e características: um período chuvoso de dezembro a maio, com chuvas intensas e outro período, seco, de junho a novembro, com uma estiagem pronunciada em agosto/setembro.

A área apresenta clima tropical quente e úmido (AmW), segundo a classificação de Köppen e com elevados índices pluviométricos anuais, cerca de $2400 \mathrm{~mm}$, com temperaturas médias anuais variando entre 24 e $28{ }^{\circ} \mathrm{C}$, com máximas de $38^{\circ} \mathrm{C}$ ocorrendo nos meses de agosto e setembro e as mínimas em $22{ }^{\circ} \mathrm{C}$ em junho e umidade relativa do ar superior a 85\% (Sanches \& Fisch 2005).

O presente estudo baseou-se na análise dos espécimes coletados na área e em coleções depositadas no Herbário MG (Museu Paraense Emilio Goeldi) e IAN (Embrapa Amazônia Oriental). As coletas foram realizadas entre 2005 e 2009, seguindo as técnicas padrão (Fidalgo \& Bononi 1989). O material testemunho encontra-se depositado no Herbário MG e duplicatas, foram enviadas aos Herbários BHCB, MBM, RB, SP e UB.

A circunscrição para as famílias e gêneros de licófitas está de acordo com Jermy (1990) para Selaginellaceae e Wagner \& Beitel (1993) Lycopodiaceae e para as famílias e gêneros de monilófitas segue Smith et al. (2006), com alterações para o gênero Mickelia R.C. Moran, Labiak \& Sundue, que está de acordo com Moran et al. (2010). Entretanto, para o tratamento dos gêneros das famílias Cyatheaceae e Thelypteridaceae adotou-se Lellinger (1987) e Smith (1992), respectivamente.

Foram elaboradas chaves de identificação para todas as espécies. As ilustrações apresentadas neste trabalho referem-se às espécies que são novos registros para o Estado do Pará e outras por terem sido pouco ilustradas em trabalhos publicados, principalmente no Brasil. A abreviação dos nomes dos autores das espécies segue Pichi-Sermolli (1996).

Os táxons estão listados em ordem alfabética de família, gênero e espécie, dentro de cada linhagem. Os asteriscos $(*)$ indicam ocorrência nova para o Estado do Pará.

Quanto à forma de vida seguiu-se Lellinger (2002) e Zuquim et al. (2008).

A análise da distribuição geográfica das espécies segue a classificação proposta por Parris (2001) e Moran \& Smith (2001), com modificações de Schwartsburd \& Labiak (2007), segundo os quais as espécies podem ser classificadas em: circum-antárticas, atlânticas, pacíficas, americanas e sul-americanas. A distribuição geográfica das espécies nos países do continente americano, bem como sua ocorrência em outros continentes, foi feita com base em Moran \& Riba (1995), Berry et al. (1995), Mickel \& Smith (2004) e nas demais obras utilizadas na identificação das espécies.

A análise de distribuição geográfica para o Brasil observou a divisão política dos Estados, estando estes 

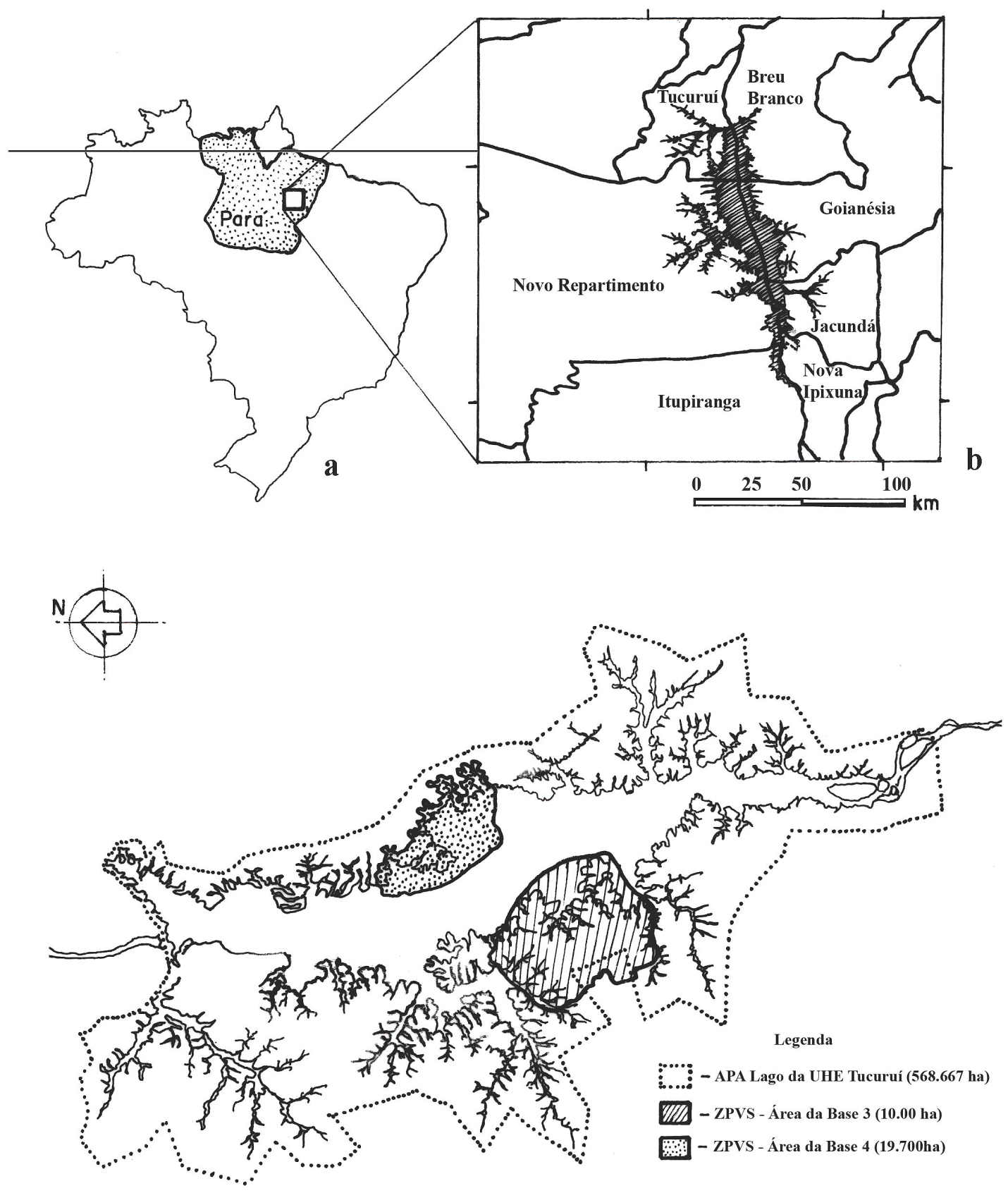

\begin{tabular}{lrrrr}
0 & 2.5 & 5 & 10 & $25 \mathrm{~km}$ \\
\hline & ESCALA: $1 / 250.000$
\end{tabular}

Figura 1. Localização do Reservatório da UHE no Estado do Pará. a. Mapa do Brasil indicando o Estado do Pará e a localização da área da UHE b. Localização dos municípios onde está inserido o Mosaico de Unidades de Conservação da UHE de Tucuruí. c. Imagem de satélite do Reservatório da UHE de Tucuruí em destaque as ZPVS - Bases 3 e 4. (Fonte: Eletronorte, com adaptação R.S. Fernandes \& J.M. Costa).

Figure 1. Location of Hydroelectric Reservoir in the state of Pará. a. Map of Brazil indicating the state of Pará and the location of the UHE area. b. Municipalities where the Mosaic of Conservation UHE Tucurui is located. c. Satellite image of the Tucuruí UHE Reservoir with the ZPVS - Bases 3 and 4 highlighted. (Source: Eletronorte, with adaptation R.S. Fernandes \& J.M. Costa). 
representados por suas siglas, em ordem alfabética, seguidos da referência. Esta análise teve como prioridade referências com material testemunho publicado, além de consulta a Flora do Brasil (Barros et al. 2012, Hirai 2012, Labiak 2012, Labiak \& Hirai 2012, Prado 2012a, b, c, d, Salino \& Almeida 2012a, b, c, Windisch 2012a, b, Windisch \& Ramos 2012, Windisch \& Kieling-Rúbio 2012).

\section{Resultados e Discussão}

No presente inventário, as licófitas e monilófitas das ZPVS Bases 3 e 4 da UHE de Tucuruí estão representadas por 82 espécies, 37 gêneros e 18 famílias, sendo quatro licófitas e 78 monilófitas. Das famílias registradas, Pteridaceae apresentou a maior riqueza específica, com 21 espécies, seguida de Hymenophyllaceae com 10 espécies, Polypodiaceae com nove espécies e Thelypteridaceae com seis. As quatro famílias juntas representam mais de $50 \%$ da riqueza total de espécies da área estudada.

Com exceção de Thelypteridaceae, que geralmente tem pouca representatividade na Amazônia (Tryon \& Conant 1975), as demais famílias como Pteridaceae, Hymenophyllaceae e Polypodiaceae reforçam os resultados obtidos nos trabalhos realizados para a microrregião de Belém e nordeste paraense, nos quais tais famílias também foram mais representativas (Costa et al. 2006b, Costa \& Pietrobom 2007, 2010, Maciel et al. 2007, Ferreira et al. 2009).

Os gêneros mais representativos foram Adiantum L. (Pteridaceae) com 14 espécies, seguido por Thelypteris Schmidel (Thelypteridaceae) com seis e Asplenium L. (Aspleniaceae), Didymoglossum Desv. e Trichomanes L. (Hymenophyllaceae) com cinco espécies cada. Adiantum, isoladamente, concentra aproximadamente $22 \%$ do número total de espécies registradas na área estudada.

Estes dados reforçam o comentário de Tryon \& Conant (1975) de que na flora da Amazônia brasileira estão bem representadas espécies dos gêneros Adiantum, Trichomanes e Didymoglossum.

As Bases 3 e 4 apresentaram uma riqueza de microhabitats como os igarapés que banham os pedrais, barrancos úmidos e afloramentos rochosos no alto platô, que propiciaram o estabalecimento de algumas espécies que na área são exclusivas destes ambientes. Para a Base 3, foram registradas 48 espécies, sendo que 17 são exclusivas. Esta área apresenta ambientes de difícil acesso, ausência de trilhas e, ainda, nela são encontrados afloramentos rochosos com altitude de aproximadamente $179 \mathrm{~m}$, onde se estabeleceram espécies rupícolas, como Hemionitis palmata L., H. rufa (L.) Sw. e Selaginella radiata (Aubl.) Spring.

Para a Base 4, a riqueza foi de 56 espécies, sendo 25 exclusivas desta área, dentre as quais foram registradas espécies epífitas, como Didymoglossum angustifrons Fée, D. kapplerianum (J.W. Sturm) Ebihara \& Dubuisson, D. pinnatinervium (Jenman) Pic. Serm., Huperzia dichotoma (Jacq.) Trevis., Nephrolepis biserrata (Sw.) Schott, N. brownii (Desv.) Hovenkamp \& Miyam., Polytaenium guayanense (Hieron.) Alston, Vittaria lineata (L.) Sm. e hemiepífitas como Mickelia guianensis (Aubl.) R.C. Moran. A presença de microhabitats, como barrancos úmidos e brejos no interior da floresta, possivelmente tenham favorecido a ocorrência de espécies terrícolas, como Cyathea pungens (Willd.) Domin e Trichomanes trollii Bergdolt. Além disso, a área apresenta locais periodicamente alagados pela cheia do reservatório, onde se estabeleceram as espécies Thelypteris serrata (Cav.) Alston e T. interrupta (Willd.) K. Iwats.

Foram levantadas 17 espécies no Herbário MG, nove das quais não foram coletadas novamente na área de estudo, Selaginella conduplicata Spring, Blechnum serrulatum Rich., Elaphoglossum luridum (Fée) H. Christ, Trichomanes accedens C. Presl, T. arbuscula Desv., Lindsaea guianensis (Aubl.) Dryand. ssp. guianensis, L. schomburgkii Klotzsch, Actinostachys pennula (Sw.) Hook. e Schizaea incurvata Schkuhr. O hábitat da maioria dessas espécies são campinas, terrenos planos, arenosos e as encostas dos morros, e esses ambientes foram inundados durante a cheia do reservatório, causando provavelmente o desaparecimento dessas espécies na área.

De acordo com a forma de vida, as espécies predominantes foram as exclusivamente terrícolas (47 spp.), seguidas pelas epífitas (19 spp.). Na área estudada é comum encontrar espécies com duas formas de vida, por exemplo, Asplenium stuebelianum Hieron., Nephrolepis biserrata e N. brownii foram coletadas tanto como epífitas quanto como terrícolas; Selaginella radiata e Asplenium hostmanii Hieron. foram observadas tanto como rupícolas quanto como terrícolas, Asplenium serratum L. e Phlebodium decumanum (Willd.) J. Sm. foram registradas como rupícolas e epífitas.

As ZPVS Bases 3 e 4 da UHE de Tucuruí compõem a área com maior riqueza de espécies de licófitas e monilófitas inventariada no Estado do Pará até o presente. Esta riqueza se deve, provavelmente, à 
variedade de microambientes presentes na área, dentre os quais, poderiam ser citados ambientes rupícolas no alto platô e pedrais banhados por igarapés no baixio. Nestes últimos foi onde se estabeleceu o maior número de espécies, devido, principalmente, ao estado relativamente conservado da área.

A área estudada abriga 10 espécies que, no Brasil, são restritas até o momento à região amazônica. Neste estudo, também são citados três novos registros para o Estado do Pará (Danaea nodosa, Didymoglossum ovale e Pecluma hygrometrica) e foram descobertas duas espécies novas Thelypteris amazonica Salino \& R.S. Fernandes (Salino et al. 2011), já descrita, e Adiantum sp., que está em processo de descrição por Prado \& Tuomisto. Os novos registros, os quais, aliás, têm sido frequentes nos últimos anos para o Estado do Pará, são reflexo dos poucos inventários realizados, principalmente em Unidades de Conservação.

\section{LICÓFITAS}

\section{LYCOPODIACEAE}

Phlegmariurus dichotomus (Jacq.) W. H. Wagner \& Beitel, Novon. 3: 305. 1992.

Material examinado: BRASIL. PARÁ: Breu Branco, $\mathrm{km} 25$ South of Represa Tucuruí on road (BR 422), approx. $3^{\circ} 52^{\prime} \mathrm{S}, 4^{\circ} 44^{\prime} \mathrm{W}, 16-\mathrm{III}-1980$, T. Plowman et al. 9641 (MG); idem, $23 \mathrm{~km}$. South of Tucuruí, rio Tocantins, $3^{\circ} 52^{\prime} \mathrm{S}, 4^{\circ}{ }^{\circ} 44^{\prime} \mathrm{W}, 20-\mathrm{III}-1980$, T. Plowman et al. 9812 (MG); Goianésia do Pará, ZPVS-UHE de Tucuruí, Base 4, Ilha do Marcelo, 0409'59,3"S, $49^{\circ} 32^{\prime} 38,0^{\prime \prime} \mathrm{W}$, alt. $35 \mathrm{~m}, 14-\mathrm{III}-2009$, R.S. Fernandes \& J.M. Costa 405 (MG).

Espécie com distribuição americana. No Brasil é citada para o AC, AP, CE, MT, PA, RJ, RO, RR, e SP (Nessel 1955, Øllgaard \& Windish 1987). A espécie foi observada crescendo como epífita sobre tronco em decomposição no interior de floresta úmida. Phlegmariurus dichotomus caracteriza-se pelos microfilos e esporófilos monomorfos, lineares e os esporângios solitários nas axilas dos esporófilos (Øllgaard \& Windisch 1987). Phlegmariurus dichotomus é semelhante a $P$. wilsonii (Underw. \& F.E. Lloyd) B. Øllg. No entanto, P. wilsonii difere de $P$. dichotomus por apresentar microfilos estreitos $(0,5 \mathrm{~mm})$, espaçados e com base frequentemente avermelhada (Mickel et al. 2004). Já em P. dichotomus os microfilos são lineares ou filiformes, mais largos, com até $1 \mathrm{~mm}$ largura, ramos não visíveis entre os microfilos que o revestem, arranjados em verticílos irregulares a espiralado e com base hialina a verde-clara.

\section{SELAGINELLACEAE}

Chave de identificação para as espécies de Selaginellaceae

1. Caule articulado; microfilos laterais com duas aurículas basais, membranáceas e de tamanhos diferentes .. Selaginella conduplicata

1. Caule não articulado; microfilos laterais sem aurículas

2. Microfilos laterais oval-oblongos, margem denticulada; ápice do caule flageliforme Selaginella flagellata

2. Microfilos laterais oval-lanceolados, margem ciliada; ápice do caule não flageliforme Selaginella radiata

Selaginella conduplicata Spring, F1. Bras. 1(2): 129. 1840.

Material examinado: BRASIL. PArÁ: Novo Repartimento, km 25, 4-VI-1980, M.G. Silva \& C. Rosário 5356 (MG); Breu Branco, km 25 South of Reprêsa Tucuruí on road (BR 422) approx. $3^{\circ} 52^{\prime} \mathrm{S}$, 4944'W, 15-III-1980, T. Plowman et al. 9569 (MG); idem, $25 \mathrm{~km} \mathrm{~S}$ of Tucuruí just of old BR 422 at junction with old railroad bed. approx. $3^{\circ} 58^{\prime} \mathrm{S}$, 49³8'W., 30-X-1981, D.C. Daly et al. 1090 (MG); idem, rodovia Tucuruí, Jatobal, margens da estrada do Breu Branco km 25, 28-III-1981, N.A. Rosa \& C. Rosário 4020 (MG).

Espécie com distribuição sul-americana. No Brasil é citada para o AM, CE e PA (Paula-Zárate 2005, Prado \& Freitas 2005, Maciel et al. 2007). $\mathrm{Na}$ área estudada, a espécie cresce em campina arbórea, solo arenoso úmido em ambiente ensolarado. Selaginella conduplicata pertence ao grupo das espécies articuladas, que além das articulações do caule, ainda podem ser caracterizadas pelos microfilos anisófilos e a presença de somente um megasporângio, muito raramente dois nos estróbilos (Somers \& Moran 1995). Difere das demais espécies da área estudada pela presença de duas grandes e conspícuas aurículas na base dos microfilos axilares e na base dos microfilos laterais com duas aurículas membranáceas, de tamanhos diferentes, a acroscópica maior e recurvada, a basioscópica menor.

Selaginella flagellata Spring, Bull. Acad. Roy. Sci. Bruxelles 10(1): 228. 1843.

Material examinado: BRASIL. PARÁ: Novo Repartimento, ZPVS-UHE de Tucuruí, Base 3, 10-VII-2008, R.S. Fernandes et al. 171 (MG). 
Espécie com distribuição americana. No Brasil é citada para o AP, AM, CE, MA, MT, PA, PE, RO e TO (Valdespino 1995, Barros et al. 2002, Mickel et al. 2004, Paula-Zárate 2005, Fernandes et al. 2007). Na área estudada, a espécie foi coletada em ambiente seco, no interior de floresta ombrófila aberta em afloramento rochoso. Selaginella flagellata diferencia-se das demais espécies coletadas na área pela ausência de articulações no caule e a presença de um ápice flageliforme na parte distal do caule principal.

Selaginella radiata (Aubl.) Spring, Bull. Acad. Roy. Sci. Bruxelles 10(54): 143. 1843

Material examinado: BRASIL. PARÁ: Tucuruí, Fazenda Guaripé, 14-V-1980, N.A. Rosa 3673 (MG). Novo Repartimento, Base 3, trilha 15, 0409'52,8"-

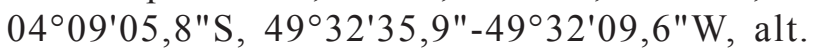
75-107 m, 24-IX-2008, R.S. Fernandes \& S. Maciel 271 (MG); idem, Lajeiro, 04²2'40"S 49³5'18,5", alt. 138 m, 12-III-2009, R.S. Fernandes \& J.M. Costa 341 (MG); Goianésia do Pará, ZPVS-UHE de Tucuruí, Base 4, trilha 8, $04^{\circ} 15^{\prime} 0,6^{\prime \prime}-04^{\circ} 15^{\prime} 47,85^{\prime \prime} \mathrm{S}$, $49^{\circ} 31^{\prime} 01,7^{\prime \prime}-49^{\circ} 30^{\prime} 17,6^{\prime \prime} \mathrm{W}$, alt. 102-179 m, 13-III-2009, R.S. Fernandes \& J.M. Costa 362 (MG).

Espécie com distribuição sul-americana. No Brasil é citada para o AM, AP, MA, MT e PA (Tryon \& Conant 1975, Alston et al. 1981). Na área estudada, a espécie foi observada crescendo no interior da mata, em margem da trilha, entre fendas das rochas, em encostas úmidas próximo a curso d'água e, ainda, em local ensolarado. Selaginella radiata caracteriza-se pelo caule ereto, a presença de rizóforos somente na base e o formato da lâmina oblongo a arredondado.

\section{MONILÓFITAS}

\section{ASPLENIACEAE}

Chave de identificação para as espécies de Aspleniaceae

1. Lâmina simples; soros 2-4 cm compr.

2. Base da lâmina abruptamente estreitada; pecíolo 8-15 cm compr.; tecido lâminar abaxialmente revestidos com escamas Asplenium stuebelianum

2. Base da lâmina decurrente; pecíolo 2-3,5 cm compr.; tecido lâminar baxialalmente glabro Asplenium serratum

1. Lâmina 1-pinada; soros $0,3-1,5 \mathrm{~cm}$ compr.
3. Pecíolo não alado; lâmina oblongodeltada; pinas 7-15,5 cm compr., 1,5-2 cm larg. Asplenium delitecens

3. Pecíolo alado; lâmina lanceolada a oblongo-lanceolada; pinas $0,7-3 \mathrm{~cm}$ compr., 0,3-1 cm larg.

4. Pecíolo revestido por escamas tortuosas na porção distal (0,3-0,5 mm compr.); ápice das pinas arredondado ............ Asplenium cruegeri

4. Pecíolo glabrescente na porção distal, escamas, se presentes, filiformes (0,1-0,2 mm compr.); ápice das pinas agudo a raramente obtuso Asplenium hostmanii

Asplenium cruegeri Hieron., Hedwigia 60: 254. 1918.

Material examinado: BRASIL. PARÁ: Novo Repartimento, ZPVS-UHE de Tucuruí, Base 3, trilha principal, 9-VII-2008, R.S. Fernandes et al. 128 (MG, RBR); idem, 9-VII-2008, R.S. Fernandes et al. 132 (MG, RBR).

Espécie com distribuição americana. No Brasil é citada para o PA (Sylvestre 2001). Na área estudada, a espécie foi observada sobre rochas em margem de cursos d'água no interior da mata e coletada junto a espécimes de Asplenium hostmanii Hieron. Asplenium cruegeri é bem próxima a $A$. hostmanii, no entanto, diferencia-se deste último por apresentar pinas mais largas (0,4-1 cm larg.), margem curto-serreada, ápice arredondado e pecíolo revestido por escamas tortuosas (0,3-0,5 mm compr.) na porção distal. Por sua vez, $A$. hostmanii possui pinas estreitas (0,3-0,7 cm larg.) e profundamente serreadas, ápice agudo e pecíolo glabrescente em direção à porção distal, ocasionalmente com tricomas pluricelulares de ápice globoso, e escamas filiformes (0,1-0,2 mm compr.).

Asplenium delitecens (Maxon) L. D. Gómez, Brenesia 8: 52.1976.

Material examinado: BRASIL. PARÁ: Novo Repartimento, ZPVS-UHE de Tucuruí, Base 3, trilha principal, 9-VII-2008, R.S. Fernandes et al. 127 (MG, RBR); idem, 10-VII-2008, R.S. Fernandes et al. 161 (MG, RBR); Goianésia do Pará, ZPVS-UHE de Tucuruí, Base 4, Ilha do Tamarindo, 04 ${ }^{\circ} 6^{\prime} 04,2^{\prime \prime}$ $04^{\circ} 16^{\prime} 37,3^{\prime \prime S}, 49^{\circ} 39^{\prime} 37,4^{\prime \prime}-49^{\circ} 39^{\prime} 11,6^{\prime \prime} \mathrm{W}$, alt. 70-103 m, 23-IX-2008, R.S. Fernandes \& S. Maciel 221 (MG, RBR). 
Espécie com distribuição americana. No Brasil é citada para o AC, MT e PA (Sylvestre 2001). Na área estudada, a espécie forma grandes populações sobre rochas, a margem de cursos d'água e em barrancos no interior da mata, geralmente cresce associada a Adiantum argutum Splitg. Asplenium delitecens difere de $A$. abscissum Willd., espécie esta que também ocorre na região amazônica, por apresentar caule reptante, raque estreitamente alada na porção distal (ala menor que $1 \mathrm{~mm}$ larg.) e a margem da pina com serras largamente truncadas (Mickel \& Smith 2004). Asplenium abscissum apresenta caule ereto a ascendente, raque estreitamente alada por toda sua extensão e margem das pinas com serras duplas a sub-inteiras.

Asplenium hostmanii Hieron., Hedwigia 60: 256. 1918.

Material examinado: BRASIL. PARÁ: Novo Repatimento, ZPVS-UHE de Tucuruí, Base 3, trilha principal, 9-VII-2008, R.S. Fernandes et al. 129 (MG, RBR); idem, Ressaca do Pirarucu, 4²2"55,3"$04^{\circ} 22^{\prime} 11,8^{\prime \prime} \mathrm{S}, 49^{\circ} 35^{\prime} 39,8^{\prime \prime}-49^{\circ} 36^{\prime} 13,3^{\prime \prime} \mathrm{W}$, alt. $72-84 \mathrm{~m}$, 12-III-2009, R.S. Fernandes \& J.M. Costa 320 (MG).

Espécie com distribuição sul-americana. No Brasil é citada para o AM, AP e PA (Sylvestre 2001). Espécie observada e coletada crescendo sobre rochas e em barrancos na margem de cursos d'água no interior da mata, associada a Asplenium cruegeri. Asplenium hostmanii é caracterizada por possuir pinas estreitas e profundamente serreadas, lâmina oblongo-lanceolada e ápice agudo.

Asplenium serratum L., Sp. P1. 2: 1079. 1753.

Material examinado: BRASIL. PARÁ: Tucurú, 12 km east of Represa Tucuruí, rio Tocantins along new road (PA 263), approx. $3^{\circ} 45^{\prime} \mathrm{S}, 49^{\circ} 40^{\prime} \mathrm{W}, 19-\mathrm{III}-1980$, T. Plowman et al. 9806 (MG); idem, estrada para Novo Repartimento, km 25, 5-VI-1980, M.G. Silva \& C. Rosário 5377 (MG); idem, ZPVS-UHE de Tucuruí, Base 3, 9-VII-2008, R.S. Fernandes et al. 121 (MG); idem, Ressaca do Pirarucu, 4²2'55,3"-04²2'11,8"S, $49^{\circ} 35^{\prime} 39,8^{\prime \prime}-49^{\circ} 36^{\prime} 13,3^{\prime \prime} \mathrm{W}$, alt. 72-84 m, 12-III-2009, R.S. Fernandes \& J.M. Costa 326 (MG); Goianésia do Pará, ZPVS-UHE de Tucuruí, Base 4, Ilha do Prefeito, $04^{\circ} 20^{\prime} 02^{\prime \prime S}, 49^{\circ} 36^{\prime} 52^{\prime \prime} \mathrm{W}$, alt. $70 \mathrm{~m}, 25$-IX-2008, R.S. Fernandes \& S. Maciel 307 (MG, RBR).

Espécie com distribuição americana. No Brasil é citada para o AC, AL, AP, AM, BA, CE, ES, GO, MA, MT, MS, MG, PA, PB, PR, PE, RJ, RO, RR, SC e SP (Sylvestre 2001, Prado 2005a, Boldrin \& Prado 2007, Maciel et al. 2007). Na área estudada, a espécie foi observada crescendo principalmente no interior da floresta mais aberta, próximo a trilhas, sobre rochas ou troncos de árvores, sempre acima de $1 \mathrm{~m}$ de altura. Espécimes de Asplenium serratum com morfologia intermediária entre $A$. angustum $\mathrm{Sw}$. e $A$. stuebelianum Hieron. são ocasionalmente encontrados. Asplenium serratum difere de $A$. angustum Sw. por apresentar ápice da lâmina obtuso a agudo, nervuras partindo da costa em ângulo de cerca de $60^{\circ}-75^{\circ}$ e a lâmina com mais de $5 \mathrm{~cm}$ de largura. Asplenium angustum possui ápice da lâmina longo-atenuado, nervuras partindo da costa em ângulo de cerca de $30^{\circ}-50^{\circ}$ e a lâmina com 3-5 cm largura. Difere de A. stuebelianum pela lâmina longo-decurrente em direção a base e pecíolo com 2-3,5 cm de comprimento (Sylvestre 2001).

Asplenium stuebelianum Hieron., Hedwigia 47: 222, t. 4, f. 13. 1908 .

Material examinado: BRASIL. PArÁ: Goianésia do Pará, ZPVS-UHE de Tucuruí, Base 4, Ilha do Marcelo, 0409'52, $8^{\prime \prime}-04^{\circ} 09^{\prime} 05,8^{\prime \prime} \mathrm{S}, 49^{\circ} 32^{\prime} 35,9^{\prime \prime}-49^{\circ} 32^{\prime} 09,6^{\prime \prime} \mathrm{W}$, alt. 75-107 m, 24-IX-2008, R.S. Fernandes \& S. Maciel 247 (MG, RBR); idem, 0409'59,3"S, $49^{\circ} 32^{\prime} 38,0^{\prime \prime} \mathrm{W}$, alt. $35 \mathrm{~m}, 14-\mathrm{III}-2009$, R.S. Fernandes \& J.M. Costa 378 (MG).

Espécie com distribuição sul-americana. No Brasil é citada para o AC, AM, ES, GO, MG, MS, MT, PA, PR, RO e SP (Sylvestre 2001). Planta terrícola, às vezes crescendo na base de tronco de árvore, a menos de $30 \mathrm{~cm}$ de altura, em ambiente úmido no interior da floresta de terra firme.

Asplenium stuebelianum pode ser confundido com $A$. serratum, espécie bastante comum, porém A. stuebelianum possui a lâmina estreitando-se abruptamente para a base, pecíolo com até $15 \mathrm{~cm}$ de compr., além de tecido e costa abaxialmente revestidos com escamas diminutas.

\section{BLECHNACEAE}

Blechnum serrulatum Rich., Actes Soc. Hist. Nat. Paris 1: 114. 1792.

Material examinado: BRASIL. PARÁ: Tucuruí, estrada para Novo Repartimento, km 25, 7-VI-1980, Silva \& C. Rosário 5411 (MG).

Espécie com distribuição pacífica. No Brasil é citada para o AL, AM, AP, BA, DF, ES, GO, MA, MG, MS, MT, PA, PE, PB, PI, PR, RJ, RO, RR, RS, SC e SP (Dittrich 2005, Dittrich \& Salino 2010). 
$\mathrm{Na}$ área estudada, a espécie cresce em campina de areia. Blechnum serrulatum é facilmente reconhecida por apresentar pinas articuladas à raque, margens das pinas cartilaginosas, bastante serreadas e soros subacrosticóides. É a única espécie do gênero que ocorre no Neotrópico a apresentar pinas articuladas com a raque (Moran 1995).

\section{CYATHEACEAE}

Cyathea pungens (Willd.) Domin, Pterid. Dominica: 263. 1929.

Material examinado: BRASIL. PARÁ: Goianésia do Pará, ZPVS-UHE de Tucuruí, Base 4, Ilha do Marcelo, 0409'52, $8^{\circ}-04^{\circ} 09^{\prime} 05,8^{\prime \prime} \mathrm{S}, 49^{\circ} 32^{\prime} 35,9^{\prime \prime}-49^{\circ} 32^{\prime} 09,6^{\prime \prime} \mathrm{W}$, alt. 75-107 m, 24-IX-2008, R.S. Fernandes \& S. Maciel 252 (MG); idem, trilha 8, 04 ${ }^{\circ} 15^{\prime} 0,6^{\prime \prime}-$ $04^{\circ} 15^{\prime} 47,85^{\prime \prime S}, 49^{\circ} 31^{\prime} 01,7^{\prime \prime}-49^{\circ} 30^{\prime} 17,6^{\prime \prime} \mathrm{W}$, alt. 102-179 m, 13-III-2009, R.S. Fernandes \& J.M. Costa 351 (MG).

Espécie com distribuição sul-americana. No Brasil é citada para o AC, AM, BA, CE, GO, MS, MT, PA, PB, PE, PR, RO e SP (Tryon \& Conant 1975, Fernandes 2003, Costa \& Pietrobom 2007). Na área estudada, a espécie foi coletada em barranco a margem de curso d'água, em local alagado no interior da mata formando caule com cerca $50 \mathrm{~cm}$ de altura. Cyathea pungens é caracterizada por apresentar as escamas da base do pecíolo fortemente bicolores, com margem castanho-clara bem evidente, raque inerme, aeróforos presentes na inserção, nervuras geralmente não ramificadas e indúsio ausente.

\section{DRYOPTERIDACEAE}

Chave de identificação para as espécies de Dryopteridaceae

1. Frondes fortemente dimorfas; soros acrosticóides.

2. Lâmina estéril inteira, com nervuras livres Elaphoglossum luridum

2. Lâmina estéril 1-2-pinada, com nervuras anastomosadas Mickelia guianensis

1. Frondes monomorfas a subdimorfas; soros arredondados, dispostos entre a margem da lâmina e costa

3. Frondes subdimorfas; tricomas catenados ausentes ................. Cyclodium inerme

3. Frondes monomorfas; tricomas catenados presentes principalmente na superfície adaxial dos eixos
4. Raque e costa sulcados adaxialmente, com duas alas laterais contínuas com o tecido lâminar do eixo adjacente (decurrentes) ................... Lastreopsis effusa

4. Raque e costa não sulcados, proeminentesadaxialmente, sealados, então alas interrompidas (não decurrentes) Ctenitis refulgens

Ctenitis refulgens (Klotzsch ex Mett.) C. Chr. ex Vareschi, Fl. Venez. 1(1): 404. 1969.

Material examinado: BRASIL. PARÁ: Novo Repartimento, ZPVS-UHE de Tucuruí, Base 3, 9-VII-2008, R.S. Fernandes et al. 118 (MG); Goianésia do Pará, ZPVS-UHE de Tucuruí, Base 4, Ilha do Tamarindo, $04^{\circ} 16^{\prime} 04,2^{\prime \prime}-04^{\circ} 16^{\prime} 37,3^{\prime \prime} \mathrm{S}, 4^{\circ} 39^{\prime} 37,4^{\prime \prime}-$ 4939'11,6"W, alt. 70-103 m, 23-IX-2008, R.S. Fernandes \& S. Maciel $218(\mathrm{MG})$; idem, Ilha

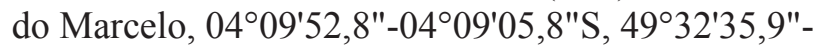
49०32'09,6"W, alt. 75-107 m, 24-IX-2008, R.S. Fernandes \& S. Maciel 261 (MG); idem, trilha 4, $04^{\circ} 15^{\prime} 18,5^{\prime \prime} \mathrm{S}, 49^{\circ} 31^{\prime} 03,7^{\prime \prime} \mathrm{W}$, alt. $60 \mathrm{~m}, 13-\mathrm{III}-2009$, R.S. Fernandes \& J.M. Costa 371 (MG).

Espécie com distribuição americana. No Brasil é citada para o AC, AM, AP, MA, MG, PA e RR (Sampaio 1930, Edwards 1998, Zuquim et al. 2008, Prado \& Moran 2009). Na área estudada, a espécie cresce em encosta úmida, em margem de brejo, no interior da mata e ainda pode ser observada em ambiente seco. Ctenitis refulgens é semelhante a C. submarginalis (Langsd. \& Fisch) Ching, sendo que a primeira apresenta pecíolo densamente escamoso por toda sua extensão, raque e costa densamente revestidas abaxialmente por escamas rígidas em forma de tricomas e pinas menos incisas $\left(1 / 3^{-2 / 3}\right.$ da costa), com os segmentos mais largos (cerca 6-7 mm larg.). Ctenitis submarginalis possui pecíolo com escamas escassas, concentradas apenas na base, raque e costa abaxialmente com escamas espalhadas e adpressas e as pinas são mais incisas ( $3 / 4$ da costa ou mais), com segmentos mais estreitos (4-5 $\mathrm{mm}$ larg.).

Cyclodium inerme (Fée) A.R. Sm., Amer. Fern J. 76(2): 75.1986.

Material examinado: BRASIL. PARÁ: Goianésia do Pará, ZPVS-UHE de Tucuruí, Base 4, trilha 8, 04 15'0,6"$04^{\circ} 15^{\prime} 47,85^{\prime \prime} \mathrm{S}, 49^{\circ} 31^{\prime} 01,7^{\prime \prime}-49^{\circ} 30^{\prime} 17,6^{\prime \prime} \mathrm{W}$, alt. 102-179 m, 25-IX-2008, R.S. Fernandes \& S. Maciel $299(\mathrm{MG})$.

Espécie com distribuição sul-americana. No Brasil é citada para o AM, AP, PA e RR (Smith 1986, 
Costa \& Pietrobom 2007). Planta coletada em local alagado no interior da mata, com poucos indivíduos, todos estéreis. Cyclodium inerme é semelhante a C. heterodum var. abreviatum, citada como novo registro para a Amazônia brasileira por Costa et al. (2006b). Outra espécie que também se assemelha ligeiramente a $C$. inerme é $C$. guianense, a qual possui a mesma distribuição (Smith 1986). Cyclodium inerme é distinguida destas espécies pela ausência de escamas verdadeiras ao longo da costa abaxial, pelas pinas geralmente menos numerosas (10-12 pares) e mais largas, por ter uma ou duas nervuras terminando na lâmina abaixo do enseio e com soros apicais. Cyclodium guianense possui escamas apenas na superfície abaxial, esparsas, adpressas, ovaladas e frágeis, pinas numerosas (15-30 pares), três ou quatro nervuras terminando na lâmina abaixo do enseio (Smith 1986).

Elaphoglossum luridum (Fée) H. Christ, Neue Denkschr. Allg. Schweis. Ges. GesammtenNaturwiss. 36: 33. 1899.

Material adicional examinado: BRASIL. PARÁ: Tucuruí, km 25 south of Represa Tucuruí on road (BR 422) to Breu Branco, approx. $3^{\circ} 52^{\prime} \mathrm{S}, 49^{\circ} 44^{\prime} \mathrm{W}$, 15-III-1980, T. Plowman et al. 9563 (MG); idem, $16 \mathrm{~km}$ east of Represa Tucuruí, rio Tocantins, along new road (PA-263), approx. $3^{\circ} 45^{\prime} \mathrm{S}, 49^{\circ} 39^{\prime} \mathrm{W}$, 18-III-1980, T. Plowman et al. 9754 (MG).

Espécie com distribuição americana. No Brasil é citada para o AC, AM, AP, DF, ES, GO, MG, MT, MS, PA, PR, RJ, RO RR, RS, SC, SP e TO (Brade 2003, Prado 2005c, Maciel et al. 2007, Prado \& Moran 2009). Na área estudada a espécie foi coletada como epífita sobre tronco de árvore vivo no sub-bosque da floresta de baixio. Elaphoglossum luridum é caracterizado por apresentar lâmina coriácea, oblanceolada a amplamente elíptica, o tecido (às vezes, incluindo a margem), costa e nervuras possuem escamas pectinadas, negras em ambas as superfícies, especialmente na região basal, na superfície abaxial as escamas pectinadas são maiores, em maior quantidade e mais escuras, às vezes ausentes adaxialmente.
Lastreopsis effusa (Sw.) Tindale, Vict. Nat. 73: 184. 1957.

Material examinado: BRASIL. PARÁ: Novo Repartimento, ZPVS-UHE de Tucuruí, Base 3, trilha 5, 29-V-2006, A.G. Alves \& M.A. Lopes 139 (MG); Goianésia do Pará, Base 4, Ilha do Marcelo, 0409'52,8"$04^{\circ} 09^{\prime} 05,8^{\prime \prime} \mathrm{S}, 49^{\circ} 32^{\prime} 35,9^{\prime \prime}-49^{\circ} 32^{\prime} 09,6^{\prime \prime} \mathrm{W}$, alt. 75-107 m, 24-IX-2008, R.S. Fernandes \& S. Maciel 248 (MG); idem, trilha $8,04^{\circ} 15^{\prime} 0,6^{\prime \prime}-04^{\circ} 15^{\prime} 47,85^{\prime \prime} \mathrm{S}$, 49॰31'01,7" -49॰30'17,6"W, alt. 102-179 m, 13-III-2009, R.S. Fernandes \& J.M. Costa 348 (MG).

Espécie com distribuição americana. No Brasil é citada para o AC, CE, ES, MA, MG, MS, MT, PA, PB, PE, PR, RJ, RS, SC e SP (Tryon \& Conant 1975, Sehnem 1979, Mickel \& Beitel 1988, Paula-Zárate 2005, Prado \& Moran 2009). Lastreopsis effusa cresce no interior da floresta, formando grande população em encostas e locais sombreados, a margem de igarapés. Foi observada a formação de plântula, já fixada no solo e ainda presa à planta mãe, a partir da gema vegetativa no ápice da fronde. Segundo Tryon \& Stolze (1991), L. effusa é uma das poucas espécies do gênero que apresenta a lâmina geralmente com uma gema escamosa no ápice da raque e os soros não possuem indúsio.

Mickelia guianensis (Aubl.) R.C. Moran, Labiak \& Sundue, Brittonia 62(4): 345. 2010.

Material examinado: BRASIL. PARÁ: Goianésia do Pará, ZPVS-UHE de Tucuruí, Base 4, Ilha do Marcelo, 24-IX-2008, R.S. Fernandes \& S. Maciel 265 (MG); idem, trilha $8,04^{\circ} 15^{\prime} 0,6^{\prime \prime}-04^{\circ} 15^{\prime} 47,85^{\prime \prime} \mathrm{S}, 49^{\circ} 31^{\prime} 01,7^{\prime \prime}-$ 4930'17,6"W, alt. 102-179 m, 13-III-2009, R.S. Fernandes \& J.M. Costa 353 (MG).

Espécie com distribuição americana. No Brasil é citada para o AC, AM, AP e PA (Moran et al. 2010). Na área estudada, poucos espécimes foram observados, crescendo como hemiepífitas, no interior da floresta e em ambiente seco. Mickelia guianensis é facilmente diferenciada das demais espécies de Dryopteridaceae coletas na área, por apresentar forma de vida hemiepifitica, frondes dimorfas, as estéreis com arranjo das nervuras anastomosado.

\section{HYMENOPHYLLACEAE}

Chave de identificação para as espécies de Hymenophyllaceae

1. Caule longo-reptante; raízes ausentes, subtituídas por tricomas rizoidais; frondes até $3 \mathrm{~cm}$ compr.

(Didymoglossum)

2. Lâminas com falsa nervura submarginal; tricomas marginais ausentes 
2. Lâminas sem falsa nervura submarginal; tricomas marginais presentes .....

3. Indúsio com lábios não distintos, sem fileiras de células marginais escurecidas (subg. Didymoglossum) Didymoglossum pinnatinervium

3. Indúsio com lábios distintos, com 1 a várias fileiras de células marginais escurecidas

4. Lábios do indúsio com 4 a 8 fileiras de células marginais escurecidas; lâmina estéril com nervura central precurrente até a região mediana da lâmina; falsas nervuras ausentes

Didymoglossum punctatum

4. Lábios do indúsio com 1 ou 2 fileiras de células marginais escurecidas; lâmina estéril com nervura central percurente até a margem da lâmina; falsas nervuras presentes e paralelas às verdadeiras, livres, abundantes

5. Soros 3-4 por fronde; lábios do indúsio com 1 fileira de células marginais escurecidas

Didymoglossum angustifrons

5. Soros 1 por fronde; lábios do indúsio com 2 fileiras de células marginais escurecidas

Didymoglossum ovale

1. Caule curto-reptante, decumbente ou ereto; raízes numerosas e robustas; fronde maior que $3 \mathrm{~cm}$ compr.

(Trichomanes)

6. Lâmina com mais da uma célula em espessura (subg. Feea) T. trollii

6. Lâmina com uma célula em espessura (subg. Trichomanes)

7. Lâmina 1-2- pinatífida; pecíolo alado até próximo a base Trichomanes arbuscula

7. Lâmina 1-pinada a pectinada; pecíolo não alado ou estreitamente alado na parte distal

8. Indúsio imerso no tecido; lâmina pilosa Trichomanes accedens

8. Indúsio livre no tecido, séssil a curto pedunculado; lâmina glabra a escassamente pilosa

9. Frondes dimorfas, as férteis lineares, inteiras Trichomanes vittaria

9. Frondes monomorfas a subdimorfas, as férteis deltóides, pinadas, ao menos os pares basais

Trichomanes pinnatum

Didymoglossum angustifrons Fée, Mém. Foug., 11: 113, t. 28, fig. 5. 1866.

Material examinado: BRASIL. PARÁ: Goianésia do Pará, ZPVS-UHE de Tucuruí, Base 4, Ilha do

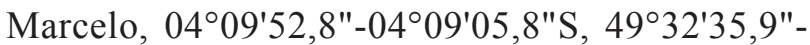
49०32'09,6"W, alt. 75-107 m, 24-IX-2008, R.S. Fernandes \& S. Maciel 268 (MG); idem, R.S. Fernandes \& S. Maciel 274 (MG); idem, $04^{\circ} 09^{\prime} 59,3^{\prime \prime S}-49^{\circ} 32^{\prime} 38,0^{\prime \prime} \mathrm{W}$, alt. $35 \mathrm{~m}, 14-\mathrm{III}-2009$, R.S. Fernandes \& J.M. Costa 392 (MG).

Espécie com distribuição americana. No Brasil é citada para o AM, AP, CE, BA, MT, PA, PE, RJ, PR, RS, SC e SP (Boer 1962, Tryon \& Conant 1975, Windisch 1996, Xavier \& Barros 2003, Mynssen $\&$ Windisch 2004). Na área estudada, foi coletada somente no interior das florestas na base de troncos vivos, ocorrendo juntamente com briófitas e/ou outras espécies de Hymenophyllaceae. Didymoglossum angustifrons é, dentre as espécies de pequeno porte, a que apresenta a maior variedade de formas da lâmina foliar num mesmo indivíduo, enquanto que as demais espécies encontradas apresentam formas lâminares mais regulares. Difere das demais espécies estudadas de porte semelhante $(0,5-2 \mathrm{~cm}$ compr.) por apresentar os lábios do indúsio com uma fileira de células marginais escurecidas (Costa 2007).

Didymoglossum kapplerianum (J.W. Sturm) Ebihara \& Dubuisson, Blumea 51(2): 236. 2006.

Material examinado: BRASIL. PARÁ: Goianésia do Pará, ZPVS-UHE de Tucuruí, Base 4, lha do

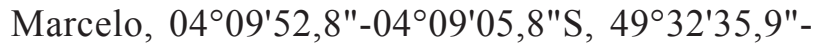
49॰32'09,6"W, alt. 75-107 m, 24-IX-2008, R.S. Fernandes \& S. Maciel 270 (MG); 275 (MG); idem, $04^{\circ} 09^{\prime} 59,3^{\prime \prime} \mathrm{S}, 49^{\circ} 32^{\prime} 38,0^{\prime \prime} \mathrm{W}$, alt. $35 \mathrm{~m}$, 14-III-2009, R.S. Fernandes \& J.M. Costa 390 (MG).

Espécie com distribuição americana. No Brasil é citada para o AP, AM, PA, RJ e SP (Boer 1962, Tryon \& Conant 1975, Costa \& Pietrobom 2007). Na área estudada, foram observados poucos indivíduos, crescendo como epífita na base dos troncos vivos no interior da floresta de terra firme, em ambiente úmido. Didymoglossum kapplerianum caracteriza-se pela venação pinada na base e flabelada distalmente, com costa não percorrente, falsas nervuras presentes, lâmina glabra com células marginais tangencialmente alongadas de forma retangular. Frequentemente é confundida com D. ekmanii (Wess. Boer) Ebihara 
\& Dubuisson citada para o Amazonas, distingue-se desta por apresentar uma falsa nervura submarginal descontínua, em vez de contínua como em $D$. ekmanii (Pacheco 1995).

*Didymoglossum ovale Fourn., Bull. Soc. Fr. 19: 240. 1872.

Figura 2a

Material examinado: BRASIL. PARÁ: Novo Repartimento, ZPVS-UHE de Tucuruí, Base 3, trilha principal, 9-VII-2008, R.S. Fernandes et al. 151 (MG); Goianésia do Pará, Base 4, Ilha do Tamarindo, 04 16'04,2"-04'16'37,3"S, 49³9'37,4"-49³9'11,6"W, alt. 70-103 m, 23-IX-2008, R.S. Fernandes \& S. Maciel $226(\mathrm{MG})$.

Espécie com distribuição americana. No Brasil é citada para o AM, AC, BA, ES, MT, PE, PR, RJ, RS, SP e SC (Boer 1962, Windisch 1996, Prado \& Moran 2009). Na área estudada, foi coletada como epífita em tronco vivo no interior da mata. Didymoglossum ovale apresenta semelhança com $D$. angustifrons, pela forma linear-oblonga das frondes, no entanto, pode ser diferenciada desta por apresentar frondes uniformes circular-obovóides a linear-oblongas, em geral diminutas (1,5-5 mm compr.), um único soro terminal e indúsio com 1-2 fileiras de células escurecidas na borda dos lábios. Em Didymoglossum angustifrons as frondes variam de simples, ovaladas, lineares a linear-oblongas ou cuneiformes (0,6-1,4 cm compr.), 3-4 soros apicais por fronde, e indúsio com apenas uma fileira de células marginais escurecidas na borda dos lábios.

Didymoglossum pinnatinervium (Jenman) Pic. Serm.,Webbia 28: 469. 1973.

Material examinado: BRASIL. PARÁ: Goianésia do Pará, ZPVS-UHE de Tucuruí, Base 4, Ilha do Marcelo, 04 09'52,8"S-49॰32'35,9"W a $04^{\circ} 09^{\prime} 05,8^{\prime \prime} \mathrm{S}-49^{\circ} 32^{\prime} 09,6^{\prime \prime} \mathrm{W}$, alt. 75-107 m, 24-IX-2008, R.S. Fernandes \& S. Maciel 267 (MG).

Espécie com distribuição americana. No Brasil é citada para o PA (Costa et al. 2006a). Na área estudada, foi coletada unicamente no interior das matas crescendo como epífita na base de troncos vivos, associada a briófitas. Didymoglossum pinnatinervium é caracterizada pela venação pinada, costa percorrente, ausência de falsas nervuras, margem da lâmina com tricomas simples ou usualmente geminados e o indúsio com lábios distintos e sem fileiras de células marginais escurecidas.
Didymoglossum punctatum (Poir.) Desv., Mém. Soc. Linn. Paris 6: 330. 1827.

Material examinado: BRASIL. PARÁ: Novo Repartimento, ZPVS-UHE de Tucuruí Base 3, 9-VII-2008, R.S. Fernandes et al. 148 (MG); idem, trilha principal, 10-VII-1008, R.S. Fernandes et al. 174 (MG); Goianésia do Pará, Base 4, lha do Prefeito, 04²0'02"S, $49^{\circ} 36^{\prime} 52^{\prime \prime} \mathrm{W}$, alt. $70 \mathrm{~m}, 25-\mathrm{IX}-2008$, R.S. Fernandes \& S. Maciel 316 (MG); idem, Ilha do Marcelo, $04^{\circ} 09^{\prime} 59,3^{\prime \prime} \mathrm{S}, 49^{\circ} 32^{\prime} 38,0^{\prime \prime} \mathrm{W}$, alt. $35 \mathrm{~m}, 14-\mathrm{III}-2009$, R.S. Fernandes \& J.M. Costa 391 (MG).

Espécie com distribuição americana. No Brasil é citada para o AC, AM, AP, MT, PA e RJ (Tryon \& Conant 1975, Windisch 1996, Prado \& Moran 2009). Na área estudada, foi observada crescendo na base de troncos vivos no interior da floresta de terra firme, junto de barranco próximo a curso d'água. Didymoglossum punctatum caracteriza-se pela venação flabelada, costa não percorrente, ausência de falsas nervuras, 1-5 soros por lâmina, usualmente, entre os enseios dos lobos ou nos lobos, indúsio com ápice expandido, bilabiado e lábios com diversas fileiras de células marginais escurecidas.

Trichomanes accedens C. Presl., Epimel. Bot.: 14. 1849 [1851].

Material examinado: BRASIL. PARÁ: Tucuruí, 12 km north of town of Tucuruí along road to Cametá, approx. $3^{\circ} 36^{\prime} \mathrm{S}-49^{\circ} 44^{\prime} \mathrm{W}, 21-\mathrm{III}-1980$, T. Plowman et al. 9866 (MG).

Espécie com distribuição americana. No Brasil é citada para o AM, AP, BA, MT, PA, RJ e SP (Sampaio 1930, Windisch 1996). Na área estudada, ocorre como epífita sobre tronco caído em decomposição. Trichomanes accedens é próxima de T. cristatum Kaulf, distinguindo-se desta última por apresentar o caule ereto a ascendente com frondes contíguas e, sobretudo, pelo indumento menos denso sobre a raque, bem como pelos segmentos mais estreitos. A diferença mais importante são as estreitas alas na parte distal do pecíolo, às vezes danificadas na coleta ou no manuseio do material (Windisch 1996).

Trichomanes arbuscula Desv., Mém. Soc. Linn. Paris 6: 326.1827.

Material examinado: BRASIL. PARÁ: Tucuruí, $16 \mathrm{~km}$ east of Represa Tucuruí, rio Tocantins, along new road (PA 263), approx. $3^{\circ} 45^{\prime} \mathrm{S}-49^{\circ} 39^{\prime} \mathrm{W}, 18-\mathrm{III}-1980$, 
T. Plowman, et al. 9713 (MG); idem, margem direita do rio Tocantins, 31-V-1980, M.G. Silva 5304 (MG).

Espécie com distribuição americana. No Brasil é citada para o AC, AM, BA, ES, MT, PA, PE e SP (Tryon \& Conant 1975, Windisch 1996, Costa \& Pietrtobom 2007). Na área estudada, cresce em capoeira de terra firme, como epífita sobre raízes de árvores. Trichomanes arbuscula assemelha-se a T. macilentum Bosch, registrada para o Amazonas (Tryon \& Conant 1975), por ambas terem lâminas pinatífidas com segmentos lobados a pinatífidos. Diferem entre si pela forma do ápice do indúsio (Smith 1995a) e o tamanho da fronde. Em T. arbuscula o indúsio é bilobado e a fronde tem cerca $12 \mathrm{~cm}$ compr. enquanto em $T$. macilentum o indúsio é truncado e a fronte tem $20 \mathrm{~cm}$ compr.

Trichomanes pinnatum Hedw., Fil. Gen. Sp., t. 4, fig. 2. 1799.

Material examinado: BRASIL. PARÁ: Novo Repartimento, Base 3, ZPVS-UHE de Tucuruí, trilha principal, 9-VII-2008, R.S. Fernandes et al. 126 (MG); idem, 10-VII-2008, R.S. Fernandes et al. 158 (MG); Goianésia do Pará, Base 4, trilha 8, Ilha do Cornélio, 04¹7'40,1"S, 49²8'12,6"W, alt. 110-120 m, 23-IX-2008, R.S. Fernandes \& S. Maciel 195 (MG), 196 (MG); idem, trilha $8,04^{\circ} 15^{\prime} 0,6^{\prime \prime}-04^{\circ} 15^{\prime} 47,85^{\prime \prime} \mathrm{S}$, $49^{\circ} 31^{\prime} 01,7^{\prime \prime}-49^{\circ} 30^{\prime} 17,6^{\prime \prime} \mathrm{W}$, alt. 102-179 m, 13-III-2009, R.S. Fernandes \& J.M. Costa 344 (MG).

Espécie com distribuição americana. No Brasil é citada para o AC, AL, AM, AP, BA, CE, ES, GO, MA, MG, MS, MT, PA, PE, PI, RO, RR e TO (Sehnem 1971, Tryon \& Conant 1975, Windisch 1996, Graçano et al. 1998, Paciencia \& Prado 2004, Pietrobom \& Barros 2003, 2006a, Costa \& Pietrobom 2007). Na área estudada, cresce no interior da floresta de terra firme junto às raízes das árvores próximo às margens de curso d'água. Segundo Tryon \& Stolze (1989), Trichomanes pinnatum é, algumas vezes, confundido nos herbários com espécimes de T. hostmannianum (Klotzsch) Kunze, devido ao hábito e divisão da lâmina. No entanto, as frondes de T. hostmannianum não excedem $30 \mathrm{~cm}$ de comprimento, as pinas raramente são maiores que $6 \mathrm{~cm}$ compr. e $1 \mathrm{~cm}$ larg. e não ocorrem falsas nervuras, enquanto que as frondes de $T$. pinnatum atingem até $70 \mathrm{~cm}$ de comprimento, as pinas têm $15 \mathrm{~cm}$ compr. e $2 \mathrm{~cm}$ larg. e com estas dimensões, as falsas nervuras são facilmente visíveis.
Trichomanes trollii Bergdolt, Fl. 127: 256, 264, t. 3. 1933.

Material examinado: BRASIL. PARÁ: Goianésia do Pará, ZPVS-UHE de Tucuruí, Base 4, Ilha do Marcelo, 040' $52,8^{\prime \prime}-04^{\circ} 09^{\prime} 05,8^{\prime \prime S}, 49^{\circ} 32^{\prime} 35,9^{\prime \prime}-49^{\circ} 32^{\prime} 09,6^{\prime \prime} \mathrm{W}$, alt. 75-107 m, 24-IX-2008, R.S. Fernandes \& S. Maciel 273 (MG); idem, trilha 8, 04 ${ }^{\circ} 15^{\prime} 0,6^{\prime \prime}-$ $04^{\circ} 15^{\prime} 47,85^{\prime \prime} \mathrm{S}, 4^{\circ} 31^{\prime} 01,7^{\prime \prime}-49^{\circ} 30^{\prime} 17,6^{\prime \prime} \mathrm{W}$, alt. 102-179 m, 25-IX-2008, R.S. Fernandes \& S. Maciel

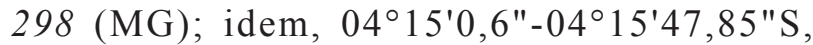
$49^{\circ} 31^{\prime} 01,7 "-49^{\circ} 30^{\prime} 17,6^{\prime \prime} \mathrm{W}$, alt. 102-179 m, 13-III-2009, R.S. Fernandes \& J.M. Costa 352 (MG).

Espécie com distribuição sul-americana. No Brasil é citada para o AC, AP, AM, MT, PA e RR (Tryon \& Conant 1975, Windisch 1996, Costa \& Pietrobom 2007, Prado \& Moran 2009). Na área estudada, foi coletada sempre no interior da floresta, crescendo em barrancos ao longo das margens de cursos d'água. Trichomanes trollii é semelhante a T. diversifrons (Bory) Mett. que ocorre no Amapá e Amazonas (Tryon \& Conant 1975), a qual se distingue por apresentar lâmina estéril com segmentos mais largos (3-6 cm larg.), nervuras anastomosadas e, ainda, a margem da lâmina fértil denteada (Windisch 1996). Em Trichomanes trollii os segmentos são estreitos (3-4 mm larg.), a venação é livre, as nervuras secundárias são duplamente bifurcadas, às vezes fundindo-se na porção marginal da lâmina e a margem da lâmina fértil é denteada.

Trichomanes vittaria DC. ex Poir., Encycl. 8: 65. 1808.

Material examinado: BRASIL. PARÁ: Goianésia do Pará, ZPVS-UHE de Tucuruí, Base 4, Ilha do Marcelo, 0409'59,3"S, 49³2'38,0"W, alt. 35 m, 14-III-2009, R.S. Fernandes \& J.M. Costa 382 (MG).

Espécie com distribuição sul-americana. No Brasil é citada para o AP, AM, MT, PA e RJ (Boer 1962, Tryon \& Conant 1975, Windisch 1996). Na área de estudo, cresce na margem de trilha, em ambiente seco, no interior da mata de terra firme ou em barrancos próximos de igarapés. Trichomanes vittaria é caracterizada por apresentar frondes fortemente dimorfas, as estéreis são pinadas com padrão de venação livre, falsas nervuras presentes e lâmina fértil linear com o indúsio livre não imerso no tecido lâminar. As frondes jovens estéreis podem ser facilmente, confundidas com espécimes de T. pinnatum. 


\section{LINDSAEACEAE}

Chave de identificação para as espécies de Lindsaeaceae

1. Lâmina 1-pinada; pecíolo arredondado, sulcado adaxialmente; pina terminal flabelada Lindsaea schomburgkii

1. Lâmina 2-pinada (às vezes 1-pinada nas frondes jovens); pecíolo quadrangular, não sulcado; pina terminal deltóide ou lanceolado a caudada

2. Pínulas reduzindo gradualmente em direção ao ápice; pínulas da região mediana conspicuamente super-postas; pínula terminal lanceolada a caudada Lindsaea guianensis ssp. guianensis

2. Pínulas reduzindo abruptamente em direção ao ápice; pínulas da região mediana não ou parcialmente superpostas, às vezes contíguas; pínula terminal deltóide Lindsaea lancea var. lancea

Lindsaea guianensis (Aubl.) Dryand. ssp. guianensis, Trans., Linn. Soc. 3: 42.1797.

Material examinado: BRASIL. PARÁ: Tucuruí, 16 km east of Represa Tucuruí, rio Tocantins, along new road (PA-263), approx. 34' ${ }^{\circ}$ S, 49³9'W, 18-III-1980, T. Plowman et al. 9738 (MG).

Espécie com distribuição americana. No Brasil é citada para o AM, CE, GO, MT, PA e SP (Huber 1908, Brade 1940, Kramer 1957, Prado 2005b). Planta coletada em floresta de baixio, terreno arenoso com densas camadas de húmus. Lindsaea guianensis ssp. guianensis é caracterizada por apresentar redução gradual das pínulas em direção ao ápice e pela pínula apical simétrica, lanceolada a caudada.

Lindsaea lancea (L.) Bedd. var. lancea, Ferns Brit. India Suppl.: 6. 1876.

Material examinado: BRASIL. PARÁ: Goianésia do Pará, ZPVS-UHE de Tucuruí, Base 4, Ilha João do Bó, 6-XI-2005 A.G. Alves \& M.A. Lopes 98 (MG);

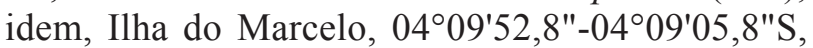
49³2'35,9"-49³2'09,6"W, alt. 75-107 m, 24-IX-2008, R.S. Fernandes \& S. Maciel 260 (MG).

Espécie com distribuição americana. No Brasil é citada para o AC, AL, AM, AP, BA, CE, GO, MG, MT, PA, PE, PI, PR, RJ, RS, RR, SC e SP (Tryon \& Conant 1975, Pietrobom \& Barros 2003, 2006b, Paula-Zárate
2005, Boldrin \& Prado 2007). Na área estudada, a espécie foi coletada crescendo em barranco próximo a igarapé no interior da floresta. Além dos caracteres apresentados na chave, Lindsaea lancea var. lancea também pode ser reconhecida pela raque (raquíola) semelhante à porção distal do pecíolo (esverdeada a paleácea), as pinas 1-pinadas, com pina terminal conforme e pínula apical com ápice longo-acuminado. Lindsaea lancea var. lancea é a mais inconstante dentre as seis variedades da espécie, quanto a forma da lâmina. Segundo Kramer (1957), a variedade pode apresentar lâmina variando de 1 a 2-pinada (esta última é a forma mais comum), característica esta observada em algumas frondes dos espécimes em desenvolvimento na área estudada.

Lindsaea schomburgkii Klotzsch, Linnaea 18: 545. 1844.

Material examinado: BRASIL. PARÁ: Tucuruí, $16 \mathrm{~km}$ east of Represa Tucuruí, rio Tocantins, along new road (PA-263), approx. $3^{\circ} 45^{\prime} \mathrm{S}, 49^{\circ} 39^{\prime} \mathrm{W}, 18-\mathrm{III}-1980$, T. Plowman et al. 9739 (MG).

Espécie com distribuição sul-americana. No Brasil é citada para o AC, AM, PA, MT e RR (Tryon $\&$ Conant 1975). Planta coletada em floresta de baixio, em terreno arenoso com densas camadas de húmus. Lindsaea schomburgkii pode ser confundida com a forma jovem (1-pinada) de L. lancea var. lancea, quanto ao formato das pinas e das numerosas nervuras. No entanto, L. schomburgkii apresenta o pecíolo adaxialmente sulcado e abaxialmente arredondado, castanho-avermelhado, e ainda a pina terminal simétrica, flabelada, com base longamente cuneada. $\mathrm{Na}$ forma jovem (1-pinada) de Lindsaea lancea var. lancea o pecíolo é quadrangular, não sulcado, paleáceo a esverdeado e com pina terminal lanceolado-deltoide, com base assimétrica.

\section{LOMARIOPSIDACEAE}

Chave de identificação para as espécies de Lomariopsidaceae

1. Frondes dimorfas; soros acrosticóides; caule longo-escandente; plantas hemiepífitas (Lomariopsis)

2. Escamas do caule castanho-escuras aenegrecidas;pinas 8-12pares, lanceoladas a oblongas, as basais reduzidas; esporos com perisporo liso ........ Lomariopsis japurensis 
2. Escamas do caule castanhoavermelhadas a alaranjadas; pinas 2-7 pares, elípticas, as basais não reduzidas; esporos com perisporo espinuloso Lomariopsis prieuriana

1. Frondes monomorfas; soros circulares; caule decumbente ou ereto; plantas terrícolas ou epífitas

3. Pina semicordada a auriculada na base, lado basioscópico com aurícula sobrepondo a raque, lado acroscópico não auriculado; soros em 4 fileiras em cada lado da costa ......... Cyclopeltis semicordata

3. Pina truncada a inequilateral na base, lado basioscópico sem aurícula sobrepondo a raque, lado acroscópico auriculado; soros uniseriados em cada lado da costa (Nephrolepis)

4. Caule com escamas concolores, patentes; costa na superfície adaxial glabra ou escamosa .... Nephrolepis biserrata

4. Caule com escamas bicolores, adpressas; costa na superfície adaxial pilosa Nephrolepis brownii

Cyclopeltis semicordata (Sw.) J. Sm., Bot. Mag. 72(compendium): 36. 1846.

Material examinado: BRASIL. PARÁ: Novo Repartimento, ZPVS-UHE de Tucuruí, Base 3, 9-VII-2008, R.S. Fernandes et al. 114 (MG); idem, Ressaca do Pirarucu, 4²2" 55,3"-04²2'11,8"S, $49^{\circ} 35^{\prime} 39,8^{\prime \prime}-49^{\circ} 36^{\prime} 13,3^{\prime \prime} \mathrm{W}$, alt. 72-84 m, 12-III-2009, R.S. Fernandes \& J.M. Costa 323 (MG); Goianésia do Pará, Base 4, Ilha do Tamarindo, 04 16'04,2"$04^{\circ} 16^{\prime} 37,3 " \mathrm{~S}, 49^{\circ} 39^{\prime} 37,4^{\prime \prime}-49^{\circ} 39^{\prime} 11,6^{\prime \prime} \mathrm{W}$, alt. 70-103 m, 23-IX-2008, R.S. Fernandes \& S. Maciel 220 (MG).

Espécie com distribuição americana. No Brasil é citada para o AC, AM, MT, PA, RO e RR (Tryon \& Conant 1975). Na área, cresce no interior da mata sobre solo rico em nutrientes, sempre próximo à margem de curso d'água. Cyclopeltis semicordata é confundida com as espécies do gênero Nephrolepis, também coletadas na área estudada; no entanto, é facilmente distinguida por apresentar os soros em 1-2 séries, próximos à costa, indúsio arredondado, peltado e, ainda, pela presença de uma aurícula basioscópica semicordada na base da pina, sobrepondo à raque (Mickel \& Smith 2004, Zuquim et al. 2008).
Lomariopsis japurensis (Mart.) J. Sm., Hist. Fil.: 140. 1875.

Material examinado: BRASIL. PARÁ: Novo Repartimento, ZPVS-UHE de Tucuruí, Base 3, 9-VII-2008, R.S. Fernandes et al. 117 (MG); idem, Ilha do Cornélio, $04^{\circ} 17^{\prime} 40,1^{\prime \prime S}, 4^{\circ} 28^{\prime} 12,6^{\prime \prime} \mathrm{W}$, alt. 110-120 m, 23-IX-2008, R.S. Fernandes \& S. Maciel 200 (MG); idem, Ressaca do Pirarucu, 4²2"55,3"$04^{\circ} 22^{\prime} 11,8^{\prime \prime} \mathrm{S}, 4^{\circ} 35^{\prime} 39,8^{\prime \prime}-49^{\circ} 36^{\prime} 13,3^{\prime \prime} \mathrm{W}$, alt. 72-84 m, 12-III-2009, R.S. Fernandes \& J.M. Costa 317 (MG); R.S. Fernandes \& J.M. Costa 324 (MG); Goianésia do Pará, Base 4, Trilha 8, 04-XI-2005, A.G. Alves \& M.A. Lopes 80 (MG); 81 (MG).

Espécie com distribuição americana. No Brasil é citada para o AC, AL, AM, CE, MT, PA, PE e RR (Moran 2000, Pietrobom \& Barros 2006b). Na área estudada $L$. japurensis foi observada crescendo exclusivamente sobre troncos vivos, em floresta de terra firme, no interior da mata, a margem de trilhas ou de igarapé. Lomariopsis japurensis é caracterizada por possuir até 12 pares de pinas, com pinas oblongas ou lanceoladas reduzidas em direção ao ápice e base, escamas do caule e da base do pecíolo adpressas e enegrecidas e os esporos com perisporo liso.

Lomariopsis prieuriana Fée, Mém. Foug. 2: 66. 1845.

Material examinado: BRASIL. PARÁ: Novo Repartimento, ZPVS-UHE de Tucuruí, Base 3, trilha principal, 9-VII-2008, R.S. Fernandes et al. 113 (MG) Goianésia do Pará, Base 4, Ilha do Cornélio $04^{\circ} 17^{\prime} 40,1^{\prime \prime S}, 49^{\circ} 28^{\prime} 12,6^{\prime \prime} \mathrm{W}$, alt. 110-120 m, 23-IX-2008, R.S. Fernandes \& S. Maciel 190 (MG); 193 (MG); idem, trilha 4, 04 $15^{\prime} 18,5^{\prime \prime} \mathrm{S}-49^{\circ} 31^{\prime \prime} 03,7 \mathrm{~W}$, alt. 60 m, 13-III-2009. R.S. Fernandes \& J.M. Costa 376 (MG).

Espécie com distribuição americana. No Brasil é citada para o AC, AP, AM, BA, MA, MT, PA e RO (Moran 2000, Prado \& Moran 2009). Na área estudada, foram observados espécimes jovens de L. prieuriana crescendo como terrícola. Os indivíduos adultos foram observados como hemiepífitas exclusivamente sobre troncos vivos, em floresta de terra firme no interior da mata, a margem de igarapé. Lomariopsis prieuriana é caracterizada pelas pinas elípticas com base cuneada a escavada, poucos pares de pinas (geralmente 3-7) e as escamas do caule castanho-avermelhadas a alaranjadas. Outra característica que a diferencia de L. japurensis, quando os espécimes estão férteis, é 


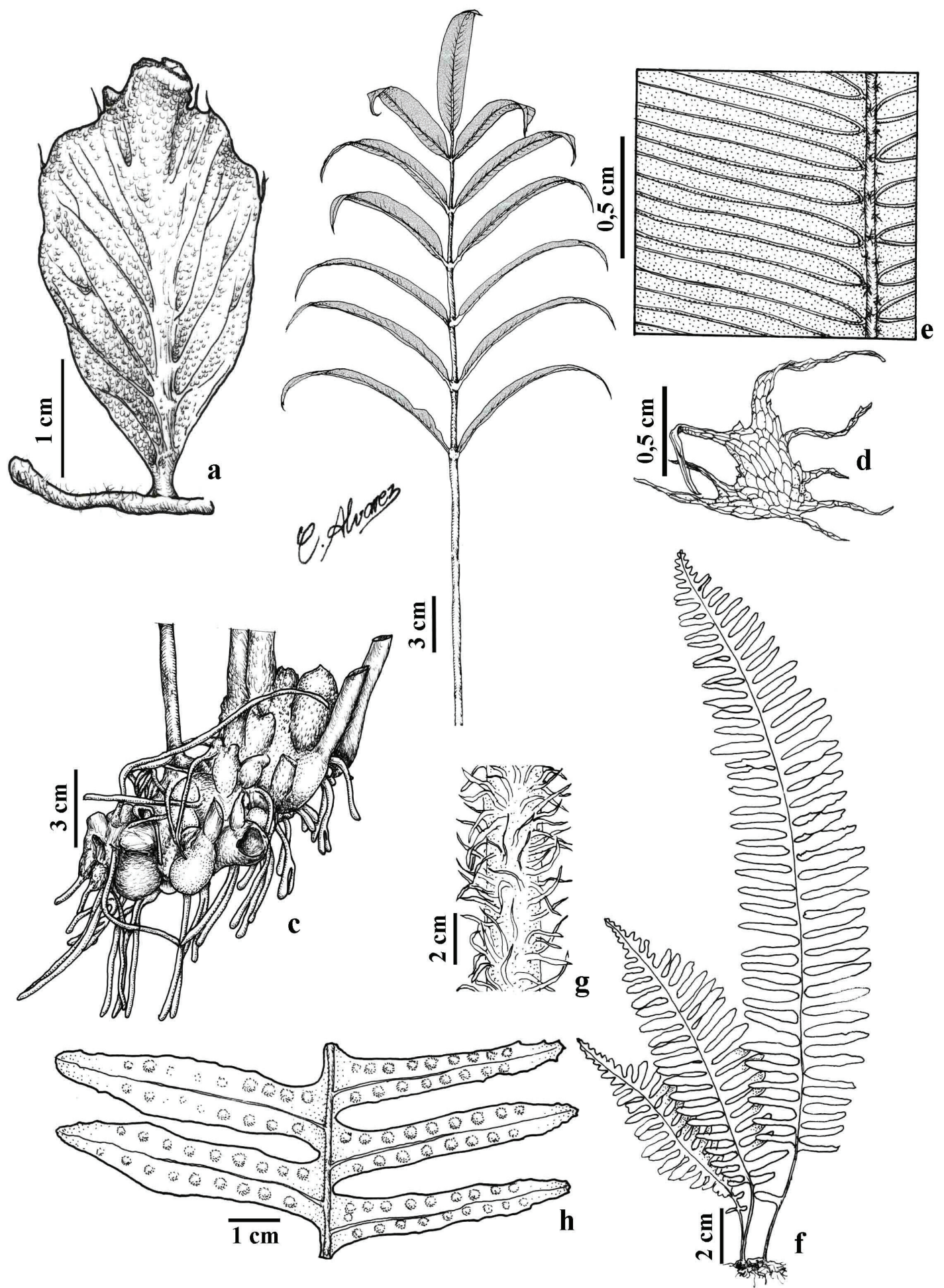

Figura 2. Espécies de monilófitas ocorrentes na área de estudo. a. Didymoglossum ovale Fourn., Hábito. b-e. Danaea nodosa (L.) Sm. b. Fronde fértil. c. Caule evidenciando as raízes robustas e estípulas. d. Escama da costa abaxial. e. Porção abaxial da lâmina evidenciando o padrão de venação. f-h. Pecluma hygrometrica (Spligt.) M.G. Price. f. Hábito. g. Detalhe dos tricomas na costa. h. Segmentos férteis (a: R.S. Fernandes \& S. Maciel 226 (MG); b-e: Fernandes \& J.M. Costa 347 (MG); f-h: R.S. Fernandes \& J.M. Costa 325 (MG)).

Figure 2. Monilophytes species occurring in the study area. a. Didymoglossum ovale Fourn., Habit. b-e. Danea nodosa (L.) Sm. b. Fertile frond. c. Stem showing the robust roots and stipules. d. Abaxial rachis scales. e. Abaxial portion of the blade showing the venation pattern. f-h. Pecluma hygrometrica (Spligt.) M.G. Price. f. Habit. g. Detail of trichomes on the trachis. h. Fertile segments (a: R.S. Fernandes \& S. Maciel 226 (MG); b-e: Fernandes \& J.M. Costa 347 (MG); f-h: R.S. Fernandes \& J.M. Costa 325 (MG)). 
a forma do perisporo espinuloso em L. prieuriana (com projeções em forma de fios), enquanto que em L. japurensis o perisporo é liso (Moran 2000).

Nephrolepis biserrata (Sw.) Schott, Gen. Fil. Pl.: t.3. 1834.

Material examinado: BRASIL. PARÁ: Novo Repartiemento, ZPVS-UHE de Tucuruí, Base 3, 9-VII-2008, R.S. Fernandes et al. 139 (MG); idem, 10-VII-2008, R.S. Fernandes et al. 159 (MG); Goianésia do Pará, ZPVS-UHE de Tucuruí, Base 4, Ilha do Prefeito, $04^{\circ} 20^{\prime} 02^{\prime \prime S}, 49^{\circ} 36^{\prime} 52^{\prime \prime} \mathrm{W}$, alt. $70 \mathrm{~m}, 25-\mathrm{IX}-2008$, R.S. Fernandes \& S. Maciel 313 (MG).

Espécie com distribuição circum-antártica. No Brasil é citada para o AC, AL, AM, AP, BA, CE, ES, MA, MT, PA, PB, PE, PR, RJ, SC e SP(Mori et al. 1983, Behar \& Viégas 1992, Fernandes et al. 2007, Santos \& Sylvestre 2001, Paula-Zárate 2005, Pietrobom \& Barros 2006a, Boldrin \& Prado 2007, Maciel et al. 2007, Prado \& Moran 2009). Na área estudada a espécie foi observada como epífita crescendo sobre palmeiras ou troncos em decomposição e ainda como terrícola no interior da mata. Nephrolepis biserrata é caracterizada principalmente pelas escamas do caule e base do pecíolo concolores, patentes, projetando-se em várias direções, pina com base equilateral, com indumento formado por tricomas e escamas submedianos a medianos.

Nephrolepis brownii (Desv.) Hovenkamp \& Miyam., Blumea 50(2): 293. 2005.

Material examinado: BRASIL. PARÁ: Goianésia do Pará, ZPVS-UHE de Tucuruí, Base 4, Ilha do Cornélio, $04^{\circ} 17^{\prime} 40,1^{\prime \prime S}, 49^{\circ} 28^{\prime} 12,6^{\prime \prime} \mathrm{W}$, alt. 110-120 m, 23-IX-2008, R.S. Fernandes \& S. Maciel 197 (MG); idem, R.S. Fernandes \& S. Maciel 192 (MG).

Espécie com distribuição pacífica. No Brasil é citada para o AC, AM, AP, BA, PA, PR, RJ e SP (Barros et al. 2012). Na área estudada a espécie foi observada crescendo no interior da mata em ambiente seco. Nephrolepis brownii é caracterizada pela costa escamosa abaxialmente e adaxialmente com tricomas, frequentemente na base. As pinas medianas apresentam o lado basioscópico arredondado a obtuso e o lado acroscópico auriculado a truncado ou obtuso (Maciel \& Pietrobom 2010b).

\section{LYGODIACEAE}

Chave de identificação para as espécies de Lygodiaceae

1. Pínulas $22-35 \mathrm{~cm}$ compr., estreitamente deltóides; pínulas de $2^{\mathrm{a}}$ ordem com base hastada, reduzindo-se gradualmente em direção ao ápice, as distais mais curtas que as proximais Lygodium venustum

1. Pínulas 6,5-14 cm compr., largamente oblongas; pínulas de $2^{\mathrm{a}}$ ordem com base lobada, truncada a arredondada ou aguda, não reduzindo gradualmente em direção ao ápice, todas do mesmo tamanho. Lygodium volubile

Lygodium venustum Sw., J. Bot. (Schrader) 1801(1): 303. 1803.

Material examinado: BRASIL. PARÁ: Novo Repartimento, Base 3, 9-VII-2008, R.S. Fernandes et al. 138 (MG); Goianésia do Pará, ZPVS-UHE de Tucuruí, Base 4, 4 15'7,9"S, 49³2'5,3"W, 19-II-2000, A.L. Ilkiu-Borges \& C.S. Rosário 1772 (MG); idem, ZPVS-UHE de tucuruí, Ilha do Cornélio, $04^{\circ} 17^{\prime} 40,1^{\prime \prime S}, 49^{\circ} 28^{\prime} 12,6^{\prime \prime} \mathrm{W}$, alt. 110-120 m, 23-IX-2008, R.S. Fernandes \& S. Maciel 183 (MG); idem, cerca de $5 \mathrm{~km}$ de Jatobal após o Breu Branco, 25-III-1981, A.S.L. Silva et al. 1459 (MG).

Espécie com distribuição americana. No Brasil é citada para o AC, AL, AP, AM, CE, MG, MA, MT, PA, PB, PE, RR e RO (Brade 1940, Tryon \& Conant 1975, Graçano et al. 1998, Bastos \& Cutrim 1999, Windisch \& Tryon 2001, Silva \& Barros 2005, Pietrobom \& Barros 2006b, Prado \& Moran 2009, Barros et al. 2010). Na área estudada, a espécie foi coletada como trepadeira, crescendo sobre a vegetação à margem das trilhas, ou em clareira, em ambiente seco e pedregoso. Lygodium venustum possui lâmina esparsa ou abundantemente pilosa sobre o tecido, costa e nervuras em ambas as superfícies e pínulas de $2^{\mathrm{a}}$ ordem com base hastada, reduzidas gradualmente em direção ao ápice.

Lygodium volubile Sw., J. Bot. (Schrader) 1801 (1): 304. 1803.

Material examinado: BRASIL. PARÁ: Goianésia do Pará, ZPVS-UHE de Tucuruí, Base 4, Ilha do Cornélio, $04^{\circ} 17^{\prime} 40,1^{\prime \prime S}, 4^{\circ} 28^{\prime} 12,6^{\prime \prime} \mathrm{W}$, alt. 110-120 m, 23-IX-2008, R.S. Fernandes \& S. Maciel 184 (MG); idem, trilha $8,04^{\circ} 15^{\prime} 0,6^{\prime \prime}-04^{\circ} 15^{\prime} 47,85^{\prime \prime} \mathrm{S}$, 
49³1'01,7-49॰30'17,6"W, alt. 102-179 m, 13-III-2009, R.S. Fernandes \& J.M. Costa 343 (MG).

Espécie com distribuição americana. No Brasil é citada para o AC, AL, AP, AM, BA, CE, DF, ES, GO, MG, MA, PA, PI, PB, PR, PE, RJ, RN, RR, RO, SC, SE e SP (Tryon \& Conant 1975, Mori et al. 1983, Behar \& Viégas 1992, Graçano et al. 1998, Bastos \& Cutrim 1999, Salino \& Joly 2001, Mynssen \& Windisch 2004, Paula-Zárate 2005, Pietrobom \& Barros 2006b, Prado \& Moran 2009). Planta crescendo como trepadeira sobre árvores no interior da floresta, alcançando vários metros de altura. Lygodium volubile apresenta tecido e nervuras na superfície abaxial densamente pilosos e na superfície adaxial com tricomas escassos, somente a costa abundantemente pilosa e as pínulas de $2^{\mathrm{a}}$ ordem com base não hastada (truncada a arredondada ou aguda) e quase todas do mesmo tamanho (Costa 2007).

\section{MARATTIACEAE}

*Danaea nodosa (L.) Sm., Mém. Acad. Roy. Sci. (Turin) 5: 420. 1793.

Figura $2 \mathrm{~b}-\mathrm{e}$
Material examinado: BRASIL. PArÁ: Novo Repartimento, ZPVS-UHE de Tucuruí, Base 3, Lajeiro, $04^{\circ} 22^{\prime} 40^{\prime \prime} \mathrm{S}, 49^{\circ} 35^{\prime} 18,5^{\prime \prime} \mathrm{W}$, alt. $138 \mathrm{~m}, 12-\mathrm{III}-2009$, R.S. Fernandes \& J.M. Costa 342 (MG); Goianésia do Pará, ZPVS-UHE de Tucuruí, Base 4, Ilha do Marcelo 0409'52, $8^{\circ}-04^{\circ} 09^{\prime} 05,8^{\prime \prime} \mathrm{S}, 49^{\circ} 32^{\prime} 35,9^{\prime \prime}-49^{\circ} 32^{\prime} 09,6^{\prime \prime} \mathrm{W}$, alt. 75-107 m, 24-IX-2008, R.S. Fernandes \& S. Maciel 251 (MG).

Espécie com distribuição americana. No Brasil é citada para o AC, AL, AM, BA, ES, MT, MG, PE, PR, RJ, RS, SC e SP (Pietrobom \& Barros 2006b, Rolleri 2004, Prado \& Moran 2009). Na área estudada, a espécie cresce em barrancos no interior da floresta, em ambiente úmido próximo a curso d'água. Danaea nodosa foi considerada por Christenhusz (2007) sinônimo de D. elliptica Sm. Diferenciam-se apenas pela ausência de nódulos no pecíolo em $D$. nodosa, pois as demais características utilizadas por Rolleri (2004), como número de pares de pinas, padrão de venação e o tipo de caule, se sobrepõem.

\section{POLYPODIACEAE}

Chave de identificação para as espécies de Polypodiaceae

1. Lâmina simples

2. Soros em 3-10 fileiras entre a costa e a margem da lâmina Campyloneurum phyllitidis

2. Soros em 1 fileira entre a costa e a margem da lâmina

3. Frondes fortemente dimorfas; soros marginais, projetando-se externamente além da superfície laminar..... Microgramma reptans

3. Frondes monomorfas a subdimorfas; soros medianos, entre a margem da lâmina e a costa 4. Lâmina linear-lanceolada, com escamas na superfície abaxial; soros arredondados Microgramma percussa

4. Lâmina oblonga a elíptica, glabra em ambas as superfícies; soros oblongos ..... Microgramma persicariifolia 1. Lâmina pinada, pinatisecta, pinatífida ou pectinada

5. Lâmina pectinada

6. Escamas ausentes na superfície adaxial da raque; lâmina membranácea; tecido lâminar piloso em ambas as superfícies, tricomas densos, longos, prateados e aciculares Plecluma hygrometrica

6. Escamas triangulares presentes na superfície adaxial da raque; lâmina subcoriácea; tecido lâminar glabro em ambas as superfícies ou com tricomas hialinos esparsos no lado abaxial próximo a costa e margem da lâmina Plecluma plumula

5. Lâmina pinada, pinatissecta a pinatífida

7. Lâmina 4-8 cm compr., tecido lâminar densamente escamoso em ambas as superfícies; soros distribuídos em 1 fileira entre a costa e a margem Pleopeltis polypodioides var. burchellii

7. Lâmina 20-98 cm compr., tecido lâminar glabro em ambas as superfícies; soros distribuídos em 2-5 fileiras entre a costa e a margem

8. Caule com densas escamas concolores, alaranjadas ou castanho-avermelhadas, não clatradas a subclatradas; aréolas com 2 nervuras excurrentes unidas em suas extremidades que abastecemos soros . Phlebodium decumanum

8. Caule com escamas bicolores, centro castanho e margem clara, clatradas; aréolas com 1 nervura excurrente que abastece os soros Serpocaulon triseriale 
Campyloneurum phyllitidis (L.) C. Presl, Suppl. Tent. Pterid.: 190. 1836.

Material examinado: BRASIL. PARÁ: Tucuruí, 23 km south of Represa Tucuruí, rio Tocantins, along higway BR-422, approx. $3^{\circ} 52^{\prime} \mathrm{S}, 4^{\circ} 44^{\prime} \mathrm{W}, 20-\mathrm{III}-1980$, T. Plowman et al. 9838 (MG); idem, área 4 da UHT, 17-XII-1979, F.F. Silva et al. 499 (MG); idem, 9-VII-2008, R.S. Fernandes et al. 122 (MG).

Espécie com distribuição americana. No Brasil é citada para o AC, AL, AP, AM, BA, CE, DF, ES, GO, MG, MT, PA, PE, PR, RJ, RO, RR, RS, SC, SP e TO (Braga 1951, Sehnem 1970, Tryon \& Conant 1975, Behar \& Viégas 1992, Windisch \& Tryon 2001, Xavier \& Barros 2005, Santiago et al. 2004, Freitas \& Prado 2005, Labiak 2005, Maciel et al. 2007). Planta crescendo sobre árvores vivas no interior da floresta, ou em ambientes ensolarados às margens das trilhas. De acordo com Smith (1995c) e Costa (2007), Campyloneurum phyllitidis assemelha-se a C. repens (Aubl.) C. Presl por ambas apresentarem, abaxialmente, nervuras secundárias proeminentes que delimitam fileiras de aréolas entre a costa e a margem. Todavia, diferenciam-se, por $C$. phyllitidis possuir caule curto-reptante e pecíolos distando não mais que $0,5 \mathrm{~cm}$ entre si, enquanto que em $C$. repens, o caule é longo-reptante e os pecíolos distam de 0,5 a $1,5 \mathrm{~cm}$ entre si.

Microgramma percussa (Cav.) de la Sota, Physis

(Buenos Aires), Secc. C, 44(106): 28. 1986.

Material examinado: BRASIL. PARÁ: Novo Repartimento, ZPVS-UHE de Tucuruí-Tucuru, Base 3, Ilha

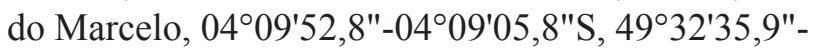
4932'09,6"W, alt. 75-107 m, 24-IX-2008, R.S. Fernandes \& S. Maciel 258 (MG); idem, trilha $8,04^{\circ} 15^{\prime} 0,6^{\prime \prime S}, 49^{\circ} 31^{\prime} 01,7^{\prime \prime} \mathrm{W}$ a $04^{\circ} 15^{\prime} 47,85^{\prime \prime} \mathrm{S}$, 49 30'17,6"W, alt. 102-179 m, 13-III-2009, R.S. Fernandes \& J.M. Costa 366 (MG).

Espécie com distribuição americana. No Brasil é citada para o AC, AL, AM, AP, BA, CE, DF, ES, GO, MA, MG, MT, PA, PB, PR, RJ, RN, RO, RS, SP, SC e TO (Labiak \& Prado 1998, Tryon \& Conant 1975, Andrade-Lima 1969, Prado \& Labiak 2001, Sampaio 1930). Na área estudada, a espécie foi observada crescendo sobre tronco caído e sobre galhos de árvores vivas à margem de trilhas no interior da mata. Microgramma percussa caracteriza-se pelos soros com densos tufos de tricomas, pequenas escamas circulares na superfície abaxial da lâmina, e lâmina coriácea, comumente com ápice longo-acuminado, a venação é claramente visível na superfície adaxial em frondes secas em contraste com outras espécies de Microgramma com lâmina escamosa.

Microgramma persicariifolia (Schrad.) C. Presl, Tent. Pterid.: 214. 1836.

Material examinado: BRASIL. PARÁ: Tucuruí, Vila Santa Rosa, área a ser inundada pela represa da hidrelétrica, IV-1981, N.C. Bastos \& C. Motta 428 (MG); Novo Repartimento, ZPVS-UHE de Tucuruí, Base 3, 10-VII-2008, R.S. Fernandes et al. 170 (MG).

Espécie com distribuição americana. No Brasil é citada para o AC, AP, AM, BA, DF, ES, GO, MG, MT, MS, PA, PE, PR, RO, RR, SC e SP (Tryon \& Conant 1975, Mori et al. 1983, Windisch \& Tryon 2001, Melo \& Salino 2002, Labiak \& Hirai 2012). $\mathrm{Na}$ área estudada, a espécie foi observada crescendo sobre tronco em decomposição e sobre galhos vivos à margem de trilhas no interior da mata. Microgramma persicariifolia é bastante semelhante a $M$. lindbergii (Mett. ex Kuhn) de la Sota, porém distingue-se pela forma oblonga dos soros e a lâmina apresenta escamas apenas na superfície abaxial. Em Microgramma lindbergii as escamas se distribuem em ambas as superfícies da lâmina e os soros são arredondados.

Microgramma reptans (Cav.) A.R. Sm., Proc. Calif. Acad. Sci., ser. 4, 40: 230. 1975.

Material examinado: BRASIL. PARÁ: Tucuruí, $\mathrm{km} 25$ south of Represa Tucuruí on road (BR 422) to Breu Branco, approx. $3^{\circ} 52^{\prime} \mathrm{S}, 49^{\circ} 44^{\prime} \mathrm{W}, 15-\mathrm{III}-1981$, T. Plowman et al. 9561 (MG); Novo Repartimento, ZPVS-UHE de Tucuruí, Base 3, Resaca do Pirarucu, $4^{\circ} 22^{\prime \prime} 55,3^{\prime \prime}-04^{\circ} 22^{\prime} 11,8^{\prime \prime} \mathrm{S}, 49^{\circ} 35^{\prime} 39,8^{\prime \prime}-49^{\circ} 36^{\prime} 13,3^{\prime \prime} \mathrm{W}$, alt. 72-84 m, 12-III-2009, R.S. Fernandes \& J.M. Costa 329 (MG); Goianésia do Pará, ZPVS-UHE de Tucuruí, Base 4, Ilha do Cornélio, 04 $17^{\circ} 40,1^{\prime \prime S}-49^{\circ} 28^{\prime} 12,6^{\prime \prime} \mathrm{W}$, alt. 110-120 m, 23-IX-2008, R.S. Fernandes \& S. Maciel 211 (MG).

Espécie com distribuição americana. No Brasil é citada para o AC, AM, AP, BA, PA, PE e RR (Tryon \& Conant 1975, Barros et al. 2002, Maciel et al. 2007, Labiak \& Hirai 2012). Na área estudada, a espécie foi observada crescendo sobre tronco em decomposição e sobre galhos de arvoretas vivas à margem de trilhas no interior da mata. Microgramma reptans assemelha-se a M. tecta (Kaulf.)Alston, que também ocorre no Pará, por ambas apresentarem frondes dimorfas e as férteis 
lineares. No entanto, em $M$. tecta as frondes estéreis são menores (0,5-2 cm compr.), as escamas sobre a lâmina são maiores (1-1,5 cm compr.) e os soros não se projetam além da margem da lâmina (Costa 2007). Em Microgramma reptans as frondes estéreis são maiores (2,7-4,5 cm compr.), as escamas sobre a lâmina são bem menores (0,5-1(-2) mm compr.) e os soros se projetam além da margem da lâmina.

*Pecluma hygrometrica (Splitg.) M.G. Price, Amer. Fern J. 73: 115. 1983

Figura 2f-h

Material examinado: BRASIL. PARÁ: Novo Repartimento, ZPVS-UHE de Tucuruí, Base 3, Ressaca do Pirarucu, 4²2"55,3"-04²2'11,8"S, $49^{\circ} 35^{\prime} 39,8^{\prime \prime}-49^{\circ} 36^{\prime} 13,3^{\prime \prime} \mathrm{W}$, alt. 72-84 m, 12-III-2009, R.S. Fernandes \& J.M. Costa 325 (MG).

Espécie com distribuição americana. No Brasil é citada para o AC, AM, PA e PE (Barros et al. 2004, Prado \& Moran 2009). Na área estudada, a espécie foi observada crescendo sobre tronco vivo no interior da mata, observados poucos indivíduos. De acordo com Tryon \& Stolze (1993), Pecluma higrometrica caracteriza-se pela costa decurrente na raque, pelas frondes pequenas mais numerosas no caule e pelo tecido lâminar apresentar-se com densos tricomas diminutos e prateados na superfície abaxial.

Pecluma plumula (Humb. \& Bonpl. ex Willd.) M.G. Price, Amer. Fer J. 73: 115. 1983.

Material examinado: BRASIL. PARÁ: Novo Repartimento, ZPVS-UHE de Tucuruí, Base 3, trilha principal, 27-V-2006, A.G. Alves \& M.A. Lopes 108 (MG).

Espécie com distribuição americana. No Brasil é citada para o AC, AM, BA, CE, ES, GO, MG, PA, PR, PE, RJ, SP, RR e SC (Brade 1940, Braga 1951, Evans 1969, Tryon \& Conant 1975, Mori et al. 1983, Paula 1993, Barros et al. 2002, Mynssen \& Windisch 2004, Paciencia \& Prado 2004, Maciel et al. 2007). $\mathrm{Na}$ área estudada, a espécie foi observada crescendo sobre tronco vivo no interior da mata e com poucos indivíduos. Pecluma plumula é caracterizada por apresentar lâmina subcoriácea, glabra ou somente com esparsos tricomas clavados, próximos à margem, raque negra, lustrosa com escamas triangulares.

Phlebodium decumanum (Willd.) J. Sm., J. Bot. (Hooker) 4: 59. 1841.

Material examinado: BRASIL. PARÁ: Tucuruí, margem esquerda do rio Tocantins, km 20 da BR-422, ramal à esquerda, 5-XI-1980, P. Lisboa 1424 (MG); Novo Repartimento, ZPVS-UHE de Tucuruí, Base 3, Lajeiro, $04^{\circ} 22^{\prime} 40^{\prime \prime} \mathrm{S}, 4^{\circ} 35^{\prime} 18,5^{\prime \prime} \mathrm{W}$, alt. $138 \mathrm{~m}$, 12-III-2009, R.S. Fernandes \& J.M. Costa 337 (MG); Goianésia do Pará, ZPVS-UHE de Tucuruí, Base 4, trapiche, 14-III-2009, R.S. Fernandes \& J.M. Costa 402 (MG).

Espécie com distribuição americana. No Brasil é citada para o AC, AL, AM, AP, BA, CE, DF, ES, GO, MA, MG, MT, MS, PA, PB, PE, PI, RJ, PR, RN, RS, RO, RR, SE, SC, TO e SP (Sehnem 1970, Tryon \& Conant 1975, Bastos \& Cutrim 1999, Freitas \& Prado 2005, Pietrobom \& Barros 2006b, Labiak \& Hirai 2012). Planta coletada em local aberto as margens do lago em troncos vivos ou em decomposição e ainda em afloramento rochoso, exposta ao sol. Phlebodium decumanum é semelhante a $P$. areolatum (Humb. \& Bonpl. ex Willd.) J. Sm., diferindo desta última por apresentar soros em 3-5 fileiras entre a costa e a margem da pina com escamas do caule longas $(1-1,5 \mathrm{~cm})$, tortuosas, além de apresentar pinas mais largas (3-7 cm larg.). Phlebodium areolatum apresenta soros uniseriados em cada lado da costa, escamas do caule diminutas $(0,5-1,0 \mathrm{~cm})$, lanceolado-peltadas e pinas com 1-3 cm larg. (Mickel \& Smith 2004).

Pleopeltis polypodioides (L.) E.G. Andrews \& Windham var.burchellii (Baker)A.R. Sm., Candollea 60(1): 281. 2005.

Material examinado: BRASIL. PARÁ: Novo Repartimento, ZPVS-UHE de Tucuruí, Base 3, trilha 5, 9-VII-2008, R.S. Fernandes et al. 134 (MG); idem, Ressaca do Pirarucu, $4^{\circ} 22^{\prime \prime} 55,3^{\prime \prime}-04^{\circ} 22^{\prime} 11,8^{\prime \prime S}$, 49³5'39, $8^{\prime \prime}-49^{\circ} 36^{\prime} 13,3^{\prime \prime} \mathrm{W}$, alt. 72-84 m, 12-III-2009, R.S. Fernandes \& J.M. Costa 328 (MG).

Espécie com distribuição sul-americana. No Brasil é citada para o AC, AP, AM, CE, DF, GO, PA, RO, RR, MS e MT (Brade 1940, Tryon \& Conant 1975, Windisch \& Tryon 2001, Labiak 2005). Planta coletada como epífita, sobre tronco em decomposição e galhos de arvoretas no interior da mata à margem de igarapés. Pleopeltis polypodioides var. burchellii difere das demais Polypodiaceaes coletadas nas ZPVS, por apresentar lâmina pinatissecta, densamente escamosa em ambas as superfícies e pelo pequeno tamanho (4-13 cm compr.) de suas frondes.

Serpocaulon triseriale (Sw.) A.R. Sm., Taxon 55(4): 929. 2006.

Material examinado: BRASIL. PARÁ: Novo Repartimento, ZPVS-UHE de Tucuruí, Base 3, 
Ressaca do Pirarucu, 4²2"55,3"-04²2'11,8"S, $49^{\circ} 35^{\prime} 39,8^{\prime \prime}-49^{\circ} 36^{\prime} 13,3^{\prime \prime} \mathrm{W}$, alt. 72-84 m, 12-III-2009, R.S. Fernandes \& J.M. Costa 334 (MG); Goianésia do Pará, ZPVS-UHE de Tucuruí, Base 4, Ilha do Marcelo, 28-V-2006, A.G. Alves \& M.A. Lopes 133 (MG).

Espécie com distribuição americana. No Brasil é citada para o AC, AL, AM, BA, CE, DF, ES, GO, MG, MT, PA, PE, PR, RJ, RS, SC e SP (Brade 1940, Tryon \& Conant 1975, Behar \& Viégas 1992, Labiak \& Prado 1998, Salino \& Joly 2001, Barros et al. 2002, Prado
\& Labiak 2003, Paciencia \& Prado 2004, Mynssen \& Windisch 2004, Labiak 2005, Pietrobom \& Barros 2006b). Planta coletada na borda da mata, geralmente, encontrada em ambientes ensolarados e epifitando palmeiras nas margens do lago. Serpocaulon triseriale caracteriza-se pelas lâminas pinatissectas, pinas estreitas (1,3-1,7 cm larg.) e os soros distribuídos em 1-2 fileiras entre a costa e a margem dos segmentos.

\section{PTERIDACEAE}

Chave de identificação para as espécies de Pteridaceae

1. Lâmina simples; escamas do caule clatradas

2. Soros em curtas linhas oblíquas irregulares, ao longo das nervuras reticuladas; lâmina oblanceolada ou elíptica Polytaenium guayanense

2. Soros em uma fileira submarginal, inseridos em sulcos rasos ou profundos; lâmina linear

3. Lâmina com uma fileira de aréolas entre a costa e a margem Vittaria lineata

3. Lâmina com 2(-4) fileiras de aréolas entre a costa e a margem Ananthacorus angustifolius

1. Lâmina lobada, pinada ou mais vezes decomposta; escamas do caule não clatradas

4. Soros marginais, protegidos pela margem da lâmina modificada em pseudo-indúsio

5. Lâmina 2-pinada-pinatífida, tripedada; soros com paráfises, pseudo-indúsio sem nervuras

5. Lâmina 1-2-pinada; soros desprovidos de paráfises, pseudo-indúsio com nervuras

Pteris propinqua

6. Lâmina 1-pinada ou com pina basal pinada

7. Raque com escamas e tricomas

8. Lâmina com escamas filiformes em ambas as superfícies; pseudo-indúsio oblongo, com escamas filiformes Adiantum obliquum

8. Lâmina glabra; pseudo-indúsio linear-arqueado, glabro Adiantum petiolatum

7. Raque glabra ou somente com escamas

9. Soros interrompidos; lâmina glabra; pina terminal sub-conforme, reduzida, labelada Adiantum lunulatum

9. Soros contínuos; lâmina com escamas; pina terminal maior que as demais, lancelado-lobada 10. Venação livre; pinas trapeziformes, base oblíqua escavada no lado basioscópico e truncada a arredondada no lado acroscópico Adiantum lucidum

10. Venação anastomosada; pinas lanceoladas a deltoide-lanceoladas, base simétrica, arredondada a truncada Adiantum dolosum

\section{Lâmina 2-pinada}

11. Caule longo-reptante, frondes distantes entre si $(5-8 \mathrm{~cm})$; pínulas trapeziformes, com ápice acuminado Adiantum argutum

11. Caule curto-reptante, frondes próximas entre si $(1-3 \mathrm{~cm})$; pínulas dimidiadas, com ápice agudo a arredondado ou truncado

12. Soros 1(2) por pina Adiantum pulverulentum

12. Soros $4-18$ por pina

13. Pecíolo e raque glabros ou somente com esparsas escamas lineares

14. Pínulas (17-)25-29 pares, imbricadas a parcialmente imbricadas, abaxialmente não glaucas. Adiantum sp. 14. Pínulas 8-16 pares, não imbricadas, abaxialmente glaucas ............. Adiantum glaucescens

13. Pecíolo e raque pubescentes ou escamosos, densas escamas linear-lanceoladas e filiformes 15. Lâmina abaxialmente com tricomas; pinas 1-3 pares 
16. Pínulas 0,2-0,3 cm larg., ápice agudo, 13-20 pares Adiantum terminatum

16. Pínulas 0,4-0,6 cm larg., ápice arredondado, até 9-12 pares Adiantum humile

15. Lâmina abaxialmente com escamas; pinas 4-7 pares

17. Raque com escamas de dois tipos, filiformes com base pectinada e linear-lanceoladas Adiantum tetraphyllum

17. Raque com escamas somente de um tipo, linear-lanceoladas

18. Pínulas estéreis com margem crenada a rasamente lobada .... Adiantum cajennense 18. Pínulas estéreis com margem serreada a biserreada ......... Adiantum cinnamomeum

4. Soros na superfície abaxial sobre as nervuras, não protegidos

19. Lâmina lanceolada; pinas com cera branca ou amarela na superfície abaxial

Pityrogramma calomelanos var. calomelanos

19. Lâmina orbicular, pedada ou elíptica; pinas sem cera branca ou amarela na superfície abaxial (Hemionitis) 20. Lâmina 1-pinada, pinas 7-12 pares, nervuras livre enre si .... Hemionitis rufa 20. Lâmina palmada ou pedadamente 3-5 lobada, nervuras anastomosada Hemionitis palmata

Adiantum argutum Splitg., Tijdschr. Nat. Gesch. 7: 427. 1840.

Material examinado: BRASIL. PARÁ: Novo Repartimento, ZPVS-UHE de Tucuruí, Base 3, 10-VII-2008, R.S. Fernandes et al. 153 (MG); idem, 12-III-2009, R.S. Fernandes \& J.M. Costa 178 (MG); idem, Goianésia do Pará, ZPVS-UHE deTucuruí, Base 4, lha

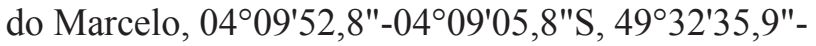
49 32'09,6"W, alt. 75-107 m, 24-IX-2008, R.S. Fernandes \& S. Maciel 254 (MG).

Espécie com distribuição sul-americana. No Brasil é citada para o AC, AP, AM, MT, PA, PE, RO e RR (Prado \& Lellinger 2002, Pietrobom \& Barros 2006a). Planta bastante comum na área, geralmente, cobrindo todo o sub-bosque, dando um aspecto de "tapete" ao chão da floresta, ocorrendo desde o interior da mata, em encostas úmidas até as margens de trilhas. Adiantum argutum pertence ao grupo de A. latifolium, por apresentar o caule longo-reptante, lâmina 2-pinada com pecíolo e raque portando escamas lanceoladas de base pectinada. Adiantum argutum pode ser diferenciada de A. latifolium Lam. por apresentar lâmina abaxialmente lustrosa com idioblastos conspícuos e adaxialmente inconspícous e diminutas escamas filiformes, pectinadas e pínulas com ápice acuminado (Prado \& Lellinger 2002). Em Adiantum latifolium os idioblastos estão dispostos na superfície adaxial da lâmina com superfície abaxial glauca, pínulas glabras em ambas as superfícies e ápice agudo.

Adiantum cajennense Willd. ex Klotzsch, Linnaea 18: 552.1845.

Material examinado: BRASIL. PARÁ: Novo Repar-timento, ZPVS-UHE de Tucuruí, Base 3,
9-VII-2008, R.S. Fernandes et al. 140 (MG); Goianésia do Pará, ZPVS-UHE de Tucuruí, Base 4, Ilha do Cornélio $04^{\circ} 17^{\prime} 40,1^{\prime \prime} \mathrm{S}, 4^{\circ} 28^{\prime} 12,6^{\prime \prime} \mathrm{W}$, alt. 110-120 m, 23-IX-2008, R.S. Fernandes \& S. Maciel 185 (MG); idem, Ilha do Marcelo, 0409'59,3"S, $49^{\circ} 32^{\prime} 38,0^{\prime \prime} \mathrm{W}$, alt. $35 \mathrm{~m}, 14-\mathrm{III}-2009$, R.S. Fernandes \& J.M. Costa 389 (MG).

Espécie com distribuição sul-americana. No Brasil é citada para o AC, AM, BA, MT, PA, PE, RO e RR (Windisch 1979, Rodrigues et al. 2004, Prado 2005d). Na área estudada, cresce no interior da mata, às margens de trilhas, em ambiente seco. Prado (2005d) caracterizou A. cajennense pela presença de escamas de base pectinada sobre o indúsio; no entanto, os espécimes das ZPVS são caracterizados pelas escamas do caule lustrosas, com margem inteira, 2-7 pares de pinas, pínulas estéreis, denteadas a rasamente lobadas nos lados acroscópicos, e as férteis com 3-13 soros.

Adiantum cinnamomeum Lellinger \& J. Prado, Amer. Fern J. 91(1): 4. 2001.

Material examinado: BRASIL. PARÁ: Goianésia, ZPVS-UHE de Tucuruí, Base 4, Ilha Bela, 04¹7'31,1"S, $49^{\circ} 30^{\prime} 18^{\prime \prime} \mathrm{W}$, alt. 97 m, 24-IX-2008, R.S. Fernandes \& S. Maciel 236 (MG) idem, 24-IX-2008, Ilha do Marcelo, 0409'52,8"-0409'05,8"S, 49³2'35,9"49³2'09,6"W, alt. 75-107 m, R.S. Fernandes \& S. Maciel 245 (MG); idem, Trilha 8, 04 $15^{\prime} 0,6^{\prime \prime}-$ $04^{\circ} 15^{\prime} 47,85^{\prime \prime S}, 49^{\circ} 31^{\prime} 01,7^{\prime \prime}-49^{\circ} 30^{\prime} 17,6^{\prime \prime} \mathrm{W}$, alt. 102-179 m, 13-III-2009, R.S. Fernandes \& J.M. Costa 367 (MG).

Espécie com distribuição sul-americana. No Brasil é citada para o AM, DF, MT, PA e RO 
(Lellinger \& Prado 2001). Na área estudada, cresce no sub-bosque da floresta em solo seco e iluminado. Adiantum cinnamomeum pode ser reconhecida por possuir até 40 pares de pínulas (nas pinas maiores), essas com ápice acuminado e margem serreada a biserreada e pelas escamas abundantes e alaranjadas sobre a raque e o pecíolo. Pode ser confundida com A. cajenense, que também possui escamas alaranjadas, porém com menor número de pares de pínulas (cerca de 20-30) e a margem das pínulas estéreis crenadas a rasamente lobadas (Zuquim et al. 2008).

Adiantum dolosum Kunze, Linnaea. 21: 219. 1848.

Material examinado: BRASIL. PARÁ: Novo Repartimento, ZPVS-UHE de Tucuruí, Base 3, 9-VII-2008, R.S. Fernandes et al. 141 (MG); Goianésia do Pará, ZPVS-UHE de Tucuruí, Base 4, Ilha do Cornélio, $04^{\circ} 17^{\prime} 40,1^{\prime \prime S}, 49^{\circ} 28^{\prime} 12,6^{\prime \prime} \mathrm{W}$, alt. 110-120 m, 23-IX-2008, R.S. Fernandes \& S. Maciel 189 (MG); idem, 04'09'59,3"S, 49³2'38,0"W, alt. $35 \mathrm{~m}$, 14-III-2009, R.S. Fernandes \& J.M. Costa 383 (MG).

Espécie com distribuição sul-americana. No Brasil é citada para o AC, AL, AM, BA, CE, MG, MT, PA, PE, RJ, RO e SP (Sehnem 1972, Prado 1997, Graçano et al. 1998, Zuquim et al. 2008, Prado \& Moran 2009, Maciel \& Pietrobom 2010a). Na área estudada, cresce no interior da mata em ambiente seco e à margem de trilha. Adiantum dolosum caracteriza-se pela lâmina 1-pinada, pinas falcadas, acuminadas, não dimidiadas, base arredondada a truncada, venação anastomosada e soros contínuos em ambas às margens. Pode ser confundida com Adiantum lucidum (Cav.) Sw., pelo pecíolo coberto com escamas castanho-avermelhadas e soros em linhas contínuas ao longo da margem da lâmina (Cremers 1997). Entretanto, A. lucidum pode apresentar lâmina com pina basal pinada, pinas ou pínulas trapeziformes com base oblíqua e nervuras livres (Kramer 1978).

Adiantum glaucescens Klotzsch, Linnaea 18: 552. 1844.

Material examinado: BRASIL. PARÁ: Goianésia do Pará, ZPVS-UHE de Tucuruí, Base 4, Ilha do Cornélio $04^{\circ} 17^{\prime} 40,1^{\prime \prime S}, 49^{\circ} 28^{\prime} 12,6^{\prime \prime} \mathrm{W}$, alt. 110-120 m, 23-IX-2008, R.S. Fernandes \& S. Maciel 201 (MG); idem, Ilha Surucucu, $04^{\circ} 17^{\prime} 28,2^{\prime \prime}-04^{\circ} 17^{\prime} 22,8^{\prime \prime} \mathrm{S}$, $49^{\circ} 29^{\prime} 50,2^{\prime \prime}-49^{\circ} 29^{\prime} 52,5^{\prime \prime} \mathrm{W}$, alt. $97 \mathrm{~m}, 24-\mathrm{IX}-2008$, R.S. Fernandes \& S. Maciel 243 (MG); idem, Ilha do Marcelo, 0409'59,3"S, 49³2'38,0"W, alt. $35 \mathrm{~m}$, 14-III-2009, R.S. Fernandes \& J.M. Costa 386 (MG).
Espécie com distribuição sul-americana. No Brasil é citada para o AL, AM, AP, BA, CE, MA, MG, MT, PA, PE, RJ, RO, RR, SC, SP e TO (Sehnem 1961, 1972, Tryon \& Conant 1975, Graçano et al. 1998, Paula-Zárate 2005). Na área estudada, cresce nas margens das trilhas e no interior da mata de terra firme. Adiantum glaucescens caracteriza-se pelo pecíolo lustroso, glabro ou com escamas esparsas principalmente na base, lâmina com idioblastos em ambas as superfícies, raque glabra, pínulas glabras, glaucas abaxialmente e pinas curvadas para o ápice (Maciel \& Pietrobom 2010a).

Adiantum humile Kunze, Linnaea 9: 80. 1834.

Material examinado: BRASIL. PArÁ: Goianésia do Pará, ZPVS-UHE de Tucuruí, Base 4, Trilha 8, $04^{\circ} 15^{\prime} 0,6^{\prime \prime}-04^{\circ} 15^{\prime} 47,85^{\prime \prime} \mathrm{S}, 49^{\circ} 31^{\prime} 01,7^{\prime \prime}-49^{\circ} 30^{\prime} 17,6^{\prime \prime} \mathrm{W}$, alt. 102-179 m, 13-III-2009, R.S. Fernandes \& J.M. Costa 364 (MG).

Espécie com distribuição americana. No Brasil é citada para o AC, AL, AM, AP, BA, MT, PA, PB, PE, PR, RR, RO, SC e SP (Pietrobom \& Barros 2006b, Tryon \& Conant 1975). Na área estudada, cresce próximo às margens de trilhas no interior da mata, em solo pedregoso. As poucas diferenças entre Adiantum humile e A.terminatum estão no número de pares de pínulas e no formato das mesmas. Entretanto, esses caracteres podem variar dentro da espécie. $\mathrm{Na}$ área estudada, $A$. humile pode ser diferenciada dos espécimes de $A$. terminatum por apresentar pinas abruptamente reduzidas em direção ao ápice e possuir até 12 pares de pínulas largas $(0,5-0,6 \mathrm{~cm}$ larg.), com ápice arredondado, margem rasamente serreada e 12-18 soros oblongos por pínula, enquanto A. terminatum apresenta pinas gradualmente reduzidas em direção ao ápice, possui até 20 pares de pínulas estreitas (0,3-0,4 cm larg.), com ápice agudo, margem serreada a duplo-serreada e 9-12 soros diminutos por pínula. Segundo Smith (1995d), essas diferenças podem não ser suficientes para dar a ambas a categoria de espécie.

Adiantum lucidum (Cav.) Sw., Syn. Fil.: 121. 1806.

Material examinado: BRASIL. PARÁ: Novo Repartimento, Base 3, 9-VII-2008, R.S. Fernandes et al. 143 (MG); Goianésia do Pará, ZPVS-UHE de Tucuruí, Base 4, Ilha Bela, $04^{\circ} 17^{\prime} 31,1^{\prime \prime S}, 4^{\circ} 30^{\prime} 18^{\prime \prime} \mathrm{W}$, alt. 97 m, 24-IX-2008, R.S. Fernandes \& S. Maciel 234 (MG); idem, Trilha $8,04^{\circ} 15^{\prime} 0,6^{\prime \prime}-04^{\circ} 15^{\prime} 47,85^{\prime \prime} \mathrm{S}$, $49^{\circ} 31^{\prime} 01,7^{\prime \prime}-49^{\circ} 30^{\prime} 17,6^{\prime \prime} \mathrm{W}$, alt. 102-179 m, 13-III-2009, R.S. Fernandes \& J.M. Costa 367 (MG). 
Espécie com distribuição americana. No Brasil é citada para o AP, AM, BA, CE, ES, MA, MG, MT, PA, PE, RO, SC e SP (Sampaio 1930, Sehnem 1961, Graçano et al. 1998, Paula-Zárate 2005). Na área estudada, cresce no interior da mata, entre folhagens em ambiente sombreado ou às margens das trilhas em terreno pedregoso. Nos espécimes examinados de Adiantum lucidum, a lâmina pode ser 1-pinada ou com pina basal 1-pinada. Segundo Tryon \& Stolze (1989), os que apresentam lâmina 2-pinada, talvez sejam híbridos com algumas espécies 2-pinadas, ou podem ser variações dentro da própria espécie. Adiantum lucidum é reconhecido pelos soros em linhas contínuas, pela lâmina pinada na base e pela base da pina assimétrica. Pode ser confundido com Adiantum dolosum, porém esta última possui menos pares de pinas, de 3 a 6 , e a base das pinas é simétrica.

Adiantum lunulatum Burm. f., Fl. Indica: 235. 1768.

Material examinado: BRASIL. PARÁ: Novo Repartimento, ZPVS-UHE de Tucuruí, Base 3, Trilha principal, 10-VII-2008, R.S. Fernandes et al. 166 (MG).

Espécie com distribuição circum-antártica. No Brasil é citada para BA, GO, MA, MT, MG, PA, PE, PI e RJ (Andrade-Lima 1969). Coletada em afloramento rochoso, ambiente seco no interior mata. Além dos caracteres já mencionados na chave, Adiantum lunulatum apresenta nervuras, geralmente, terminando em enseios na margem dos lobos, pinas orbicular-reniformes, de base truncada a amplamente cuneada, formando um ângulo de 130 a $180^{\circ}$, pecíolos das pinas não articulados e soros pardos a acinzentados (Mickel \& Smith 2004). Pode ser confundida com A. deflectens, diferindo por esta apresentar nervuras terminando em dentes na margem da lâmina serreada, pinas flabeladas, base cuneada em ângulos de $80 \mathrm{a}$ $110^{\circ}$, pinas articuladas e soros amarelo-claros.

Adiantum obliquum Willd., Sp. P1., ed. 4, 5(1): 429. 1810.

Material examinado: BRASIL. PARÁ: Goianésia do Pará, Trilha 8, ZPVS-UHE de Tucuruí, Base 4, 17-II-2005, A.G. Alves \& M.A. Lopes 24 (MG).

Espécie com distribuição americana. No Brasil é citada para o AC, AM, AP, BA, CE, ES, MA, MG, MT, PA, PE, PR, RJ, RO, RS, SP e TO (Sehnem 1961, Tryon \& Conant 1975, Graçano et al. 1998, Pietrobom \& Barros 2006b, Prado 2003). Na área estudada, a espécie cresce com poucos indivíduos, em solo seco próximo a pedras às margens de trilha no interior mata. De acordo com Mickel \& Smith (2004), Adiantum obliquum é caracterizada por apresentar tricomas e densas escamas linear-lanceoladas com base pectinada sobre a raque e pecíolo. Entretanto, outros caracteres são peculiares como a lâmina 1-pinada (com um par de pinas proximal 1-pinada), escamas filiformes de base pectinada em ambas as superfícies, pínulas não dimidiadas e idioblastos facilmente visíveis adaxialmente e oblíquos abaxialmente.

Adiantum petiolatum Desv., Berl. Mag. 5: 326. 1811.

Material examinado: BRASIL. PARÁ: Goianésia do Pará, ZPVS-UHE de Tucuruí, Base 4, trilha principal, 10-VII-2008, R.S. Fernandes et al. 164 (MG).

Espécie com distribuição americana. No Brasil é citada para o AC, AM, AP, BA, CE, MT, PA, PE, RO, RR, SC, SP e TO (Senhem 1961, Tryon \& Conant 1975, Edwards 1998, Salino \& Joly 2001, Windisch \& Tryon 2001, Paula-Zárate 2005). Na área estudada, a espécie cresce em solo seco, próximo a rochas, no interior da mata e às margens das trilhas. Dentre os espécimes examinados de Adiantum petiolatum, um espécime apresentou a lâmina com um par de pinas proximal 1-pinada. Segundo Tryon \& Stolze (1989), híbridos podem ser formados a partir da mistura de A. petiolatum com lâmina 1-pinada e A. latifolium L. com lâmina 2-pinada. Adiantum petiolatum é caracterizada por apresentar ambas as superfícies da lâmina glabra e pina abaxialmente glauca, com idioblastos visíveis adaxialmente paralelos entre as nervuras, abaxialmente não visíveis e margem estéril da pina ou pínula biserreada.

Adiantum pulverulentum L., Sp. P1. 2: 1096. 1753.

Material examinado: BRASIL. PARÁ: Novo Repartimento, ZPVS-UHE de Tucuruí, Base 3, 10-VII-2008, R.S. Fernandes et al. 154 (MG); idem, Ressaca do Pirarucu $4^{\circ} 22^{\prime} 55,3^{\prime \prime}-04^{\circ} 22^{\prime} 11,8^{\prime \prime} \mathrm{S}$, 49 $35^{\prime} 39,8^{\prime \prime}-\mathrm{S}-49^{\circ} 36^{\prime} 13,3^{\prime \prime} \mathrm{W}$, alt. 72-84 m, 12-III-2009, R.S. Fernandes \& J.M. Costa 327 (MG); Goianésia do Pará, ZPVS-UHE de Tucuruí, Base 4, Trilha $8,04^{\circ} 15^{\prime} 0,6^{\prime \prime}-04^{\circ} 15^{\prime} 47,85^{\prime \prime} \mathrm{S}, 49^{\circ} 31^{\prime} 01,7^{\prime \prime}$ 49 $30^{\prime} 17,6^{\prime \prime} \mathrm{W}$, alt. 102-179 m, 13-III-2009, R.S. Fernandes \& J.M. Costa 358 (MG).

Espécie com distribuição americana. No Brasil é citada para o AC, AL, AM, AP, BA, CE, ES, GO, MG, MT, PA, PE, PR, RJ, RR, SE e SP (Brade 1947, Tryon \& Conant 1975, Graçano et al. 1998, Mynssen 
et al. 2002, Paula-Zárate 2005, Pietrobom \& Barros 2006b, Prado 2012c). Na área estudada, foi coletada crescendo no sub-bosque da floresta, em áreas iluminadas e sobre solos ricos em nutrientes, comum nas ZPVS; cresce nas bordas da floresta, próximas às margens das trilhas. Adiantum pulverulentum pode ser facilmente reconhecida pelas pínulas retangulares ou falcadas e, quando férteis, pelos soros geralmente únicos na margem acroscópica da pínula. Difere das outras espécies do gênero coletadas na área por apresentar de 5-10 pares de pinas.

Adiantum terminatum Kunze ex Miq., Inst. Versl. Meded. Kon. Naderl. Inst. Wetensch. 1842: 187. 1843.

Material examinado: BRASIL. PARÁ: Novo Repartimento, Base 3, 9-VII-2008, R.S. Fernandes et al. 144 (MG); Goianésia do Pará, ZPVS-UHE de Tucuruí, Base 4, Ilha do Cornélio 04²17'40,1"S, 49 $28^{\prime} 12,6^{\prime \prime} \mathrm{W}$, alt. 70-110 m, 10-VII-2008, R.S. Fernandes et al. 182 (MG); idem, Ilha do

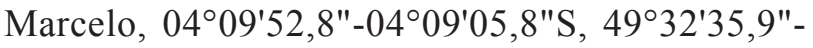
49³2'09, 6"W, alt. 75-107 m, 14-03-2009, R.S. Fernandes \& J.M. Costa 387 (MG).

Espécie com distribuição americana. No Brasil é citada para o AC, AL, AM, AP, BA, CE, DF, ES, MA, MG, MT, PA, PE, PR, RO, RJ, RR, RS, SC e SP (Senhem 1961, Tryon \& Conant 1975, Paula-Zárate 2005, Salino \& Almeida 2008, Pietrobom \& Barros 2006b, Prado \& Moran 2009). Na área estudada, cresce comumente próximo às margens das trilhas, em ambiente seco no interior da mata. Os espécimes examinados de Adiantum terminatum apresentaram somente 2-3 pares de pinas. Segundo Zuquim et al. (2008), essa espécie pode apresentar 4 pares de pinas ou mais. Adiantum terminatum é mais semelhante a Adiantum humile, diferenciando-se por esta última apresentar as pínulas glaucas e abruptamente reduzidas em direção ao ápice, bem como pelo pseudo-indúsio glabro, enquanto em $A$. terminatum as pinas são levemente glaucas e gradualmente reduzidas em direção ao ápice e o pseudo-indúsio é piloso, com tricomas septados e avermelhados.

Adiantum tetraphyllum Humb. \& Bonpl. ex Willd., Sp. Pl., ed. 4, 5(1): 441. 1810.

Material examinado: BRASIL. PARÁ: Novo Repartimento, ZPVS-UHE de Tucuruí, Base 3, 9-VII-2008, R.S. Fernandes et al. 146 (MG); idem, Ilha do Tamarindo, $04^{\circ} 16^{\prime} 04,2^{\prime \prime}-04^{\circ} 16 ' 37,3^{\prime \prime} \mathrm{S}, 49^{\circ} 39^{\prime} 37,4^{\prime \prime}-$ 4939'11,6"W, alt. 70-103 m, 23-IX-2008,
R.S. Fernandes \& S. Maciel 224 (MG); Goianésia do Pará, ZPVS-UHE de Tucuruí, Base 4, Ilha

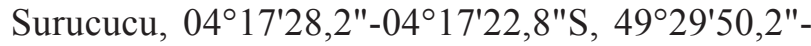
$49^{\circ} 29^{\prime} 52,5^{\prime \prime} \mathrm{W}$, alt. 97 m, 24-IX-2008, R.S. Fernandes \& S. Maciel 244 (MG).

Espécie com distribuição americana. No Brasil é citada para o AC, AP, AM, BA, CE, DF, ES, MG, MT, MS, PA, PE, PR, RJ, RR, RS e SP (Huber 1900-1902, Sehnem 1961, Tryon \& Conant 1975, Graçano et al. 1998, Salino \& Joly 2001, Prado \& Moran 2009). Na área estudada, a espécie cresce no interior da floresta ombrófila aberta, em solo pedregoso às margens das trilhas ou em solo arenoso. Adiantum tetraphyllum é uma espécie do grupo tetraphyllum, bastante polimorfa, caracterizada por apresentar lâmina 2-pinada, abaxialmente com poucas escamas filiformes, base pectinada sobre as nervuras, adaxialmente glabra, raque com escamas diminutas de dois tipos, filiformes e linear-lanceoladas de base pectinada, e as pínulas com ápice agudo e curvado em direção ao ápice da pina.

\section{Adiantum sp.}

Figura 3a-f

Material examinado: BRASIL. PARÁ: Novo Repartimento, ZPVS-UHE de Tucuruí, Base 3, Ilha do Acapú, 24-IX-2005, A.G. Alves \& M.A. Lopes 74

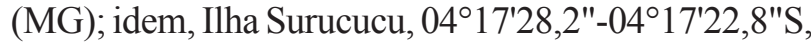
49 $29^{\prime} 50,2^{\prime \prime}-49^{\circ} 29^{\prime} 52,5^{\prime \prime W}$, alt. 97 m, 24-IX-2008, R.S. Fernandes \& S. Maciel 241 (MG); Trilha 8, $04^{\circ} 15^{\prime} 0,6^{\prime \prime}-04^{\circ} 15^{\prime} 47,85^{\prime \prime} \mathrm{S}, 49^{\circ} 31^{\prime} 01,7^{\prime \prime}-49^{\circ} 30^{\prime} 17,6^{\prime \prime} \mathrm{W}$, alt. 102-179 m, 13-III-2009, R.S. Fernandes \& J.M. Costa 359 (MG).

$\mathrm{Na}$ área estudada, foi coletada no interior da mata nas margens das trilhas, em solo pedregoso. Segundo J. Prado (dados não publicados), esta espécie nova é semelhante a Adiantum glaucescens, entretanto, difere desta por apresentar superfície abaxial das pínulas não glaucas, geralmente com maior número de pínulas (25-29) parcialmente imbricadas, pecíolo, raque, lâmina e costas com escamas lineares, base pectinada. Os espécimes examinados da área de estudo serão citados pelo especialista na descrição original da espécie como um dos parátipos.

Ananthacorus angustifolius (Sw.) Underw. \& Maxon in Maxon, Contr. U.S. Natl. Herb. 10: 487. 1908.

Material examinado: BRASIL. PARÁ: Novo Repartimento, ZPVS-UHE de Tucuruí, Base 3, Ilha do Tamarindo, 29-V-2006, A.G. Alves \& M.A. Lopes 144 (MG). 


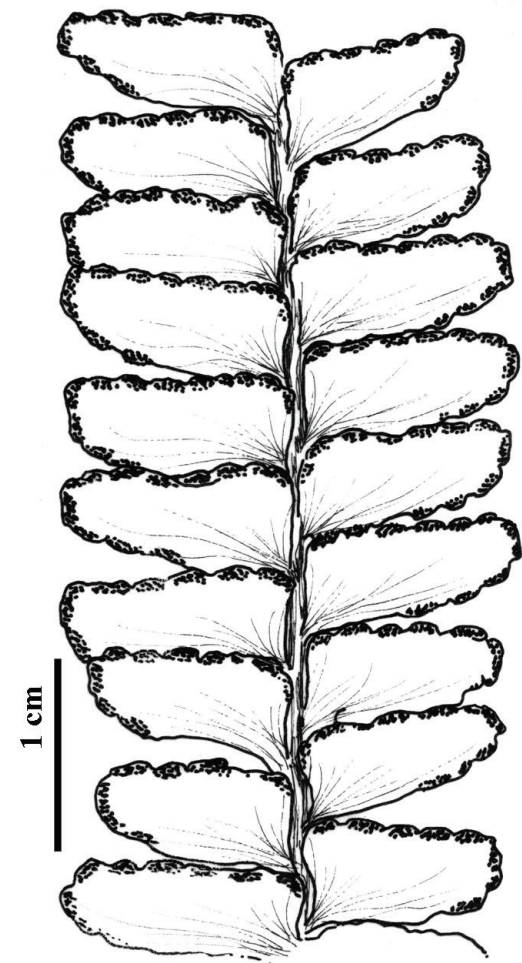

b<smiles>CC(C)C</smiles>
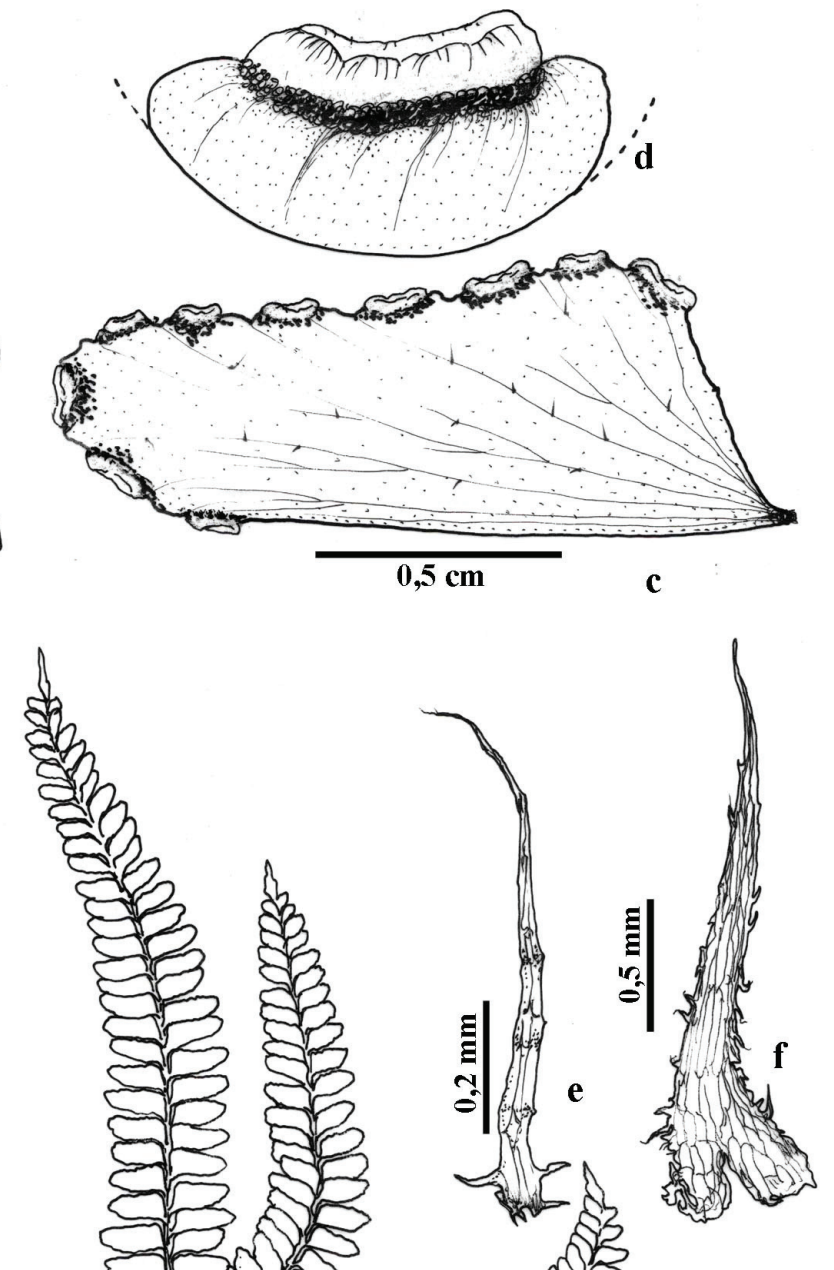

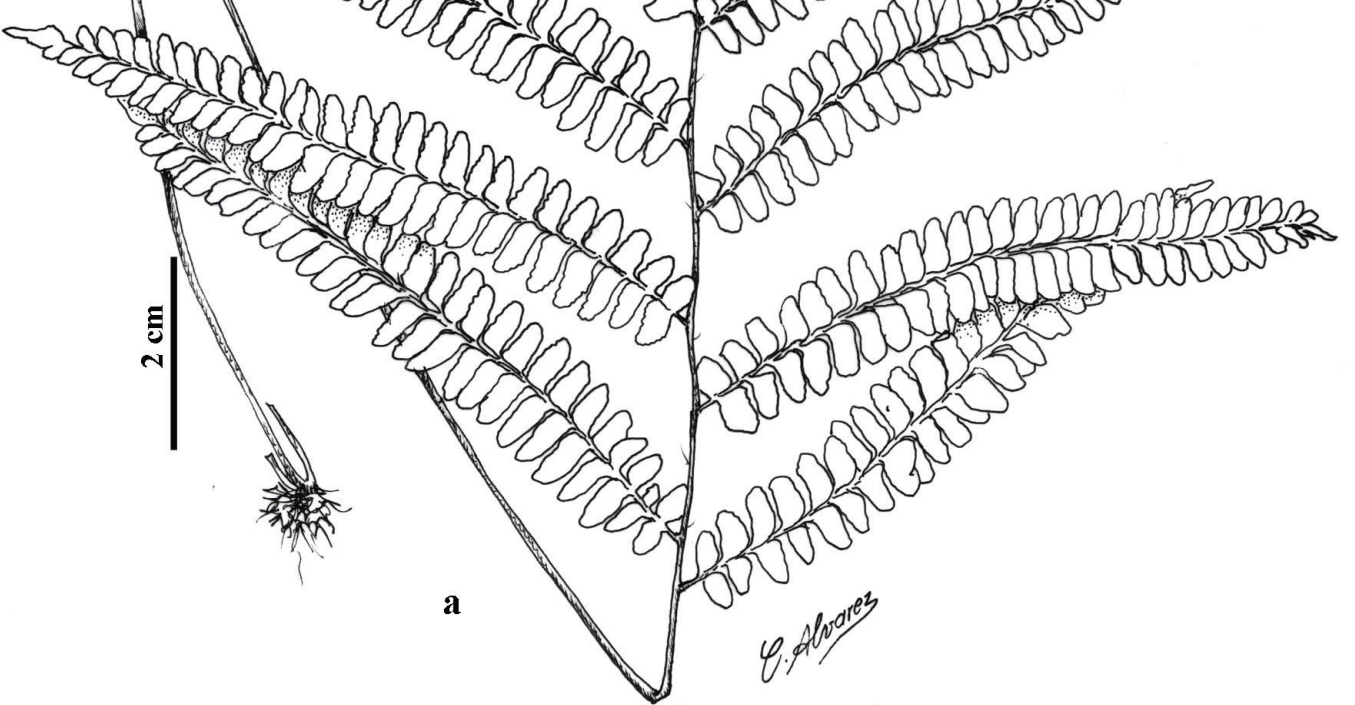

Figura 3. a. Adiantum sp., Hábito. b. Detalhe da parte mediana da pina. c. Pínula fértil. d. Indúsio. e. Escama da raque. f. Escama do caule (a-f: R.S. Fernandes \& J.M. Costa 359 (MG)).

Figure 3. a. Adiantum sp., Habit. b. Detail of the middle part of the pinna. c. Fertile pinnule. d. Indusium. e. Rachis scale. f. Stem scale (a-f: R.S. Fernandes \& J.M. Costa 359 (MG)). 
Espécie com distribuição americana. No Brasil é citada para o AC, AL, AM, AP, BA, CE, ES, MG, MT, PA, PB, PE, PR, RJ, RO, RR, RS, SC e SP (Tryon \& Conant 1975, Sehnem 1959, Felix et al. 1996, Windisch \& Tryon 2001, Pietrobom \& Barros 2006b, Maciel et al. 2007). Na área estudada, cresce no interior da mata de terra firme, em ambiente úmido. Ananthacorus angustifolius é caracterizada pelo caule esponjoso, frondes pendentes, lâmina linear, venação com duas a quatro fileiras de aréolas alongadas entre a costa e a margem, esporângios em soros em uma fileira submarginal, inseridos em sulcos rasos ou profundos e paráfises com célula apical filiforme.

Hemionitis palmata L., Sp. Pl. 2: 1077. 1753.

Material examinado: BRASIL. PARÁ: Novo Repartimento, ZPVS-UHE de Tucuruí, Base 3, Ilha do Tamarindo, Lajeiro, $04^{\circ} 22^{\prime} 40^{\prime \prime} \mathrm{S}, 4^{\circ} 35^{\prime} 18,5^{\prime \prime}$, alt. 138 m, 12-III-2009, R.S. Fernandes \& J.M. Costa 338 (MG).

Espécie com distribuição americana. No Brasil é citada para o AM, AL, BA, CE, GO, MT, PA, PE, PR, RJ, RS, SE, SC e SP (Sehnem 1972, Tryon \& Conant 1975, Barros et al. 2002). Na área estudada, foi coletada crescendo sobre rocha humosa, em local parcialmente sombreado, formando pequena população com alguns indivíduos espalhados. No mesmo ambiente, foi observada Hemionitis rufa (L.) Sw. Hemionitis palmata é caracterizada por apresentar as escamas do caule concolores, estramíneas a castanho-claras, lâminas palmadas com cinco lobos, nervuras principais escuras e usualmente com uma gema no enseio maior (Mickel \& Beitel 1988).

Hemionitis rufa (L.) Sw., J. Bot. (Schrader) 1800

(2): 16. 1801.

Material examinado: BRASIL. PARÁ: Novo Repartimento, ZPVS-UHE de Tucuruí, Base 3, Ilha do Tamarindo, 10-VII-2008, R.S. Fernandes et al. 157 (MG); Goianésia do Pará, ZPVS-UHE de Tucuruí, Base 4, Lajeiro, $04^{\circ} 22^{\prime} 40^{\prime \prime} \mathrm{S}, 4^{\circ} 35^{\prime} 18,5^{\prime \prime} \mathrm{W}$, alt. $138 \mathrm{~m}$, 12-III-2009, R.S. Fernandes \& J.M. Costa 339 (MG).

Espécie com distribuição americana. No Brasil é citada para o AM, PA e RR (Sampaio 1930, Tryon \& Conant 1982). Na área estudada, foi coletada crescendo sobre rocha humosa no interior da mata, poucos indivíduos espalhados. Hemionitis rufa é caracterizada por apresentar lâmina 1-pinada, escamas do caule bicolores, margem hialina e centro enegrecido.
Pityrogramma calomelanos (L.) Link var. calomelanos, Handbuch 3: 20. 1833.

Material examinado: BRASIL. PARÁ: Novo Repartimento, ZPVS-UHE de Tucuruí, Base 3, 9-VII-2008, R.S. Fernandes et al. 123 (MG); Goianésia do Pará, Ilha do Acapú, ZPVS-UHE de Tucuruí, Base 4, trilha $4,04^{\circ} 15^{\prime} 18,5^{\prime \prime} \mathrm{S}, 49^{\circ} 31^{\prime} 03,7^{\prime \prime} \mathrm{W}$, alt. $60 \mathrm{~m}$, 13-III-2009, R.S. Fernandes \& J.M. Costa 368 (MG).

Espécie com distribuição pacífica. No Brasil é citada para o AC, AL, AP, AM, BA, CE, DF, ES, GO, MG, MS, MT, PA, PB, PE, PI, PR, RN, RJ, RO, RS, SC e SP (Tryon \& Conant 1975, Windisch \& Tryon 2001, Prado 2005d, Pietrobom \& Barros 2006b, Boldrin \& Prado 2007). Na área estudada, foi observada crescendo em locais abertos e alterados como nas margens do lago, clareiras ou próximo às trilhas. Pityrogramma calomelanos var. calomelanos é distinguida de $P$. ebenca (L.) Proctor, pela base das pinas equilateral e a lâmina cartácea, enquanto $P$. ebenca possui as pinas com base fortemente inequilateral, pinas distais pinatilobadas e lâmina subcoriácea a coriácea.

Polytaenium guayanense (Hieron.) Alston, Kew Bull. 7: 134. 1932.

Material examinado: BRASIL. PARÁ: Goianésia do Pará, ZPVS-UHE de Tucuruí, Base 4, Ilha do Cornélio, $04^{\circ} 17^{\prime} 40,1^{\prime \prime S}, 49^{\circ} 28^{\prime} 12,6^{\prime \prime} \mathrm{W}$, alt. 110-120 m, 23-IX-2008, R.S. Fernandes \& S. Maciel 205 (MG); idem, Ilha do Marcelo, 14-III-2009, R.S. Fernandes \& J.M. Costa 285 (MG).

Espécie com distribuição americana. No Brasil é citada para o AC, AP, AM, PA, PE, RO e RR (Tryon \& Conant 1975, Pietrobom \& Barros 2006b, Maciel et al. 2007). Na área estudada, cresce sobre tronco vivo, próximo as trilhas, as margens do lago e no interior da mata de terra firme. Polytaenium guayanense é caracterizada por apresentar o caule com raízes densamente tomentosas, com tricomas amarelados, conferindo um aspecto esponjoso; pecíolo esverdeado abaxialmente, estreitamente alado; costa percorrente, sendo proeminente na superfície abaxial e esverdeada na base, aréolas formando fileiras oblíquas em relação à costa.

Pteris propinqua J. Agardh, Recens. Spec. Pter.: 65. 1839.

Material examinado: BRASIL. PARÁ: Novo Repartimento, ZPVS-UHE de Tucuruí, Base 3, 9-VII-2008, 
R.S. Fernandes et al. 133 (MG); Goianésia do Pará, ZPVS-UHE de Tucuruí, Base 4, Ilha do Prefeito, $04^{\circ} 20^{\prime} 02^{\prime \prime S}, 49^{\circ} 36^{\prime} 52^{\prime \prime} \mathrm{W}$, alt. $70 \mathrm{~m}, 25-\mathrm{IX}-2008$, R.S. Fernandes \& S. Maciel 315 (MG).

Espécie com distribuição americana. No Brasil é citada para o AC, AM, BA, ES, GO, MG, MT, PA, PE, PR, RO, SC e SP (Prado \& Windisch 2000). Na área estudada, a espécie foi coletada no interior da mata, próximo a cursos d'água. Pteris propinqua é caracterizada pela lâmina tripedada, 2-pinado-pinatífida, oblongo-lanceolada e com as pinas basais decurrentes no pecíolo, venação anastomosada, aréolas costais maiores, as marginais menores com nervuras livres inclusas (Prado \& Windisch 2000).

Vittaria lineata (L.) Sm., Mém. Acad. Roy. Sci. (Turin) 5: 421. t. 9. fig. 5. 179.

Material examinado: BRASIL. PARÁ: Goianésia do Pará, ZPVS-UHE de Tucuruí, Base 4, 9-VII-2008, R.S. Fernandes et al. 172 (MG).

Espécie com distribuição americana. No Brasil é citada para o AC, AL, AM, AP, BA, CE, ES, MA, MG, MS, MT, PA, PB, PE, PR, RJ, RO, RS, SC e SP (Brade 1940, Sehnem 1959, Tryon \& Conant 1975, Felix et al. 1996, Labiak \& Prado 1998, Windisch \& Tryon 2001, Barros et al. 2002, Paciencia \& Prado 2004, Nonato \& Windisch 2004, Pietrobom \& Barros 2006b). Na área estudada, cresce sobre palmeiras às margens das trilhas, em ambiente seco e ensolarado. Vittaria lineata é caracterizada por apresentar soros em sulcos profundos, formando aletas em cada margem da lâmina. É bastante próxima de V. graminifolia Kaulf., sendo diferenciada pela forma dos esporos, que neste caso são triletes (Nonato \& Windisch 2000). Difere das demais pteridáceas, coletadas na área, por apresentar lâmina inteira, linear-estreita (cerca de $0,3 \mathrm{~cm}$ ) com margens revolutas, soros contínuos com paráfises filiformes e esporos monoletes.

\section{SACCOLOMATACEAE}

Saccoloma elegans Kaulf., Berlin. Jahrb. Pharm. Verbundenen Wiss. 21: 51. 1820.

Material examinado: BRASIL. PARÁ: Goianésia do Pará, ZPVS-UHE de Tucuruí, Base 4, Ilha do Marcelo,

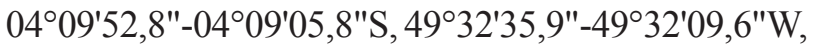
alt. 75-107 m, 24-IX-2008, R.S. Fernandes \& S. Maciel 250 (MG).
Espécie com distribuição americana. No Brasil é citada para o AC, AM, BA, ES, MG, PA, PE, PR, RJ, RO, RR, SC e SP (Cremers \& Kramer 1989, Tryon \& Conant 1975, Pietrobom \& Barros 2003, Prado \& Moran 2009, Schwartsburd 2012). Cresce em barranco úmido no interior da floresta, formando grande população, coletada próxima a espécimes de Danaea. Saccoloma elegans difere de S. inaequale (Kunze) Mett., pelas frondes 1-pinadas, com pinas inteiras, enquanto $S$. inaequale possui frondes 3-pinado-pinatífidas. Segundo Cremers \& Kramer (1989), Saccoloma elegans possui duas subespécies: S. elegans Kaulf. ssp. elegans G.B. Nair ex Cremers \& Kramer e S. elegans ssp. chartaceum G.B. Nair ex Cremers \& Kramer. Saccoloma elegans ssp. elegans apresenta a raque estramínea, frequentemente 15-20 pares de pinas, pina com menos de $3 \mathrm{~cm}$ de largura, herbácea, nervuras furcadas, (8-)11-17(-23) furcas a cada $3 \mathrm{~cm}$ de comprimento da pina, enquanto S. elegans ssp. chartaceum apresenta a raque castanhoescura a avermelhada, frequentemente 8-15(-17) pares de pinas com 3-4 cm de largura, cartáceas, nervuras furcadas, 1-6(-15) venas furcadas a cada $3 \mathrm{~cm}$ de comprimento. Entretanto, no presente trabalho, não foi considerado o nível de subespécie, uma vez que os caracteres usados para separar essas subespécies se sobrepõem.

\section{SALVINIACEAE}

Chave de identificação para as espécies de Salviniaceae

1. Frondes flutuantes 1,6-2 cm compr.; papilas das frondes flutuantes $2-3 \mathrm{~mm}$ alt., cada uma com 3-4 tricomas unidos no ápice, castanho-claros na base e negros na região da união dos tricomas; lâmina geralmente glabra entre as papilas .. Salvinia auriculata

1. Frondes flutuantes $0,9-1,5 \mathrm{~cm}$ compr.; papilas das frondes flutuantes sésseis, cada uma com 4 tricomas unidos no ápice, hialinos na base e castanho-claros a negros na região da união; lâmina com tricomas simples entre as papilas ........ Salvinia radula

Salvinia auriculata Aubl., Hist. P1. Guian. 2: 969, tab. 367. 1775.

Material examinado: BRASIL. PARÁ: Novo Repartimento, ZPVS-UHE de Tucuruí, Base 3, 9-VII-2008, 
R.S. Fernandes et al. 147 (MG); idem, 10-VII-2008, R.S. Fernandes et al. 173 (MG).

Espécie com distribuição americana. No Brasil é citada para o AM, BA, CE, ES, MG, MS, MT, PA, PB, PE, PR, RJ, RS, SC e SP (Braga 1951, Tryon \& Conant 1975, Windisch 1975, Behar \& Viégas 1992, Santos \& Sylvestre 2001, Barros et al. 2002, Figueiredo \& Salino 2005, Costa et al. 2006b, Prado 2006). Plantas aquáticas flutuantes, com muitos indivíduos, crescendo frequentemente às margens do lago ou em ambiente, periodicamente, alagado próximo a palmeiras de açaí. Esta espécie, juntamente com as outras quatro, pertencem ao complexo Salvinia auriculata, caracterizado pelos tricomas unidos no ápice (Mickel \& Smith 2004). De acordo com Salino $\&$ Mota (2007), S. auriculata pode ser eventualmente confundida com $S$. minima, entretanto esta última apresenta folhas flutuantes geralmente menores e os tricomas adaxiais apresentam as extremidades livres, enquanto que em $S$. auriculata as folhas flutuantes são geralmente maiores e os tricomas são unidos nas extremidades.

Salvinia radula Baker, J. Bot. 24: 98. 1886.

Material examinado: BRASIL. ParÁ, Novo Repartimento, ZPVS-UHE de Tucuruí, Base 3, 27-V-2006, A.G. Alves \& M.A. Lopes 121 (MG).

Espécie com distribuição americana. No Brasil é citada para o PA e RJ (Palacios-Rios et al. 2006). Plantas aquáticas flutuantes, com poucos indivíduos, crescendo às margens do lago ou em ambiente, periodicamente, alagado e ensolarado. A posição taxonômica de Salvinia radula é confusa. Herzog (1935) a inclui como sinônimo de S. auriculata, e Weatherby (1937) a considerou como espécie separada. Segundo este autor $S$. radula difere de $S$. auriculata por apresentar suas frondes menores, planas, com papilas baixas ou sésseis e pela presença de tricomas entre as fileiras de papilas. No entanto, de la Sota (1976) comentou sobre a existência de formas intermediárias entre ambas as espécies e que talvez fosse mais correto dar a $S$. radula um nível de variedade. Desta forma, enquanto não for proposta uma revisão taxonômica para o gênero, e mais trabalhos experimentais não forem realizados com as duas espécies, não se pode opinar sobre uma possível sinonímia.

\section{SCHIZAEACEAE}

Chave de identificação para as espécies de Schizaeaceae

1. Lâmina fértil 1-2 vezes furcada; esporangióforos com segmentos pinatífidos dispostos na extremidade da lâmina; esporângios dispostos em 1 fileira de cada lado da costa dos segmentos Schizaea incurvata

1. Lâmina fértil simples; esporangióforos com segmentos digitados dispostos na extremidade da lâmina; esporângios dispostos em 2 fileiras de cada lado da costa dos segmentos Actinostachys pennula

Actinostachys pennula (Sw.) Hook., Gen. Fil., t. 111A. 1842.

Material examinado: BRASIL. PARÁ: Tucuruí, próximo à localidade Breu Branco, 24-III-1980, A.S.L. Silva et al. 1416 (MG); idem, margem direita do rio Tocantins, 30-V-1980, M.G. Silva 5274 (MG).

Espécie com distribuição americana. No Brasil é citada para o AM, AP, BA, CE, DF, ES, MT, PA, PB, PE, PR, RJ, RO, RN, RR, SP e SC (Brade 1972, Sehnem 1974, Tryon \& Conant 1975, Silva \& Barros 2005, Pietrobom \& Barros 2006b). Planta observada crescendo em campina de areia branca, em local mais aberto. Actinostachys pennula caracteriza-se por apresentar a lâmina simples, linear e os esporangióforos terminais digitados com 6-8 segmentos.

Schizaea incurvata Schkuhr, Vier Zwan. Kl. Linn. Pfl. Krypto. Gew. 1: 138, t. 137. 1809.

Material examinado: BRASIL. PARÁ: Tucuruí,16 km est of Represa Tucuruí, rio Tocantins, along new road (PA-263), approx. 345'S, 49³9'W, 18-III-1980, T. Plowman et al. 9717 (MG).

Espécie com distribuição sul-americana. No Brasil é citada para o AC, AP, AM, PA e RO (Tryon \& Conant 1975, Prado \& Moran 2009). Planta coletada em campina de areia branca, junto a moitas de vegetação arbustiva. De acordo com Tryon \& Stolze (1989), Schizaea incurvata assemelha-se a S. pusilla Pursh no aspecto geral e na pubescência do esporangióforo. Entretanto, são facilmente diferenciadas pelo fato de S. pusilla não apresentar lâminas furcadas e possuir 
apenas 5-7 pares de segmentos nos esporangióforos, enquanto $S$. incurvata apresenta lâminas 1 a mais vezes furcadas e esporangióforos com (10-)12-25 pares de segmentos (Costa 2007).

\section{TECTARIACEAE}

Chave de identificação para as espécies de Tectariaceae

1. Caule geralmente subereto a ereto; venação areolada Tectaria incisa 1. Caule reptante; venação livre ............. (Triplophyllum) 2. Margem da lâmina e indúsio glabros . Triplophyllum glabrum

2. Margem da lâmina com tricomas esparsos; indúsio com tricomas ou glândulas sésseis

3. Superfície adaxial da raque da pina glabra ou esparsamente pubescente; indúsio pubescente Triplophyllum funestum

3. Superfície adaxial da raque da pina pubescente e glandular; indúsio glandular Triplophyllum dicksonioides

Tectaria incisa Cav., Descr. P1.: 249. 1801.

Material examinado: BRASIL. PARÁ: Novo Repartimento, ZPVS-UHE de Tucuruí, Base 3, Ressaca do Pirarucu, 4²2'55,3"-04'22'11,8"S, $49^{\circ} 35^{\prime} 39,8^{\prime \prime}-49^{\circ} 36^{\prime} 13,3^{\prime \prime} \mathrm{W}$, alt. 72-84 m, 12-III-2009, R.S. Fernandes \& J.M. Costa 322, 332 (MG); Goianésia do Pará, ZPVS-UHE de Tucuruí, Base 4, Ilha do Tamarindo, $04^{\circ} 16^{\prime} 04,2^{\prime \prime}-04^{\circ} 16^{\prime} 37,3^{\prime \prime} \mathrm{S}$, 49³9'37,4"-49॰39'11,6"W, alt. 70-103 m, 23-IX-2008, R.S. Fernandes \& S. Maciel 219 (MG).

Espécie com distribuição americana. No Brasil é citada para o AC, AL, AM, AP, BA, CE, ES, MG, MS, MT, PA, PE, PR, RJ, RO, RS, RR, SC e SP (Tryon \& Conant 1975, Colli et al. 2004, Mynssen \& Windisch 2004, Dittrich et al. 2005, Figueiredo \& Salino 2005, Pietrobom \& Barros 2006b, Prado 2012d). Planta terrícola, bastante comum na área, crescendo em margens de cursos d'água, em barranco ou próximo a igarapé e, ainda, em locais com muitas pedras e sobre solos ricos em nutrientes. Tectaria incisa ocorre em quase todos os locais de distribuição do gênero na América (Tryon \& Tryon 1982), sendo bastante variável em relação à divisão da lâmina e ao número de pinas (Moran 1995) e pode ser confundida com Tectaria trifoliata (L.) Cav., que também ocorre no Pará (Prado 2012d). Entretanto, difere desta por apresentar usualmente 3-8 pares de pinas e soros nitidamente bisseriados, geralmente restritos a uma série em cada lado das cóstulas, enquanto T. trifoliata possui geralmente 1 ou 2 pares de pinas e soros irregularmente arranjados, raramente bisseriados (Smith 1995b).

Triplophyllum dicksonioides (Fée) Holttum, Kew Bull. 41(2): 257. 1986.

Material selecionado: BRASIL. PARÁ: Goianésia do Pará, ZPVS-UHE de Tucuruí, Base 4, Ilha do Cornélio, cerca $04^{\circ} 17^{\prime} 40,1^{\prime \prime S}, 4^{\circ} 28^{\prime} 12,6^{\prime \prime} \mathrm{W}$, alt. 110-120 m, 23-IX-2008, R.S. Fernandes \& S. Maciel

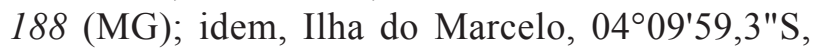
$49^{\circ} 32^{\prime} 38,0^{\prime \prime} \mathrm{W}$, alt. $35 \mathrm{~m}, 14-\mathrm{III}-2009$, R.S. Fernandes \& J.M. Costa 393, 401 (MG).

Espécie com distribuição sul-americana. No Brasil é citada para o AC, AL, AM, BA, MT, PA, PE e RO (Pietrobom \& Barros 2006b, Prado \& Moran 2008). Planta terrícola coletada na margem de trilha em ambiente seco e em barracos úmidos no interior da floresta. Triplophyllum dicksonioides é distinguido pelas glândulas no indúsio (tricomas ausentes) e em ambas as superfícies da lâmina. As glândulas têm cerca de 0,1 mm compr., e são esféricas, amareladas a avermelhadas. Em algumas espécies as glândulas são densas e substituem a maioria ou todos os tricomas da superfície adaxial da raque da pina. A lâmina dessas espécies é geralmente mais dividida (com últimos segmentos pequenos) incluindo as espécies neotropicais (Prado \& Moran 2008).

Triplophyllum funestum (Kunze) Holttum, Kew Bull. 41(2): 255. 1986

Material selecionado: BRASIL. PARÁ: Novo Repartimento, ZPVS-UHE de Tucuruí, Base 3, 9-VII-2008, R.S. Fernandes et al. 115 (MG); Goianésia do Pará, ZPVS-UHE de Tucuruí, Base 4, idem, Ilha do Marcelo, 04 $09^{\prime} 59,3^{\prime \prime} \mathrm{S}, 4^{\circ} 32^{\prime} 38,0^{\prime \prime} \mathrm{W}$, alt. $35 \mathrm{~m}$, 14-III-2009, R.S. Fernandes \& J.M. Costa 400 (MG).

Espécie com distribuição americana. No Brasil é citada para o AC, AL, AM, AP, BA, CE, ES, MA, MG, MT, PA, PE, RJ, RO e RR (Maciel et al. 2007, Paula-Zárate 2005, Prado \& Moram 2008). Planta coletada crescendo no interior da floresta ombrófila aberta, em barranco úmido próximo a igarapé ou entre rochas em solo seco a margem de trilha. Triplophyllum funestum é distinguida de $T$. dicksonioides por 
apresentar a superfície adaxial da raque da pina glabra a esparsamente pubescente, com tricomas articulados na superfície abaxial, densos e escuros, com 0,1-0,2 mm comprimento (Prado \& Moran 2008).

Triplophyllum glabrum J. Prado \& R.C. Moran, Britt 60(2): 121. 2008.

Material selecionado: BRASIL. PARÁ: Novo Repartimento, ZPVS-UHE de Tucuruí, Base 3, 9-VII-2008, R.S. Fernandes et al. 119 (MG); Goianésia do Pará, ZPVS-UHE de Tucuruí, Base 4, idem, trilha 8, $04^{\circ} 15^{\prime} 0,6^{\prime \prime}-04^{\circ} 15^{\prime} 47,85^{\prime \prime} \mathrm{S}, 49^{\circ} 31^{\prime} 01,7^{\prime \prime}-49^{\circ} 30^{\prime} 17,6^{\prime \prime} \mathrm{W}$, alt. 102-179 m, 13-III-2009, R.S. Fernandes \& J.M. Costa 354 (MG).

Espécie com distribuição sul-americana. No Brasil é citada para o AM, PA e RO (Prado \& Moram 2008). Planta coletada fértil na margem de trilha em ambiente seco, em barranco úmido no interior da floresta e ainda próximo a igarapé. Segundo Prado \& Moran (2008), Triplophyllum glabrum é a única espécie do gênero com indúsio glabro e margem da lâmina não ciliada.

\section{THELYPTERIDACEAE}

Chave de identificação para as espécies de Thelypteridaceae

1. Indumento de tricomas simples aciculares presentes em toda ou em algumas partes da planta

2. Lâmina 1-pinada; nervuras regularmente anastomosadas; indúsio ausente (subg. Meniscium) Thelypteris serrata

2. Lâmina 1-pinado-pinatífida; nervuras livres; indúsio presente

. (subg. Cyclosorus) Thelypteris interrupta

1. Indumento de tricomas furcados e/ ou estrelados presentes pelo menos na raque e na costa às vezes também nas escamas do ápice do caule, podendo estar presentes em outras partes da folha (subg. Goniopteris)

3. Indúsio ausente; pinas com margens crenadas a crenado-serreadas, 1-4 pares; venação areolada Thelypteris poiteana

3. Indúsio presente ou inconspícuo; pinas com margens incisas, 7-27 pares; venação livre
4. Tricomas estrelados sésseis, presentes entreas nervuras em ambas as superfícies da lâmina e às vezes no indúsio; superfície abaxial da lâmina, entre as nervuras, pilosa e verrucosa Thelypteris biolleyi

4. Tricomas estrelados pedicelados, presentes nas escamas, no pecíolo e na raque; superfície abaxial da lâmina, entre as nervuras, glabra e lisa

5. Lâmina com ápice confluente a pinatífido; o primeiro par basal de nervuras adjacente unindo-se antes do enseio, formando uma nervura excurrente, que se dirige ao enseio

Thelypteris abrupta

5. Lâmina com pina terminal conforme; nervuras proximais dos segmentos adjacentes coniventes no enseio, não se unindo para formar nervura excurrente Thelypteris amazonica

Thelypteris abrupta (Desv.) Proctor, Rhodora 61: 306. 1959 (1960).

Figura 4a-c

Material examinado: BRASIL. PARÁ: Novo Repartimento, ZPVS-UHE de Tucuruí, Base 3, 9-VII-2008, R.S. Fernandes et al. 125 (MG); Goianésia do Pará, ZPVS-UHE de Tucuruí, Base 4, Ilha do Prefeito, $04^{\circ} 20^{\prime} 02^{\prime \prime S}, 49^{\circ} 36^{\prime} 52^{\prime \prime} \mathrm{W}$, alt. $70 \mathrm{~m}, 25-\mathrm{IX}-2008$, R.S. Fernandes \& S. Maciel 311 (MG, BHCB).

Espécie com distribuição americana. No Brasil é citada para o AC, AL, AM, BA, MT, PA, PE, RO e RR (Ponce 2007, Salino \& Almeida 2012). Thelypteris abrupta pertence ao subgênero Goniopteris e caracteriza-se por apresentar lâmina geralmente terminando em ápice pinatífido, pinas basais não reflexas, tricomas simples aciculares presentes na costa, nervuras e no indúsio, o primeiro par basal de nervuras dos segmentos adjacentes unindo-se antes do enseio formando uma nervura excurrente, que se dirige ao enseio.

Thelypteris amazonica Salino \& R.S. Fernandes, Nordic J. Bot. 29: 611. 2011.

Material selecionado: BRASIL. PARÁ: Novo Repar-timento, ZPVS-UHE de Tucuruí, Base 3, 9-VII-2008, R.S. Fernandes et al. 130; idem R.S. 


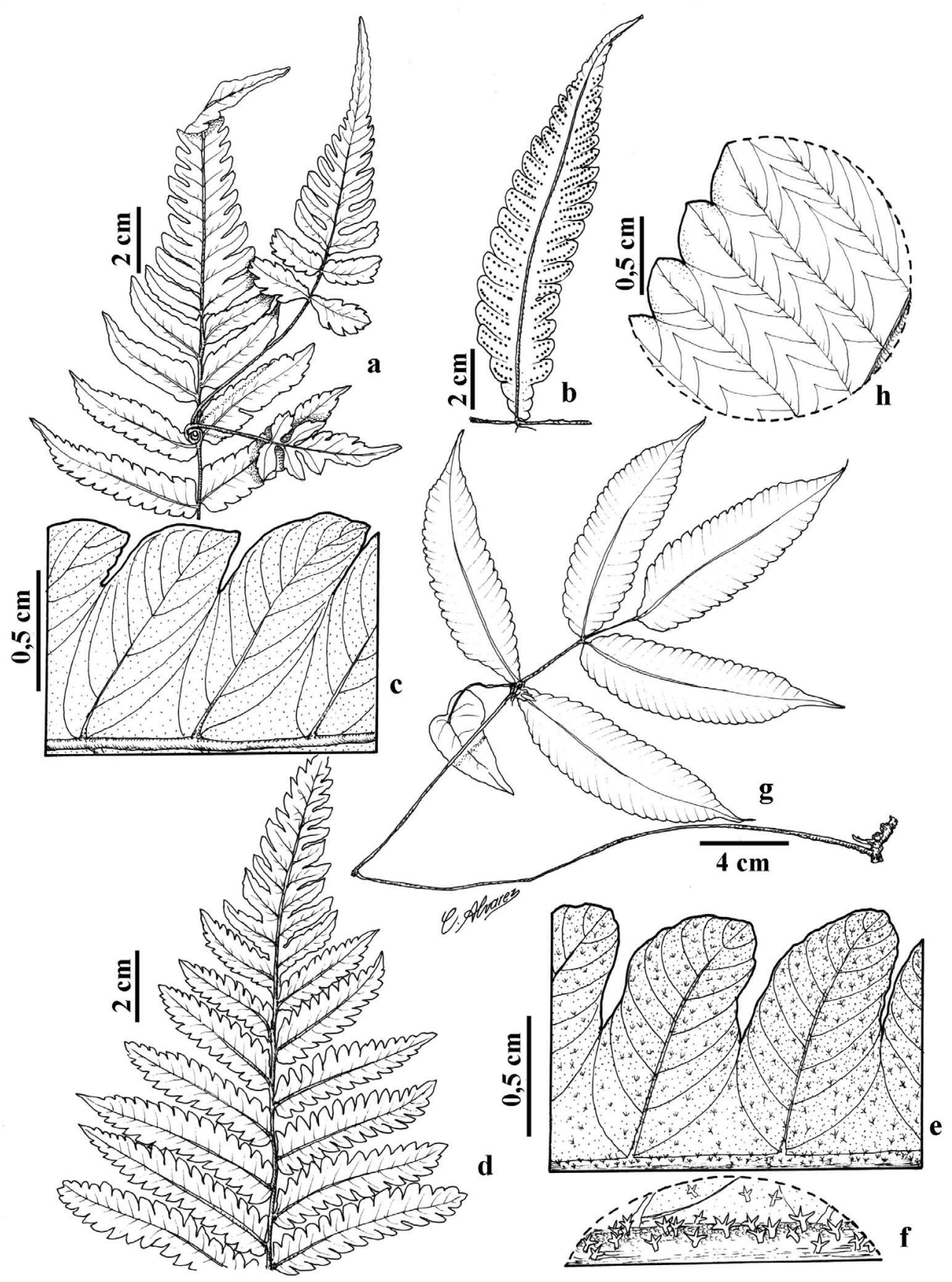

Figura 4. a-c. Thelypteris abrupta (Desv.) Proctor: a. Porção distal da lâmina mostrando a gema e o ápice pinatífido. b. Pina basal mostrando os soros medianos. c. Detalhe da superfície abaxial do segmento estéril mostrando o padrão de venação. d-f. Thelypteris biolleyi (Christ) Proctor. d. Porção distal da lâmina mostrando o ápice pinatífido. e. Detalhe da superfície abaxial do segmento estéril mostrando o padrão de venação e tricomas estrelados. f. Detalhe da costa com tricomas estrelados. g-h. Thelypteris poiteana (Bory) Proctor. g. Hábito. h. Detalhe da pina mostrando o padrão de venação e a margem da pina (a-c: R.S. Fernandes \& S. Maciel 311 (MG, BHCB); d-f: R.S. Fernandes et al. 116 (MG, BHCB); g-h: R.S. Fernandes \& J.M. Costa 321 (MG, BHCB)).

Figure 4. a-c. Thelypteris abrupta (Desv.) Proctor: a. Distal portion of the blade showing the bud and the apex pinnatifid. b. Pinna basal showing the median sori. c. Detail of abaxial surface of the sterile segment showing venation pattern. d-f. Thelypteris biolleyi (Christ) Proctor. d. Distal portion of the blade showing the apex pinnatifid. e. Detail of abaxial surface of the sterile segment showing venation pattern and stellate trichomes. f. Detail of the rachis with stellate trichomes. g-h. Thelypteris poiteana (Bory) Proctor. g. Habit. h. Detail of pinna showing the venation pattern and the margin of the pinna (a-c: R.S. Fernandes \& S. Maciel 311 (MG, BHCB); d-f: R.S. Fernandes et al. 116 (MG, BHCB); g-h: R.S. Fernandes \& J.M. Costa 321 (MG, BHCB)). 
Fernandes et al. 145 (MG); Goianésia do Pará, ZPVS-UHE de Tucuruí, Base 4, trilha 8, 04 15'0,6"$49^{\circ} 31^{\prime} 01,7^{\prime \prime} \mathrm{W}$ a $04^{\circ} 15^{\prime} 47,85^{\prime \prime} \mathrm{S}-49^{\circ} 30^{\prime} 17,6^{\prime \prime} \mathrm{W}$, alt. 102-179 m, 25-IX-2008, R.S. Fernandes \& S. Maciel 300 (MG, BHCB).

Espécie com distribuição sul-americana. No Brasil é citada para o MA e PA (Salino et al. 2011). As espécies brasileiras mais próximas são Thelypteris anoptera (Kunze) C. Chr. e T. abrupta (Desv.) Proctor, mas difere de ambas por possuir nervuras proximais dos segmentos adjacentes, não se unindo abaixo do enseio, e pecíolo piloso com tricomas estrelados e simples. Thelypteris amazonica possui gemas nas pinas distais, tecido laminar não verrugoso e indúsio apenas com tricomas simples.

Thelypteris biolleyi (H. Christ) Proctor, Bull. Inst. Jamaica, Sci. Ser. 5: 58. 1953.

Figura 4d-f

Material examinado: BRASIL. PARÁ: Novo Repartimento, ZPVS-UHE de Tucuruí, Base 3, trilha principal, 27-V-2006, A.G. Alves \& M.A. Lopes 112 (MG, BHCB); idem, 9-VII-2008, R.S. Fernandes et al. $116(\mathrm{MG}, \mathrm{BHCB})$.

Espécie com distribuição americana. No Brasil é citada para o AL, AM, BA, ES, MG, MT, PA, PE e SP (Melo \& Salino 2002, Pietrobom \& Barros 2006b, Salino \& Almeida 2012). Na área estudada, é pouco comum. Cresce no sub-bosque de florestas ombrófila aberta, em barranco próximo a curso d'água, sobre solos ricos em nutrientes. Thelypteris biolleyi difere das demais espécies do subgênero Goniopteris coletadas na área estudada por apresentar superfície adaxial da lâmina geralmente verrugosa, presença de tricomas estrelados sésseis, entre as nervuras em ambas as faces da lâmina e, às vezes, no indúsio, glândulas sésseis e amareladas na face abaxial, nervuras basais dos segmentos adjacentes unindo-se antes do enseio a uma nervura excurrente, que se dirige ao enseio, e pela ausência de gemas na axila das pinas. A presença de glândulas na superfície abaxial da lâmina não é comum nesta espécie.

Thelypteris interrupta (Willd.) K. Iwats., J. Bot. 38: 314. 1963.

Material selecionado: BRASIL. PARÁ: Goianésia do Pará, ZPVS-UHE de Tucuruí, Base 4, Ilha do Marcelo,

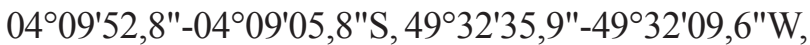
alt. 75-107 m, 24-IX-2008, R.S. Fernandes \&
S. Maciel 256 (MG, BHCB); idem, trilha 8, 04 $15^{\prime} 0,6^{\prime \prime}-$ $04^{\circ} 15^{\prime} 47,85^{\prime \prime} \mathrm{S}, 49^{\circ} 31^{\prime} 01,7^{\prime \prime}-49^{\circ} 30^{\prime} 17,6^{\prime \prime} \mathrm{W}$, alt. 102-179 m, 25-IX-2008, R.S. Fernandes \& S. Maciel 301 (MG).

Espécie com distribuição circum-antártica. No Brasil é citada para o AM, AP, AL, BA, CE, DF, ES, GO, MA, MG, MS, MT, PA, PE, PB, PR, RJ, RS, SC, SP e TO (Pietrobom \& Barros 2006b, Salino \& Almeida 2012). Na área estudada, a espécie foi observada crescendo à margem do lago, em local alagado ou em clareiras. Thelypteris interrupta é a única espécie encontrada na área estudada pertencente ao subgênero Cyclosorus. É caracterizada pela lâmina elíptica, 1-pinado-pinatífida a crenada, com pinas pinatífidas e segmentos com ápice arredondado, agudo ou obtuso.

Thelypteris poiteana (Bory) Proctor, Bull. Inst. Jamaica, Sci. Ser. 5: 63. 1953.

Figura 4g-h

Material selecionado: BRASIL. PARÁ: Novo Repartimento, ZPVS-UHE de Tucuruí, Base 3, trilha 5, 9-VII-2008, R.S. Fernandes et al. 124 (MG); idem, Ressaca do Pirarucu, 422'55,3"-04²2'11,8"S, 49³5'39,8"-49³6'13,3"W, alt. 72-84 m, 12-III-2009, R.S. Fernandes \& J.M. Costa 321 (MG, BHCB).

Espécie com distribuição americana. No Brasil é citada para o AL, AM, AP, BA, CE, MG, PA e PE (Sampaio 1930, Pietrobom \& Barros 2006b, Zuquim et al. 2008, Salino \& Almeida 2012). Na área estudada, é pouco comum, crescendo entre rochas úmidas dentro de curso d'água ou no sub-bosque de florestas ombrófila aberta sobre solos ricos em nutrientes. Thelypteris poiteana pode ser reconhecida pelas pinas verde-escuras, pilosas, com margem levemente recortada (Zuquim et al. 2008). Difere das demais espécies do subgênero Goniopteris coletadas na área por apresentar até três pares de pinas e venação anastomosada.

Thelypteris serrata (Cav.) Alston, Kew Bull. 1932: 309. 1932.

Material examinado: BRASIL. PARÁ: Goianésia do Pará, ZPVS-UHE de Tucuruí, Base 4, Ilha do Marcelo, 0409'52, $8^{\circ}-04^{\circ} 09^{\prime} 05,8^{\prime \prime} \mathrm{S}, 49^{\circ} 32^{\prime} 35,9^{\prime \prime}-49^{\circ} 32^{\prime} 09,6^{\prime \prime} \mathrm{W}$, alt. 75-107 m, 24-IX-2008, R.S. Fernandes \& S. Maciel 257 (MG, BHCB); trilha 4, 04 $15^{\prime} 18,5^{\prime \prime} \mathrm{S}$, $49^{\circ} 31^{\prime} 03,7^{\prime \prime} \mathrm{W}$, alt. $60 \mathrm{~m}, 13-\mathrm{III}-2009$, R.S. Fernandes \& J.M. Costa $372(\mathrm{MG})$. 
Espécie com distribuição americana. No Brasil é citada para o $\mathrm{AC}, \mathrm{AL}, \mathrm{AM}, \mathrm{AP}, \mathrm{BA}, \mathrm{CE}, \mathrm{DF}, \mathrm{ES}$, GO, MA, MG, MS, MT, PA, PB, PE, PR, RJ, RN, RO, RR, RS, SC e SP (Dutra 1938, Salino \& Semir 2004, Pietrobom \& Barros 2006b). Na área estudada, a espécie foi observada crescendo em clareiras de solo ocasionalmente alagado de floresta de terra firme. Thelypteris serrata é a única espécie pertencente ao subgênero Meniscium encontrada na área estudada. Apresenta lâmina lanceolada, 1-pinada, gradualmente reduzida em direção ao ápice, as pinas apresentam margens serreadas ou uncinado-serreadas e a venação é areolada (venação meniscióide).

\section{Agradecimentos}

Os autores agradecem ao REUNI (Reestruturação e Expansão das Universidades Federais) pela concessão de bolsa de mestrado à primeira autora; à Eletronorte pelo apoio logístico nas coletas de campo; ao Museu Paraense Emilio Goeldi, Coordenação de Botânica e Universidade Federal Rural da Amazônia pela infra-estrutura fornecida; ao Dr. Alexandre Salino, Dr. Jefferson Prado e Dra. Lana Sylvestre pela revisão nas identificações das espécies dos gêneros Thelypteris, Adiantum e Asplenium respectivamente, ao biólogo Jeferson Mirando Costa pelo auxílio nas coletas e identificação das espécies.

\section{Literatura citada}

Alston, A.H.G., Jermy, A.C. \& Rankin, J.M. 1981. The genus Selaginella in tropical South America. Bulletin of the British Museum (Natural History), Botany 9: 233-330.

Andrade-Lima, D. 1969. Pteridófitas que ocorrem nas Floras Extra-Amazônica e Amazônica do Brasil e proximidades. In: Anais do XX Congresso Nacional de Botânica. Sociedade Botânica do Brasil, Goiânia, pp. 34-39.

Barros, I.C.L., Santiago, A.C.P., Xavier, S.R.S., Pietrobom, M.R. \& Luna, C.P.L. 2002. Diversidade e aspectos ecológicos das pteridófitas (avencas, samambaias e plantas afins) ocorrentes em Pernambuco. In: M. Tabarelli \& J.M.C. Silva (orgs.). Diagnóstico da biodiversidade de Pernambuco. Editora Massangana e Secretaria de Ciência e Tecnologia - SECTMA, Recife, v.1, pp. 153-171.

Barros I.C.L., Silva, M.R.P., Santiago, A.C.P. \& Xavier, S.R.S. 2004. Os gêneros Campyloneurum, Dicranoglossum, Niphidium, Pecluma e Pleopeltis (Polypodiaceae-Pteridophyta) na Região Nosdeste Setentrional Brasileira. Bradea 10: 35-64.
Barros, I.C.L., Santiago, A.C.P. \& Pereira, A.F.N. 2012. Lomariopsidaceae In: R.C. Forzza, A. Costa, B.M.T. Walter, J.R. Pirani, M.P. Morim, L.P. Queiroz, G. Martinelli, A.L. Peixoto, M.A.N. Coelho, J.F.A. Baumgratz, J.R. Stehmann, L.G. Lohmann, M. Hopkins. Lista de Espécies da Flora do Brasil. Jardim Botânico do Rio de Janeiro, Rio de Janeiro. http://floradobrasil. jbrj.gov.br/2012/FB091343 (acesso em 09.03.2012).

Bastos, C.C.C. \& Cutrim, M.V.J. 1999. Pteridoflora da Reserva Florestal do Sacavém, São Luiz - Maranhão. Boletim do Museu Paraense Emílio Goeldi, série Botânica 15: 3-37.

Behar, L. \& Viégas, G.M.F. 1992. Pteridófitas da Restinga do Parque Estadual de Setiba, Espírito Santo. Boletim do Museu de Biologia Mello Leitão, nova série 1:39-59.

Berry, P.E., Holst, B.K. \& Yatskievych, K. (eds.). 1995. Pteridophytes, Spermatophytes: Acanthaceae-Araceae. In: J.S. Steyermark, P.E. Berry \& B.K. Holst, (eds.). Flora of the Venezuelan Guayana. Timber Press, Portland, v.2, pp. 706.

Boer, J.G.W. 1962. The new world species of Thichomanes sect. Didymoglossum and Microgonium. Acta Botanica Neerlandica 11: 277-330.

Boldrin, A.H.L. \& Prado, J. 2007. Pteridófitas terrestres e rupícolas do Forte dos Andradas, Guarujá, São Paulo, Brasil. Boletim Botânico da Universidade de São Paulo 25: 1-69.

Brade, A.C. 1940. Contribuição para o Estudo da Flora Pteridophyta da Serra de Baturité Estado do Ceará. Rodriguésia 4: 289-314.

Brade, A.C. 1947. Contribuição para o conhecimento da Flora do Estado do Espírito Santo (I. Pteridophyta). Rodriguésia 21: 25-33.

Brade, A.C. 1972. Contribuição ao conhecimento das espécies brasileiras do gênero Schizaea, com especial referência às espécies do Brasil Austral. Bradea 1: 285-299.

Brade, A.C. 2003. O gênero Elaphoglossum (Pteridophyta) no Brasil. Apresentação póstuma do texto inédito. Disponível em: http://www.saude.unisinos.br/ pteridos (acesso em 14.06.2006)

Braga, R. 1951. Pteridófitas Cearenses. Boletim da Secretaria da Agricultura e Obras Públicas do Ceará 2: 77-101

Christenhusz, M.J.M. 2007. Two new epitypes in Danaea (Marattiaceae, Pteridophyta) selected from original historical collections in Paris. Candollea 62: 221-226.

Colli, A.M.T., Souza, S.A., Salino, A., Lucca, A.L.T. \& Silva, R.T. 2004. Pteridófitas do Parque Estadual de Vassununga, Santa Rita do Passa Quatro (SP). Revista do Instituto Florestal 16: 121-127.

Costa, J.M. 2007. Licófitas e monilófitas (Pteridófitas) da Ilha de Mosqueiro, município de Belém, Estado do Pará, Brasil. Dissertação de Mestrado, Universidade Federal Rural da Amazônia, Museu Paraense Emilio Goeldi, Belém. 
Costa, J.M., Pietrobom, M.R. \& Souza, M.G.C. 2006a. Primeiro registro de Trichomanes pinnatinervium Jenman (Hymenophyllaceae - Monilophyta) para o Brasil. Bradea 11: 33-36.

Costa, J.M., Souza, M.G.C. \& Pietrobom, M.R. 2006 b. Levantamento florístico das pteridófitas (Lycophyta e Monilophyta) do Parque Ambiental de Belém (Belém, Pará, Brasil). Revista de Biologia Neotropical 3: 4-12.

Costa, J.M. \& Pietrobom, M.R. 2007. Pteridófitas (Licófitas e Monilófitas) da Ilha de Mosqueiro, município de Belém, Estado do Pará, Brasil. Boletim do Museu Paraense Emílio Goeldi, Ciências Naturais 2: 45-55.

Costa, J.M. \& Pietrobom, M.R. 2010. Samambaias e licófitas do Parque Ecológico do Gunma, município de Santa Bárbara do Pará, Estado do Pará, Brasil. Rodriguésia 61: 223-232.

Cremers, G. 1997. Pterophyta. In: S.A. Mori, G. Cremers, C. Gracie, J-J. Granville, M. Hoff \& J.D. Mitchell (eds.). Guide to the Vascular Plants of Central French Guiana. Part 1. Pteridophytes, Gymnosperms, and Monocotyledons. New York Botanical Graden, New York, v.76, pp. 65-162.

Cremers, G. \& Kramer, K.U. 1989. A new subspecies of Saccoloma elegans Kaulfuss (Dennstaedtiaceae). Botanica Helvetica 99: 45-48.

De la Sota, E.R. 1976. Sinopsis de las especies argentinas del genero Salvinia Adanson (Salviniaceae-Pteridophyta). Boletin de la Sociedad Argentina de Botánica 17: 47-50.

Dittrich, V.A.O. 2005. Estudos taxonômicos no gênero Blechnum L. (Pteridophyta: Blechnaceae) para as regiões Sudeste e Sul do Brasil. Tese de Doutorado, Universidade Estadual Paulista, Rio Claro.

Dittrich, V.A.O., Waechter, J.L. \& Salino, A. 2005. Species richness of pteridophytes in a montane Atlantic rain forest plot of Souther Brazil. Acta Botanica Brasilica 19: 519-525.

Dittrich, V.A.O. \& Salino, A. 2010. Blechnaceae. In: R.C. Forzza, A. Costa, B.M.T. Walter, J.R. Pirani, M.P. Morim, L.P. Queiroz, G. Martinelli, A.L. Peixoto, M.A.N. Coelho, J.F.A. Baumgratz, J.R. Stehmann, L.G. Lohmann, M. Hopkins. Lista de Espécies da Flora do Brasil. Jardim Botânico do Rio de Janeiro, Rio de Janeiro. http://floradobrasil.jbrj.gov.br/2012/FB091343 (acesso em 19.07.2010).

Dutra, J. 1938. A flora pteridofítica do Estado do Rio Grande do Sul. Anais da $1^{\circ}$ Reunião Sul-Americana de Botânica 2: 19-65.

Edwards, P.J. 1998. The Pteridophytes of the Ilha de Maracá. In: W. Milliken \& J.A. Ratter (eds.). Maracá: the biodiversity and environment of an Amazonian rainforest. John Wiley \& Sons, pp. 113-129.

Evans, A.M. 1969. Interspecific relationships in the Polypodium pectinatum-plumula complex. Annals of the Missouri Botanical Garden 55: 193-293.
Félix, L.P., Sousa M.A. \& Oliveira, I.C. 1996. Pteridófitas do Herbário Prof. Jayme Coelho de Moraes (EAN), Areia - Paraíba, Brasil: I - Vittariaceae. Revista Nordestina de Biologia 11: 57-71.

Fernandes, I. 2003. Taxonomia dos representantes de Cyatheaceae do Nordeste Oriental do Brasil. Pesquisas, Botânica 53: 7-53.

Fernandes, R.S., Conceição, G.M., Brito, E.S. \& PaulaZárate, E.L. 2007. Diversidade florística de pteridófitas da Área de Preservação Ambiental do Inhamum, Caxias, Maranhão, Brasil. Revista Brasileira de Biociências 5 (suplemento 2): 411-413.

Ferreira, L.S.L., Costa, J.M. \& Pietrobom, M.R. 2009. As pteridófitas. In: M.A.G. Jardim (org.). Diversidade biológica das áreas de proteção ambiental Ilhas do Combu e Algodoal-Maiandeua, Pará, Brasil. Museu Paraense Emilio Goeldi, Ministério de Ciência e Tecnologia, Belém, pp. 13-40.

Fidalgo, O. \& Bononi, V.L.R. 1989. Técnicas de coleta, preservação e herborização de material botânico. Instituto de Botânica, São Paulo.

Figueiredo, J.B. \& Salino, A. 2005. Pteridófitas de quatro reservas particulares do Patrimônio Natural ao Sul da região metropolitana de Belo Horizonte, Minas Gerais, Brasil. Lundiana 6: 83-94.

Fisch, G.F., Januário, M. \& Senna, R.C. 1990. Impacto ecológico em Tucuruí (PA): Climatologia. Acta Amazonica 20: 49-60.

Freitas, C.A.A. \& Prado, J. 2005. Lista anotada das pteridófitas de florestas inundáveis do alto Rio Negro, Município de Santa Isabel do Rio Negro, AM, Brasil. Acta Amazonica 19: 399-403.

Graçano, D., Prado, J. \& Azevedo, A.A. 1998. Levantamento Preliminar de Pteridophyta do Parque Estadual do Rio Doce (MG). Acta Botanica Brasilica 12: 165-181.

Herzog, R. 1935. Ein beiträg zur Systematik der Gattung Salvinia. Hedwigia 74: 257-284.

Hirai, R.Y. 2012. Selaginellaceae. In: R.C. Forzza, A. Costa, B.M.T. Walter, J.R. Pirani, M.P. Morim, L.P. Queiroz, G. Martinelli, A.L. Peixoto, M.A.N. Coelho, J.F.A. Baumgratz, J.R. Stehmann, L.G. Lohmann, M. Hopkins. Lista de Espécies da Flora do Brasil. Jardim Botânico do Rio de Janeiro, Rio de Janeiro. http:// floradobrasil.jbrj.gov.br/2012/FB091343 (acesso em 09.03.2012).

Huber, J. 1900-1902. Materiais para a flora amazônica. III. Fetos do Amazonas inferior e de algumas regiões limítrofes, colecionados pelo Dr. J. Huber e determinados pelo Dr. Hermann Christ, Basilea (Suíça). Boletim do Museu Paraense de História Natural e Ethnografia (Museu Goeldi) 3: 1-60.

Huber, J. 1908. Plantas do Ceará. Revista Trimestral do Instituto do Ceará. Typografia Minerva, Fortaleza, t.22, pp. 189-192. 
Jermy, A.C. 1990. Selaginellaceae. In: K.U. Kramer, \& P.S. Green, (eds.). Pteridophytes and Gymnosperms Vol. I. In: Kubitzki, K. (ed.). The Families and Genera of Vascular Plants. Springer-Verlag, Berlin. pp. 39-45.

Kramer, K.U. 1957. A revision of the genus Lindsaea in the New World. Acta Botanica Neerlandica 6: 97-290.

Kramer, K.U. 1978. The Pteridophytes of Suriname: An enumeration with keys of the ferns and fern-allies. Natuurwetenschappelijke Studiekring voor Suriname en de Nederlandse Antillen, Utrecht 93: 1-198.

Labiak, P.H. 2005. Polypodiaceae. In: T.B. Cavalcanti \& A.E. Ramos (orgs.). Flora do Distrito Federal, Brasil. Embrapa Recursos Genéticos e Biotecnologia, Brasília 4: $159-182$.

Labiak, P.H. 2012. Marattiaceae. In: R.C. Forzza, A. Costa, B.M.T. Walter, J.R. Pirani, M.P. Morim, L.P. Queiroz, G. Martinelli, A.L. Peixoto, M.A.N. Coelho, J.F.A. Baumgratz, J.R. Stehmann, L.G. Lohmann, M. Hopkins. Lista de Espécies da Flora do Brasil. Jardim Botânico do Rio de Janeiro, Rio de Janeiro. http://floradobrasil. jbrj.gov.br/2012/FB091343 (acesso em 09.03.2012).

Labiak, P. H. \& Prado, J. 1998. Pteridófitas epífitas da reserva Volta Velha, Itapoá - Santa Catarina, Brasil. Boletim do Instituto de Botânica da Universidade de São Paulo 11: 1-79.

Labiak, P.H. \& Hirai, R.Y. 2012. Polypodiaceae In: R.C. Forzza, A. Costa, B.M.T. Walter, J.R. Pirani, M.P. Morim, L.P. Queiroz, G. Martinelli, A.L. Peixoto, M.A.N. Coelho, J.F.A. Baumgratz, J.R. Stehmann, L.G. Lohmann, M. Hopkins. Lista de Espécies da Flora do Brasil. Jardim Botânico do Rio de Janeiro, Rio de Janeiro. http://floradobrasil.jbrj.gov.br/2012/FB091343 (acesso em 09.03.2012).

Leão, N.V., Vieira, I.C.G. \& Ohashi, S.T. 2005a. Levantamento florestal para implantação da reserva "in situ" na Ilha de Germoplasma - Tucuruí. Relatório do programa de revitalização do Banco de Germoplasma da UHE de Tucuruí, Tucuruí, Pará.

Leão, N.V.M., Ohashi, S.T., Vieira, I.C.G. \& Ghilardi R. 2005b. Ilha de Germoplasma. Uma reserva da biodiversidade para o futuro. Eletronorte, Brasília.

Lellinger, D.B. 1987. The disposition of Trichipteris (Cyatheaceae). American Fern Journal 77: 90-94.

Lellinger, D.B. 2002. A modern multilingual glossary for taxonomic Pteridology. Pteridologia 3: 1-263.

Lellinger, D.B. \& Prado, J. 2001. The group of Adiantum gracile in Brazil and environs. American Fern Journal 91: 1-8.

Maciel, S. \& Pietrobom, M.R. 2010a. Pteridaceae (Polypodiopsida) do Campo Experimental da Embrapa Amazônia Oriental, município de Moju, Estado do Pará, Brasil. Acta Botanica Brasilica 24: 8-19.

Maciel, S. \& Pietrobom, M.R. 2010b. Dryopteridaceae e Lomariopsidaceae (Polypodiopsida) do Campo Experimental da Embrapa Amazônia Oriental, Moju, Pará, Brasil. Rodriguésia 61: 405-414.
Maciel, S., Pietrobom, M.R. \& Souza, M.G. 2007. Licófitas e monilófitas do Bosque Rodrigues Alves Jardim Botânico da Amazônia, município de Belém, Estado do Pará, Brasil. Boletim do Museu Paraense Emílio Goeldi, Ciências Naturais 2: 1-27.

Melo, L.C.N. \& Salino, A. 2002. Pteridófitas de duas áreas de floresta da Bacia do Rio Doce no Estado de Minas Gerais, Brasil. Lundiana 3: 129-139.

Mickel, J.T. \& Beitel, J.M. 1988. Pteridophyte flora of Oaxaca, Mexico. Memoirs of the New York Botanical Garden 46: 1-568.

Mickel, J.T. \& Smith, A.R. 2004. The Pteridophytes of Mexico. Memoirs of the New York Botanical Gardens 88: 1-1054.

Mickel, J.T., Smith, A.R. \& Valdespino, I.A. 2004. Selaginella. In: J.T. Mickel \& A.R. Smith, (orgs.). The Pteridophytes of Mexico. Memoirs of the New York Botanical Garden 88: 550-602.

Moran, R.C. 1995. Blechnaceae. In: R.C. Moran \& R. Riba (eds.). Flora Mesoamericana 1. Psilotaceae a Salviniaceae. Universidad Nacional Autónoma de México, Ciudad de México, v.1, pp. 325-333.

Moran, R.C. 1995. Tectaria. In: R.C. Moran \& R. Riba, (eds.). Psilotaceae a Salviniaceae. In: G. Davidse, M. Sousa, S. Knapp (eds.). Flora Mesoamericana. Universidad Nacional Autonoma de Mexico, Ciudad de Mexico, v.1, pp. 204-209.

Moran, R.C. 2000. Monograph of the Neotropical species of Lomariopsis (Lomariopsidaceae). Brittonia 52: 55-111.

Moran, R.C. \& Riba, R. 1995. Flora Mesoamericana. 1. Psilotaceae a Salviniaceae. Universidad Nacional Autónoma de México, Ciudad de México.

Moran, R.C. \& Smith, A.R. 2001. Phytogeographic relationships between neotropical and AfricanMadagascan pteridophytes. Brittonia 53: 304-351.

Moran, R.C., Labiak, P.H. \& Sundue, M. 2010. Synopsis of Mickelia, a newly recognized genus of bolbitidoid ferns (Dryopteridaceae). Brittonia 62: 337-356.

Mori, S.A., Boom, B.M., Carvalho, A.M. \& Santos, T.S. 1983. Southern bahian moist forests. The Botanical Review 49: 155-232.

Mynssen, C.M., Sylvestre, L.S. \& Andreata, R.H.P. 2002. Pteridófitas das matas de encosta do Jardim Botânico do Rio de Janeiro. Pesquisas, São Leopoldo 52: 47-87.

Mynssen C.M. \& Windisch P.G. 2004. Pteridófitas da Reserva Rio das Pedras, Mangaratiba, Rio de Janeiro, Brasil. Rodriguésia 55: 125-156.

Nessel, H. 1955. Lycopodiaceae. In: F.C. Hoehne (ed.). Flora Brasilica. Instituto de Botânica, São Paulo, v.2, fasc. 11, pp. 1-131.

Nonato, F.R. \& Windisch, P.G. 2004. Vittariaceae (Pteridophyta) do Sudeste do Brasil. Revista Brasileira Botânica 27: 149-161.

Øllgaard, B. \& Windisch, P.G. 1987. Sinopse das Licopodiáceas do Brasil. Bradea 5: 1-43. 
Pacheco, L. 1995. Hymenophyllaceae. In: R.C. Moran \& R. Riba (eds.). Psilotaceae a Salviniaceae. In: G. Davidse, M. Sousa \& S. Knapp (eds.). Flora Mesoamericana. Universidad Autônoma de México, Ciudad de México, v.1, pp. 62-83.

Paciencia, M.B. \& Prado, J. 2004. Efeitos de borda sobre a comunidade de pteridófitas na Mata Atlântica da região de Una, sul da Bahia, Brasil. Revista Brasileira de Botânica 27: 641-653.

Palacios-Rios, M., Caluff, M.G. \& Oviedo, R. 2006. Salviniaceae. In: W. Greuter \& R.R. Rodriguez (eds.). Flora de la Republica de Cuba. Koeltz Scientific Books, Konigstein v.11, pp. 3-8.

Parris, B.S. 2001.Circum-Antarctic continental distribution patterns in pteridophyte species. Brittonia 53: 270-283.

Paula, E.L. 1993. Pteridófitas da Serra do Baturité-Ceará. Dissertação de Mestrado, Universidade Federal de Pernambuco, Recife.

Paula-Zárate, E.L. 2005. Florística e fitogeografia das pteridófitas do Estado do Ceará, Brasil. Tese de Doutorado, Universidade de São Paulo, São Paulo.

Pichi-Sermolli, R.E.G. 1996. Authors of scientifc names in Pteridophyta. Royal Botanical Gardens, Kew.

Pietrobom, M.R. \& Barros, I.C.L. 2003. Pteridófitas de um fragmento florestal na Serra do Mascarenhas, Estado de Pernambuco, Brasil. Insula 32: 73-118.

Pietrobom, M.R. \& Barros, I.C.L. 2006a. Pteridoflora do Engenho Água Azul, município de Timbaúba, Pernambuco, Brasil. Rodriguésia 58: 85-94.

Pietrobom, M.R. \& Barros, I.C.L. 2006b. Associações entre as espécies de pteridófitas em dois fragmentos de Floresta Atlântica do Nordeste Brasileiro. Biotemas, Florianópolis 19: 15-26.

Pietrobom, M.R., Maciel, S., Costa, J.M., Souza, M.G.C., Trindade, M.J. \& Fonseca, M.S.S. 2009. Licófitas ocorrentes na Floresta Nacional de Caxiuanã, Estado do Pará, Brasil: Lycopodiaceae e Selaginellaceae. Boletim Museu Paraense Emílio Goeldi, Ciências Naturais 4: 37-45.

Ponce, M. 2007. Sinopsis de las Thelypteridaceae de Brasil central y Paraguay. Hoehnea 34: 283-333.

Prado, J. 1997. Estudo da diversidade de espécies de Pteridófitas no Estado de São Paulo. Disponível em: http://www.biota.org.br/info/historico/workshop/ revisoes/pteridofitas.pdf (acesso em 05.03.2012)

Prado, J. 2003. Revisões e monografias como base para análise da diversidade, o quanto conhecemos sobre a nossa flora. In: M.A.G. Jardim, M.N.C. Bastos \& J.U.M. Santos (eds.). Desafios da Botânica no novo milênio: inventário, sistematização e conservação da diversidade vegetal. Museu Paraense Emílio Goeldi, Universidade Federal Ruaral da Amazônia, Embrapa, Belém, pp. 278-279.
Prado, J. 2005a. Flora da Reserva Ducke, Amazonas, Brasil: Pteridophyta - Aspleniaceae. Rodriguésia 56: 29-32.

Prado, J. 2005b. Flora da Reserva Ducke, Amazonas, Brasil: Pteridophyta - Dennstaedtiaceae. Rodriguésia 56: 43-48.

Prado, J. 2005c. Flora da Reserva Ducke, Amazonas, Brasil: Pteridophyta - Lomariopsidaceae. Rodriguésia 56: 59-66.

Prado, J. 2005d. Flora da Reserva Ducke, Amazonas, Brasil: Pteridophyta - Pteridaceae. Rodriguésia 56: 85-92.

Prado, J. 2006. Criptógamos do Parque Estadual das Fontes do Ipiranga, São Paulo, SP. Pteridophyta: 18. Salviniaceae. Hoehne 33: 107-110.

Prado, J. 2012a. Lastreopsis In: R.C. Forzza, A. Costa, B.M.T. Walter, J.R. Pirani, M.P. Morim, L.P. Queiroz, G. Martinelli, A.L. Peixoto, M.A.N. Coelho, J.F.A. Baumgratz, J.R. Stehmann, L.G. Lohmann, M. Hopkins. Lista de Espécies da Flora do Brasil. Jardim Botânico do Rio de Janeiro, Rio de Janeiro. http://floradobrasil. jbrj.gov.br/2012/FB091343 (acesso em 09.03.2012).

Prado, J. 2012b. Lindsaeaceae. In: R.C. Forzza, A. Costa, B.M.T. Walter, J.R. Pirani, M.P. Morim, L.P. Queiroz, G. Martinelli, A.L. Peixoto, M.A.N. Coelho, J.F.A. Baumgratz, J.R. Stehmann, L.G. Lohmann, M. Hopkins. Lista de Espécies da Flora do Brasil. Jardim Botânico do Rio de Janeiro, Rio de Janeiro. http://floradobrasil. jbrj.gov.br/2012/FB091343 (acesso em 09.03.2012).

Prado, J. 2012c. Pteridaceae In: R.C. Forzza, A. Costa, B.M.T. Walter, J.R. Pirani, M.P. Morim, L.P. Queiroz, G. Martinelli, A.L. Peixoto, M.A.N. Coelho, J.F.A. Baumgratz, J.R. Stehmann, L.G. Lohmann, M. Hopkins. Lista de Espécies da Flora do Brasil. Jardim Botânico do Rio de Janeiro, Rio de Janeiro. http://floradobrasil. jbrj.gov.br/2012/FB091343 (acesso em 09.03.2012).

Prado, J. 2012d. Tectariaceae. In: R.C. Forzza, A. Costa, B.M.T. Walter, J.R. Pirani, M.P. Morim, L.P. Queiroz, G. Martinelli, A.L. Peixoto, M.A.N. Coelho, J.F.A. Baumgratz, J.R. Stehmann, L.G. Lohmann, M. Hopkins. Lista de Espécies da Flora do Brasil. Jardim Botânico do Rio de Janeiro, Rio de Janeiro. http://floradobrasil. jbrj.gov.br/2012/FB091343 (acesso em 09.03.2012)

Prado, J. \& Freitas, C.A.A. 2005. Flora da Reserva Ducke, Amazonas, Brasil: Pteridophyta - Selaginellaceae. Rodriguésia 56: 98-102.

Prado, J. \& Labiak, P.H. 2001. Pteridófitas. In: M.C.H. Mamede, I. Cordeiro \& L. Rossi (orgs.). Flora Vascular da Serra da Juréia, município de Iguape, São Paulo, Brasil. Boletim do Instituto de Botânica 15: 63-124.

Prado, J. \& Labiak, P.H. 2003. Flora de Grão-Mogol, Minas Gerais: Pteridófitas. Boletim de Botânica da Universidade de São Paulo 21: 25-47.

Prado, J. \& Lellinger, D.B. 2002. Adiantum argutum, an unrecognized species of the A. latifolium group. American Fern Journal 92: 23-29. 
Prado, J. \& Moran, R.C. 2008. Revision of the neotropical species of Triplophyllum (Tectariaceae). Brittonia 60: 103-130.

Prado, J. \& Moran, R.C. 2009. Checklist of the ferns and lycophytes of Acre State, Brazil. Fern Gazette 18: 230-263.

Prado, J. \& Windisch, P.G. 2000. The genus Pteris L. (Pteridaceae) in Brazil. Boletim do Instituto de Botânica 13: 103-199.

Prado, J. \& Sylvestre, L. 2012. Pteridófitas In: R.C. Forzza, A. Costa, B.M.T. Walter, J.R. Pirani, M.P. Morim, L.P. Queiroz, G. Martinelli, A.L. Peixoto, M.A.N. Coelho, J.F.A. Baumgratz, J.R. Stehmann, L.G. Lohmann, M. Hopkins. Lista de Espécies da Flora do Brasil. Jardim Botânico do Rio de Janeiro, Rio de Janeiro. http://floradobrasil.jbrj.gov.br/2012/FB091343 (acesso em 08.04.2012).

Rodrigues, S.T., Almeida, S.S., Andrade, L.H.C., Barros, I.C.L. \& Van Den Berg, M.E. 2004. Composição florística e abundância de pteridófitas em três ambientes da bacia do Rio Guamá, Belém, Pará, Brasil. Acta Amazonica 34: 35-42.

Rolleri, C.H. 2004. Revisión del género Danaea (Marattiaceae - Pteridophyta). Darwiniana 42: 217-301.

Sanches, F. \& Fisch, G. 2005. As possíveis alterações microclimáticas devido a formação do lago artificial da hidrelétrica de Tucuruí - PA. Acta Amazonica 35: 41-50.

Salino, A. \& Joly, C.A. 2001. Pteridophytes of three remnants of gallery forests in the Jacaré-Pepira river basin, São Paulo state, Brazil. Boletim do Herbário Ezechias Paulo Heringer, Brasília 8: 5-15.

Salino, A. \& Mota, N.F.O. 2007. Salviniaceae. In: T.B. Cavalcanti \& A.E. Ramos (orgs.). Flora do Distrito Federal, Brasil. Embrapa Recursos Genéticos e Biotecnologia, Brasília, v.6, pp. 155-159.

Salino, A. \& Almeida, T.E. 2008. Pteridófitas do Parque Estadual do Jacupiranga, São Paulo, Brasil. Acta Botanica Brasilica 22: 983-991.

Salino, A. \& Almeida, T.E. 2012a. Ctenitis. In: R.C. Forzza, A. Costa, B.M.T. Walter, J.R. Pirani, M.P. Morim, L.P. Queiroz, G. Martinelli, A.L. Peixoto, M.A.N. Coelho, J.F.A. Baumgratz, J.R. Stehmann, L.G. Lohmann, M. Hopkins. Lista de Espécies da Flora do Brasil. Jardim Botânico do Rio de Janeiro, Rio de Janeiro. http://floradobrasil.jbrj.gov.br/2012/FB091343 (acesso em 09.03.2012).

Salino, A. \& Almeida, T.E. 2012b. Salviniaceae. In: R.C. Forzza, A. Costa, B.M.T. Walter, J.R. Pirani, M.P. Morim, L.P. Queiroz, G. Martinelli, A.L. Peixoto, M.A.N. Coelho, J.F.A. Baumgratz, J.R. Stehmann, L.G. Lohmann, M. Hopkins. Lista de Espécies da Flora do Brasil. Jardim Botânico do Rio de Janeiro, Rio de Janeiro. http://floradobrasil.jbrj.gov.br/2012/FB091343 (acesso em 09.03.2012).
Salino, A. \& Almeida, T.E. 2012c. Thelypteridaceae In: R.C. Forzza, A. Costa, B.M.T. Walter, J.R. Pirani, M.P. Morim, L.P. Queiroz, G. Martinelli, A.L. Peixoto, M.A.N. Coelho, J.F.A. Baumgratz, J.R. Stehmann, L.G. Lohmann, M. Hopkins. Lista de Espécies da Flora do Brasil. Jardim Botânico do Rio de Janeiro, Rio de Janeiro. http://floradobrasil.jbrj.gov.br/2012/FB091343 (acesso em 09.03.2011).

Salino, A. \& Semir, J. 2004. Thelypteris subg. Meniscium (Thelypteridaceae - Pterophyta) no Estado de São Paulo, Brasil. Revista Brasileira de Botânica 27: 103-114.

Salino, A., Fernandes, R.S. \& Pietrobom, M.R. 2011. Thelypteris amazonica sp. nov. (Thelypteridaceae) from Amazonian Brazil. Nordic Journal of Botany 29: 611-614.

Sampaio, A.J. 1930. Eufilicineas do Rio Cuminá. Arquivos do Museu Nacional 32: 8-60.

Santiago, A.C.P., Barros, I.C.L. \& Sylvestre, L.S. 2004. Pteridófitas ocorrentes em três fragmentos florestais de um brejo de altitude (Bonito, Pernambuco, Brasil). Acta Botanica Brasilica 18: 781-792.

Santos, M.G. \& Sylvestre, L.S. 2001. Pteridófitas. In: A.F. Costa \& I.C.A. Dias (orgs.). Flora do Parque Nacional da Restinga de Jurubatiba e arredores, Rio de Janeiro, Brasil. Museu Nacional, Rio de Janeiro, pp. 143-152.

Schwartsburd, P.B. 2006. Pteridófitas do Parque Estadual de Vila Velha, Paraná, Brasil. Dissertação de Mestrado, Universidade Federal do Paraná, Curitiba.

Schwartsburd, P.B. 2012. Saccolomataceae. In: R.C. Forzza, A. Costa, B.M.T. Walter, J.R. Pirani, M.P. Morim, L.P. Queiroz, G. Martinelli, A.L. Peixoto, M.A.N. Coelho, J.F.A. Baumgratz, J.R. Stehmann, L.G. Lohmann, M. Hopkins. Lista de Espécies da Flora do Brasil. Jardim Botânico do Rio de Janeiro, Rio de Janeiro. http://floradobrasil.jbrj.gov.br/2012/FB091343 (acesso em 04.03.2012).

Sehnem, A. 1959. Uma coleção de pteridófitos do Rio Grande do Sul, III. Pesquisas, Porto Alegre 3: 495-576.

Sehnem, A. 1961. Uma coleção de pteridófitos do Rio Grande do Sul, V. Pesquisas, Porto Alegre, 13: 5-52.

Sehnem, A. 1970. Polipodiáceas. In: R. Reitz (ed.). Flora Ilustrada Catarinense. Herbário Barbosa Rodrigues, Itajaí, pp. 1-173.

Sehnem, A. 1971. Himenofiláceas. In: R. Reitz (ed.). Flora Ilustrada Catarinense. Herbário Barbosa Rodrigues, Itajaí, pp. 1-98.

Sehnem, A. 1972. Pteridáceas. In: R. Reitz (ed.). Flora Ilustrada Catarinense. Herbário Barbosa Rodrigues, Itajaí, pp. 1-244.

Sehnem, A. 1974. Esquizeáceas. In: R. Reitz (ed.). Flora Ilustrada Catarinense. Herbário Barbosa Rodrigues, Itajaí, pp. 1-78. 
Sehnem, A. 1979. Aspidiáceas. In: R. Reitz (ed.). Flora Ilustrada Catarinense. Herbário Barbosa Rodrigues, Itajaí, pp. 1-360.

Silva, M.R.P. \& Barros, I.C.L. 2005. Schizaeaceae. In: T.B. Cavalcanti \& A.E Ramos (orgs.). Flora do Distrito Federal. Embrapa Recursos Genéticos e Biotecnologia, Brasília, v.4, pp. 216-247.

Silva, M.R.P. \& Rosário, S.M. 2008. Licófitas e monilófitas (Pteridophyta) da Floresta Nacional de Caxiuanã, Estado do Pará, Brasil: chave para as famílias e as espécies de Aspleniaceae e Blechnaceae. Boletim Museu Paraense Emílio Goeldi, Ciências Naturais 3: 151-163.

Smith, A.R. 1986. Revision of the Neotropical fern genus Cyclodium. American Fern Journal 76: 56-98.

Smith, A.R. 1992. Thelypteridaceae. In: R.M. Tryon \& R.G. Stolze (orgs.). Pteridophyta of Peru. Part III. 16. Thelypteridaceae. Fieldiana, Botany 29: 1-80.

Smith, A.R. 1995a. Hymenophyllaceae. In: P.E. Berry, B.K. Holst \& K. Yatskievych (eds.). Pteridophytes, Spermatophytes: Acanthaceae-Araceae. In: J.S. Steyermark, P.E. Berry \& B.K. Holst (eds.). Flora of the Venezuelan Guayana. Timber Press, Portland, v.2, pp. 159-185.

Smith, A.R. 1995b. Dryopteridaceae. In: P.E. Berry, B.K. Holst \& K. Yatskievych (ed.). Pteridophytes, Spermatophytes: Acanthaceae-Araceae. In: J.S. Steyermark, P.E. Berry \& B.K. Holst, (ed.). Flora of the Venezuelan Guayana. Timber Press, Portland, v.2, pp. 296-314.

Smith, A.R. 1995c. Polypodiaceae. In: P.E. Berry, B.K. Holst \& K. Yatskievych (eds.). Pteridophytes, Spermatophytes: Acanthaceae-Araceae. In: J.S. Steyermark, P.E. Berry \& B.K. Holst (eds.). Flora of the Venezuelan Guayana. Timber Press, Portland, v.2, pp. 219-249.

Smith, A.R. 1995d. Adiantum. In: P.E. Berry, B.K. Holst \& K. Yatskievych (eds.). Pteridophytes, Spermatophytes: Acanthaceae-Araceae. In: J.S. Steyermark, P.E. Berry \& B.K. Holst (eds.). Flora of the Venezuelan Guayana. Timber Press, Portland, v.2, pp. 256-162.

Smith, A.R., Pryer, K.M, Schuettpelz, E., Korall, P., Schneider, H. \& Wolf, P.G. 2006. A classification for extant ferns. Taxon 55: 705-731.

Somers Jr., P. \& Moran, R.C. 1995. Espécies articuladas de Selaginella. In: R.C. Moran \& R. Riba, (eds.). Flora Mesoamericana 1. Psilotaceae a Salviniaceae. Universidad Nacional Autónoma de México, Ciudad de México, v.1, pp. 25-29.

Sylvestre, L.S. 2001. Revisão taxonômica das espécies de Aspleniaceae A.B. Frank ocorrentes no Brasil. Tese de Doutorado, Universidade de São Paulo, São Paulo.

Tryon, R.M. \& Conant, D.S. 1975. The ferns of Brazilian Amazonia. Acta Amazonica 5: 23-34.
Tryon, R.M. \& Stolze, R.G. 1989. Pteridophyta of Peru. Part. II. 13. Pteridaceae - 15. Dennstaedtiaceae. Fieldiana, Botany 22: 1-128.

Tryon, R.M. \& Stolze, R.G. 1991. Pteridophyta of Peru. Part. IV. 17. Dryopteridaceae. Fieldiana, Botany 27: 1-176.

Tryon, R.M. \& Stolze, R.G. 1993. Pteridophyta of Peru. Part. V. 18. Aspleniaceae-21. Polypodiaceae. Fieldiana, Botany 32: 1-190.

Tryon, R.M. \& Tryon, A.F. 1982. Ferns and allied plants, with special reference to Tropical America. Spring-Verlag, New York, pp. 1-857.

Wagner, W. \& J. Beitel. 1993. Lycopodiaceae, In: M. Windham. Flora of North America v.1. Oxford University Press. pp.18-37.

Weatherby, C.A. 1937. A Further Note on Salvinia. American Fern Journal 27: 98-102.

Windisch, P.G. 1975. Contribuição ao conhecimento das pteridófitas da Serra Ricardo Franco (Estado de Mato Grosso). Bradea 2: 1-4.

Windisch, P.G. 1979. Adições ao Inventário das Pteridófitas do Acre. Bradea 3: 29-30.

Windisch, P.G. 1996. Pteridófitas do Estado de Mato Grosso: Hymenophyllaceae. Bradea 6: 400-423.

Windisch, P.G. 2012a. Cyatheaceae. In: R.C. Forzza, A. Costa, B.M.T. Walter, J.R. Pirani, M.P. Morim, L.P. Queiroz, G. Martinelli, A.L. Peixoto, M.A.N. Coelho, J.F.A. Baumgratz, J.R. Stehmann, L.G. Lohmann, M. Hopkins. Lista de Espécies da Flora do Brasil. Jardim Botânico do Rio de Janeiro, Rio de Janeiro. http:// floradobrasil.jbrj.gov.br/2012/FB091343 (acesso em 09.03.2012).

Windisch, P.G. 2012b. Hymenophyllaceae. In: R.C. Forzza, A. Costa, B.M.T. Walter, J.R. Pirani, M.P. Morim, L.P. Queiroz, G. Martinelli, A.L. Peixoto, M.A.N. Coelho, J.F.A. Baumgratz, J.R. Stehmann, L.G. Lohmann, M. Hopkins. Lista de Espécies da Flora do Brasil. Jardim Botânico do Rio de Janeiro, Rio de Janeiro. http://floradobrasil.jbrj.gov.br/2012/FB091343 (acesso em 09.03.2012).

Windisch, P.G. \& Tryon, R.M. 2001. The Serra Ricardo Franco (State of Mato Grosso, Brazil) as probable migration route and its present fern flora. Bradea 8: 267-276.

Windisch, P.G. \& Kieling-Rúbio, M.A. 2012. Elaphoglossum In: R.C. Forzza, A. Costa, B.M.T. Walter, J.R. Pirani, M.P. Morim, L.P. Queiroz, G. Martinelli, A.L. Peixoto, M.A.N. Coelho, J.F.A. Baumgratz, J.R. Stehmann, L.G. Lohmann, M. Hopkins. Lista de Espécies da Flora do Brasil. Jardim Botânico do Rio de Janeiro, Rio de Janeiro. http://floradobrasil. jbrj.gov.br/2012/FB091343 (acesso em 09.03.2012). 
Windisch, P.G. \& Ramos, C.G.V. 2012. Lycopodiaceae. In: R.C. Forzza, A. Costa, B.M.T. Walter, J.R. Pirani, M.P. Morim, L.P. Queiroz, G. Martinelli, A.L. Peixoto, M.A.N. Coelho, J.F.A. Baumgratz, J.R. Stehmann, L.G. Lohmann, M. Hopkins. Lista de Espécies da Flora do Brasil. Jardim Botânico do Rio de Janeiro, Rio de Janeiro. http://floradobrasil.jbrj.gov.br/2012/FB091343 (acesso em 09.03.2012)

Valdespino, I.A. 1995. A monographic revision of Selaginella P. Beauv. Subgenus Heterostachys Baker in Central and South America. Ph.D thesis, The City University of New York, New York.
Xavier, S.R.S. \& Barros, I.C.L. 2003. Pteridófitas ocorrentes em fragmentos de Floresta Serrana no Estado de Pernambuco, Brasil. Rodriguésia 54: 13-21.

Xavier, S.R.S. \& Barros, I.C.L. 2005. Pteridoflora e seus aspectos ecológicos ocorrentes no Parque Ecológico João Vasconcelos Sobrinho, Caruaru, PE, Brasil. Acta Botanica Brasilica 19: 775-781.

Zuquim, G., Costa, F.R.C., Prado, J. \& Tuomisto, H. 2008. Guide to the ferns and lycophytes of REBIO Uatumã, Central Amazonia, Guia de samambaias e licófitas da REBIO Uatumã, Amazônia Central. Áttema Manaus. 
